UNIVERSIDADE DE SÃO PAULO

ESCOLA DE EDUCAÇÃO FISICA E ESPORTE DE RIBEIRÃO PRETO

CARLOS DELLAVECHIA DE CARVALHO

Respostas fisiológicas e moleculares de três modelos de treinamento de corrida com cargas equiparadas em ratos Wistar

(Processo FAPESP n. 2017/04445-8, Período - 01/08/2017 a 31/07/2019)

RIBEIRÃO PRETO 


\section{CARLOS DELLAVECHIA DE CARVALHO}

Respostas fisiológicas e moleculares de três modelos de treinamento de corrida com cargas equiparadas em ratos Wistar

\section{Versão corrigida}

Dissertação apresentada à Escola de Educação Física e Esporte de Ribeirão Preto da Universidade de São Paulo para obtenção do título de Mestre em Ciências, Programa de Pós-graduação Educação Física e Esporte.

Área de Concentração: Atividade física e esporte

Orientador: Prof. Dr. Marcelo Papoti

RIBEIRÃO PRETO 
Autorizo a reprodução e divulgação total ou parcial deste trabalho, por qualquer meio convencional ou eletrônico, para fins de estudo e pesquisa, desde que citada a fonte.

$$
\text { Catalogação na publicação }
$$

Serviço de Biblioteca e Documentação

Escola de Educação Física e Esporte de Ribeirão Preto da Universidade de São Paulo

Carvalho, Carlos Dellavechia de

Respostas fisiológicas e moleculares de três modelos de treinamento de corrida com cargas equiparadas em ratos Wistar / Carlos Dellavechia de Carvalho; orientador, Marcelo Papoti. - 2020.

iv, 96p.

Dissertação (Mestrado em Educação Física e Esporte) - Escola de Educação Física e Esporte de Ribeirão Preto da Universidade de São Paulo.

Versão original

1. Treinamento 2. Isocarga 3. Ratos I. Papoti, Marcelo, orient. II. Respostas fisiológicas e moleculares de três modelos de treinamento de corrida com cargas equiparadas em ratos Wistar. 
CARVALHO, C.D. Respostas fisiológicas e moleculares de três modelos de treinamento de corrida com cargas equiparadas em ratos Wistar. 2020. $96 \mathrm{f}$. Dissertação (Mestrado em Educação Física e Esporte) - Escola de Educação Física e Esporte de Ribeirão Preto, Universidade de São Paulo, Ribeirão Preto, 2020.

Aprovado em:

Banca Examinadora

Prof. Dr.

Instituição:

Julgamento:

Prof. Dr.

Instituição:

Julgamento:

Prof. Dr.

Instituição:

Julgamento: 
DEDICATÓRIA

"Dedico a presente dissertação à minha família, alicerce e inspiração de todas as minhas conquistas, e que não mediram esforços para me ajudar nessa etapa tão importante da minha vida." 


\section{AGRADECIMENTOS}

Agradeço imensamente a todos que direta ou indiretamente contribuíram ou ainda contribuem no caminho que me trouxe até este momento. Tenho consciência de que, sem ajuda, eu não teria chegado a ponto de escrever esses agradecimentos.

À Deus, por suas bênçãos na forma de saúde, inspiração, amizades e sabedoria.

Aos meus familiares que amo muito e, em especial a meus pais, Sandra Maria Dellavechia de Carvalho e Carlos Alberto de Carvalho, minha avó Odilla Donegá Dellavechia, pois além de trabalhar incansavelmente todos dias para me proporcionar todas as condições para que eu possa seguir o caminho que escolhi para minha vida, eles também são responsáveis pela formação de meu caráter através da transmissão de valores como respeito, dedicação, companheirismo, humildade. A meu irmão, Roberto Dellavechia de Carvalho pelo companheirismo, amizade e especialmente por ter me concedido a privilégio de ser padrinho de seu primeiro filho, meu sobrinho Davi. Também a todos os meus familiares que mesmo de longe acompanham e auxiliam minha trajetória.

A meu orientador, professor Marcelo Papoti por todo aprendizado que me proporcionou no decorrer de mais de 7 anos de orientação, desde 2012, quando estava ainda no primeiro ano de graduação e o procurei com interesse em iniciar um projeto de iniciação científica. Além de todo o ensinamento acadêmico relacionado a Fisiologia do Exercício, o professor Papoti sempre me foi um exemplo de postura profissional, e também sua forma de conduzir as orientações aos alunos contribui para a criação de um ambiente extremamente sádio e produtivo.

Aos meus companheiros de laboratório, do Grupo de Estudos em Ciências Fisiológicas e Exercício, Carlos Kalva, Danilo, Tarine, Ronaldo, Vitor Serrano, Vitor Andrade, Paulinho, Felipe, Yan, Gabriel, Júlia, Isabella, Matheus, Leonardo, Camila e demais colegas que passaram por aqui nos últimos anos, que estão sempre dispostos a auxiliar em qualquer experimento de qualquer colega, tendo em visto que em sua grande maioria, estes experimentos demandam uma equipe de pessoas para sua realização. Assim, não apenas contém com a ajuda de meus colegas nos experimentos que contemplados neste documento, como também aprendi o valor, na forma de aprendizado, que contribuir em experimento traz a formação de quem, como eu, almeja seguir a carreira 
acadêmica. Além disso, os tenho como grandes amigos, além de apenas colegas. Como costumamos dizer por aqui, “Gecifex: mais que um lab, um rep!”.

Ao laboratório do professor Adelino Sanchez Ramos da Silva, pela oportunidade da parceria que possibilitou a realização do primeiro experimento que compõem este documento, e especialmente a seu aluno Alisson Luiz da Rocha pela paciência no ensino das técnicas laboratoriais empregadas nestes estudos. A ajuda destas pessoas foi indispensável, pois nosso laboratório ainda não possui domínio e autonomia de algumas ferramentas que necessitei utilizar.

Ao laboratório de professor Luiz Carlos Carvalho Navegantes e as pessoas que compõem seu laboratório, especialmente Rafael Rossi Valentim, que junto ao professor Navegantes nos deram a oportunidade, em forma de parceira, do desenvolvimento de análises que trouxeram maior elegância metodológica aos nossos estudos, além do aprendizado que tive das técnicas utilizadas.

Aos alunos do laboratório do professor Carlos Roberto Bueno Júnior, Karine, Andressa, Ester e Guilherme, pois tive a oportunidade de auxiliar na coleta de dados de seus projetos, o que me trouxe um importante aprendizado, além da amizade que hoje cultivamos.

Aos alunos de graduação e ensino que participaram respectivamente dos projetos intitulados "Suporte Fisiológico" "Pré-iniciação científica", do qual eu tive a oportunidade de coordenar as reuniões semanais nos últimos semestres. E aos professores Enrico Fuini Puggina e Marcelo Papoti através do Programa de Aperfeiçoamento de Ensino, que mesmo inconscientemente me deram a oportunidade de praticar o exercício da docência, que me foi muito enriquecedor.

E finalmente, a todas as pessoas, dentre moradores, ex-moradores e agregados que fizeram e ainda fazem parte da República Benzadeus, que tem sido minha casa em Ribeirão Preto desde fevereiro de 2013, quando eu e meus colegas de turma decidimos inaugurar essa república. Como em qualquer ambiente onde existe convivência, nós tivemos alguns desentendimentos, porém imensamente superados pela amizade, companheirismo, respeito e amor que cultivamos uns pelos outros no decorrer destes anos. 
Nosso maior medo não é sermos inadequados. Nosso maior medo é não saber que nós somos poderosos, além do que podemos imaginar. É a nossa luz, não nossa escuridão, que mais nos assusta. Nós nos perguntamos: "Quem sou eu para ser brilhante, lindo, talentoso, fabuloso?". Na verdade, quem é você para não ser? Você é um filho de Deus. Você, pensando pequeno, não ajuda o mundo. Não há nenhuma bondade em você se diminuir, recuar para que os outros não se sintam inseguros ao seu redor. Todos nós fomos feitos para brilhar, como as crianças brilham. Nós nascemos para manifestar a glória de Deus dentro de nós. Isso não ocorre somente em alguns de nós; mas em todos. Enquanto permitimos que nossa luz brilhe, nós, inconscientemente, damos permissão a outros para fazerem o mesmo. Quando nós nos libertamos do nosso próprio medo, nossa presença automaticamente libertará outros.

(Williamson, 1992) 


\section{SUMÁRIO}

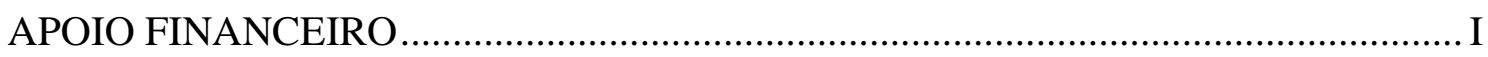

LISTA DE SIGLAS E ABREVIATURAS …………………....................................

LISTA DE TABELAS ……………………………………………………….... III

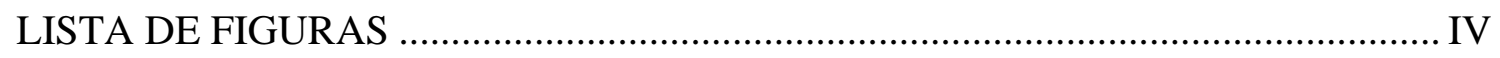

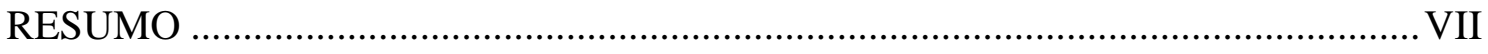

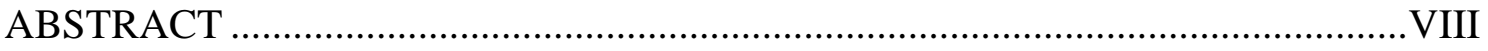

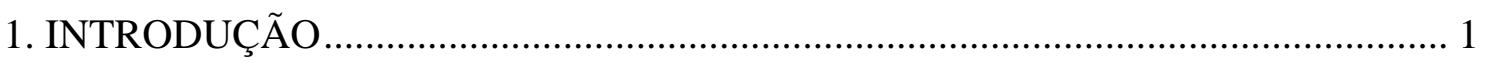

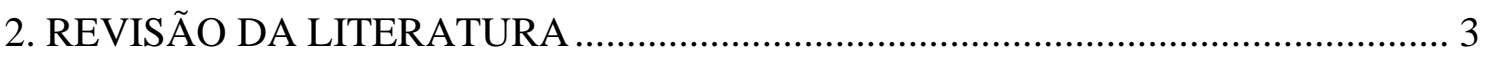

2.1. MODELOS DE PERIODIZAÇÃO …………………………………………..... 3

2.2. ZONAS DE TREINAMENTO E MODELO DE TREINAMENTO

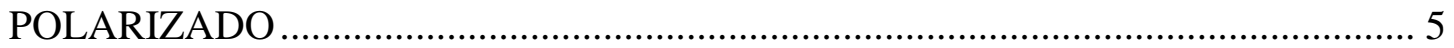

2.3. SESSÕES AGUDAS DE EXERCÍCIO, DINÂMICA DE RECUPERAÇÃO E

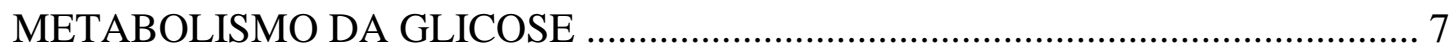

2.4. EXERCÍCIO AERÓBIO E RESPOSTAS BIOMOLECULARES ...................... 10

2.5. SESSÃO AGUDA DE EXERCÍCIO E REGULAÇÃO NO TRANSPORTE DE

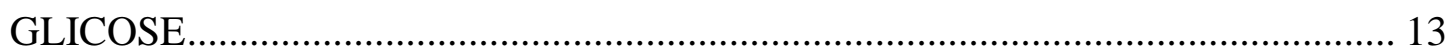

2.6. MODELOS DE TREINAMENTO FÍSICO E ADAPTAÇÕES

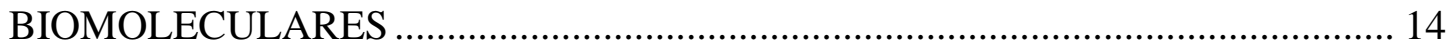

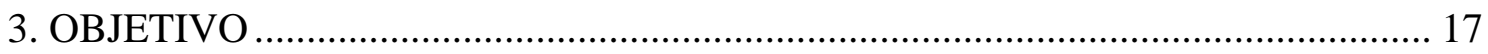

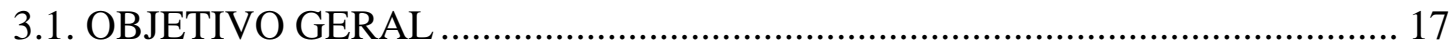

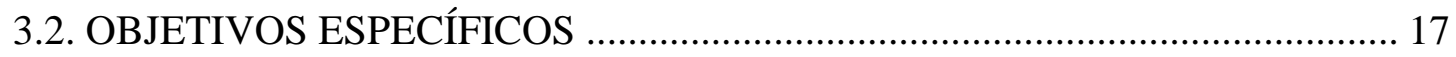

4. FLUXOGRAMA DOS PROCEDIMENTOS ……………………………........... 18

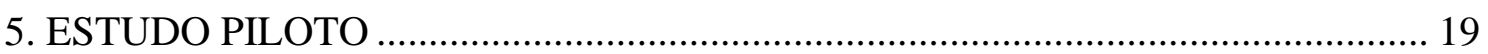

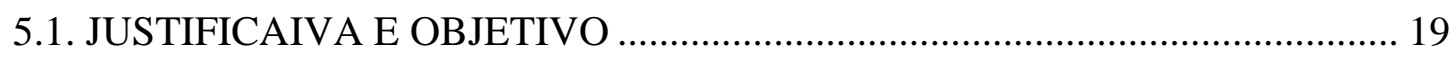

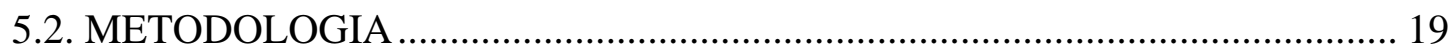

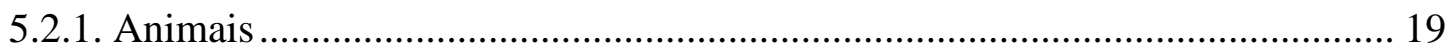


5.2.3. Teste incremental (TI) para determinação do limiar anaeróbio (Lan) e da Velocidade máxima de corrida (Vmáx) .................................................................. 19

5.2.4. Coleta e análise de amostras sanguíneas ........................................................ 20

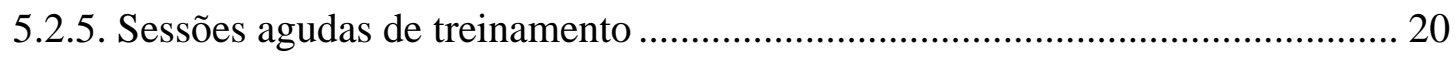

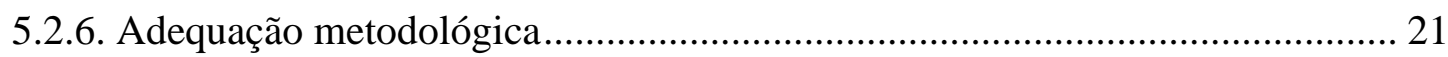

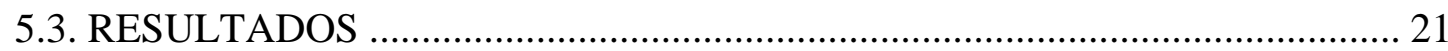

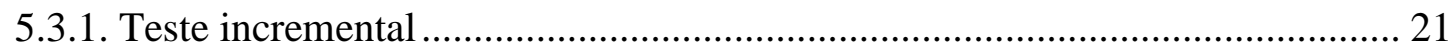

5.3.2. Tentativa 1 de aplicação da sessão em Z3 _..................................................... 23

5.3.3. Tentativa 2 de aplicação da sessão em Z3 _.................................................... 23

5.4. CONCLUSÕES E ALTERAÇÕES PARA AS PRÓXIMAS ETAPAS .............. 23

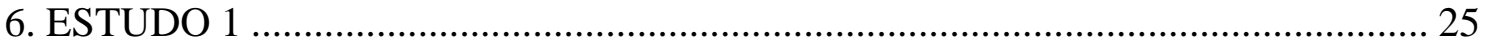

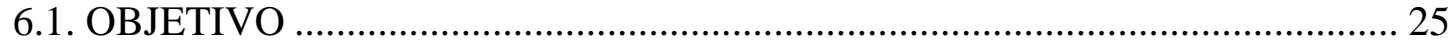

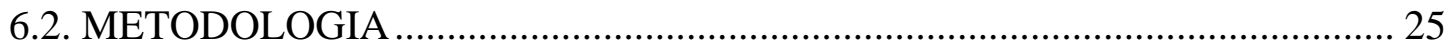

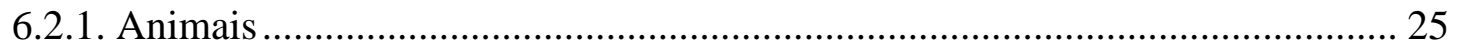

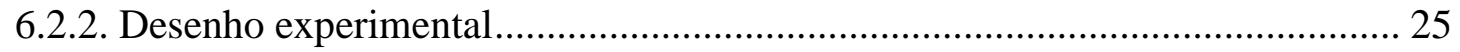

6.2.3. Teste incremental (TI) para determinação da Velocidade máxima de corrida

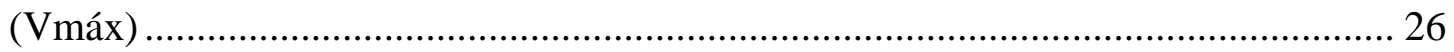

6.2.4. Sessões agudas e quantificação das cargas dos treinamentos ........................... 26

6.2.5. Extração do músculo esquelético................................................................... 28

6.2.6. Estimativa do Glicogênio muscular ............................................................... 28

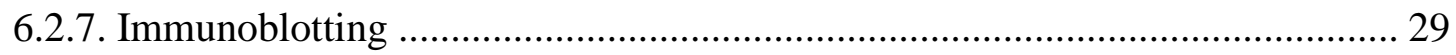

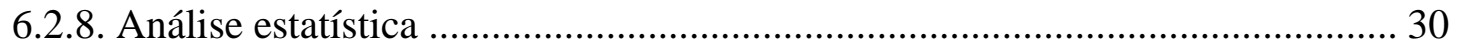

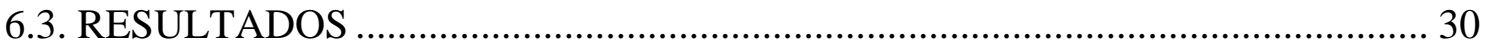

6.3.1. Caracterização das sessões de treinamento ................................................... 31

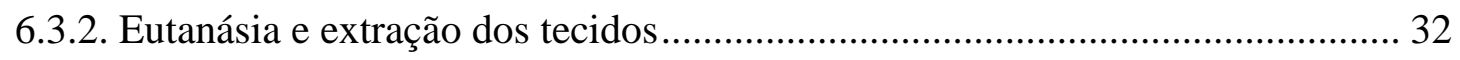

6.3.3. Estimativa do Glicogênio muscular e hepático................................................ 34 


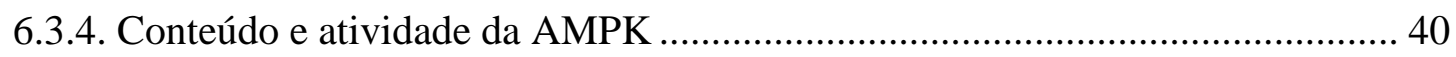

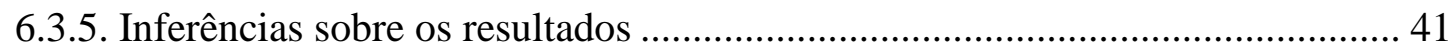

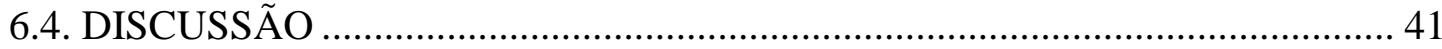

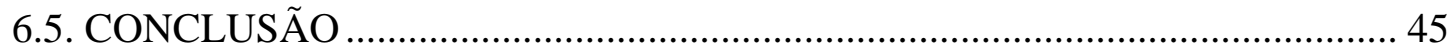

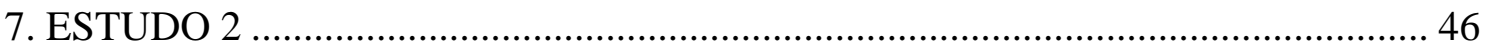

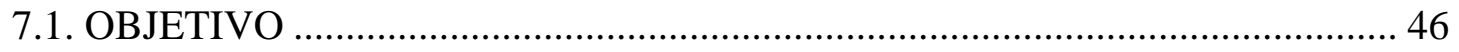

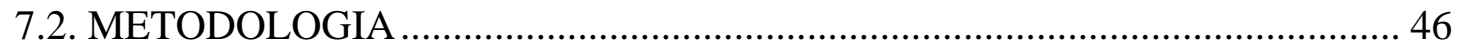

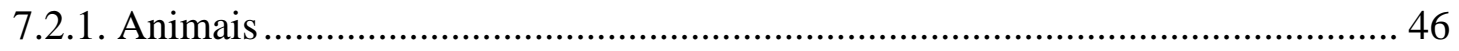

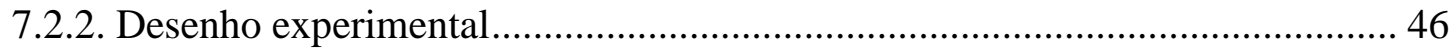

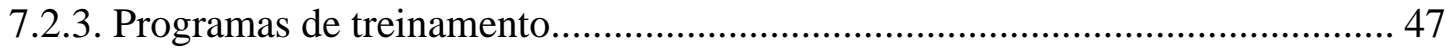

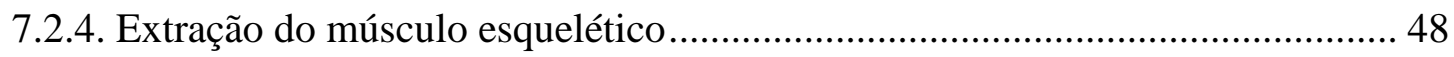

7.2.5. Estimativa do Glicogênio muscular ............................................................ 48

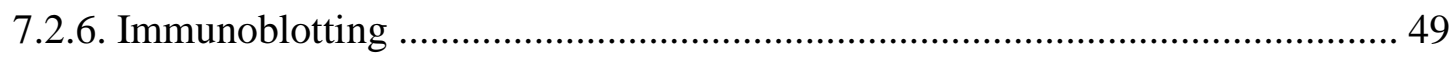

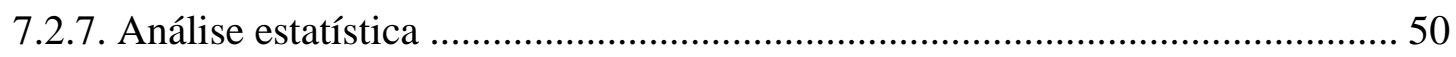

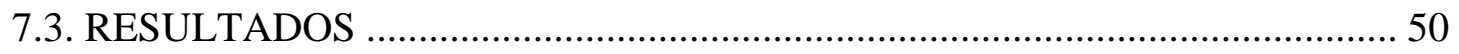

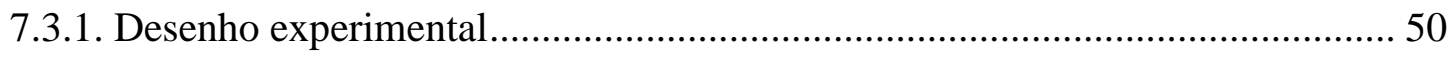

7.3.3. Efeito de 4 semanas sobre o desempenho no teste incremental....................... 52

7.3.4. Estimativa do glicogênio muscular e hepático ................................................. 53

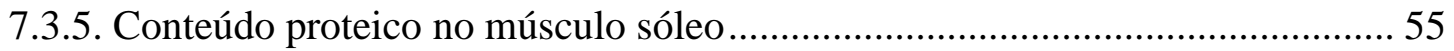

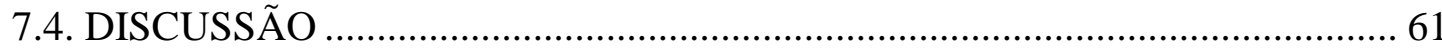

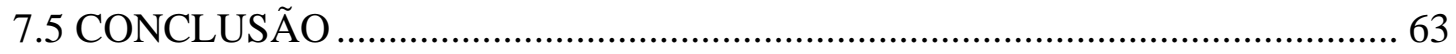

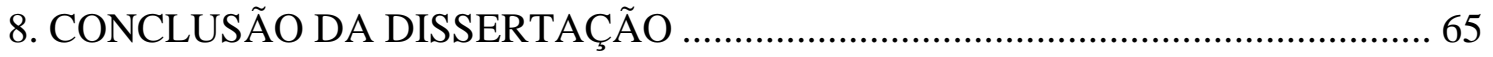

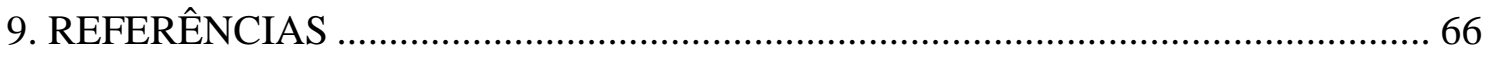




\section{APOIO FINANCEIRO}

A presente dissertação de mestrado e todos os estudos vinculados a este projeto de pesquisa tiveram o apoio financeiro da Fundação de Amparo à Pesquisa do Estado de São Paulo (FAPESP); Processo n. 2017/04445-8, Período - 01/08/2017 a 31/07/2019 


\section{LISTA DE SIGLAS E ABREVIATURAS}

Lan = limiar anaeróbio

HIIT = High intensity interval training

$\mathrm{ET}=$ Endurance training

$\mathrm{CS}=$ citrato sintase

MFEL = máxima fase estável de lactato

[La] = concentração sanguínea de lactato

$\mathrm{VO}_{2}=$ consumo de oxigênio

PGC1- $\alpha=$ Peroxisome proliferator-activated receptor gamma coactivator 1-alpha

$\mathrm{CO}_{2}=$ dióxido de carbono

$\mathrm{Z1}$ = zona 1 de intensidade

$\mathrm{Z} 2$ = zona 2 de intensidade

$\mathrm{Z3}$ = zona 3 de intensidade

$\mathrm{ATP}=$ adenosina trifosfato

$\mathrm{AMP}=$ adenosina monofosfato

AMPK = proteína quinase ativada por AMP

$\mathrm{PDK}=$ piruvato desidrogenase quinase

GLUT-1 = transportador de glicose tipo 1

GLUT-4 = transportador de glicose tipo 4

CaMK = proteína quinase dependente de cálcio calmodulina

Vmáx = velocidade máxima de corrida

$\mathrm{TI}=$ teste incremental

$\mathrm{G}_{\mathrm{Z} 1}=$ grupo treinamento sub-limiar

$\mathrm{G}_{\mathrm{Z} 2}=$ grupo treinamento na intensidade relativa ao limiar anaeróbio

$\mathrm{G}_{\mathrm{Z3}}=$ grupo treinamento supra limiar

TRIMP = impulso de treinamento

$\mathrm{G}_{\text {Base }}=$ grupo linha de base

t0 = eutanásia imediatamente após a sessão aguda de treinamento

t6 = eutanásia 6 horas após a sessão aguda de treinamento

t12 = eutanásia 12 horas após a sessão aguda de treinamento

t24 = eutanásia 24 horas após a sessão aguda de treinamento

$\mathrm{EDL}=$ extensor digitorum longus 


\section{LISTA DE TABELAS}

Tabela 1. Caracterização das sessões de treinamento em baixa (Z1), moderada (Z2) e alta (Z3) intensidade. .

Tabela 2. Variáveis que compõem as sessões de treinamento prescritas. .48 


\section{LISTA DE FIGURAS}

Figura 1. Fluxograma dos procedimentos e experimentos que compõem a presente dissertação.

Figura 2. Representação esquemática da relação entre volume e intensidade, expressa em unidades arbitrárias, que foram utilizadas para as composições das sessões dos treinamentos realizados abaixo, na intensidade de limiar anaeróbio e acima do limiar anaeróbio.

Figura 3. Comportamento das concentrações sanguíneas de lactato ([La]) durante o teste incremental.

Figura 4. Representação esquemática dos procedimentos experimentais que envolveram a adaptação com todos os animais ao ergômetro, testes incrementais $\left(\mathrm{G}_{\mathrm{Base}}, \mathrm{G}_{\mathrm{Z1}}, \mathrm{G}_{\mathrm{Z} 2} \mathrm{e}\right.$ $\mathrm{G}_{\mathrm{Z3}}$ ), sessões agudas experimentais de treinamento e momentos de eutanásia.

Figura 5. Representação esquemática da relação entre volume e intensidade, expressa em unidades arbitrárias (u.a.), que foram utilizadas para as composições das sessões dos treinamentos realizados abaixo (Z1), na intensidade de limiar anaeróbio (Z2) e acima do limiar anaeróbio $(\mathrm{Z} 3)$.

Figura 6. Peso dos ratos e do consumo de ração referentes a todo o período de avaliações.

Figura 7. Caracterização das sessões de treinamento através da taxa de acúmulo de lactato.

Figura 8. Tempo do sacrifício em relação à sessão de treinamento para os diferentes grupos e diferentes momentos de eutanásia.

Figura 9. Peso dos tecidos extraídos durante a eutanásia nos diferentes grupos.

Figura 10. Cinética de depleção e recuperação do glicogênio no músculo sóleo e comparação entre as sessões de treinamento.

Figura 11. Cinética de depleção e recuperação do glicogênio no músculo gastrocnêmio e comparação entre as sessões de treinamento. 
Figura 12. Cinética de depleção e recuperação do glicogênio no músculo EDL (extensor digitorum longus) e comparação entre as sessões de treinamento.

Figura 13. Cinética de depleção e recuperação do glicogênio no fígado e comparação entre as sessões de treinamento.

Figura 14. Comparação da variação percentual da cinética de depleção e recuperação do glicogênio nos músculos sóleo e EDL e no fígado.

Figura 15. Conteúdo proteico total (A), da proteína fosforilada (B) e atividade (C) da AMPK no músculo sóleo.

Figura 16. Cronograma de aplicação de avaliações que incluem adaptação à esteira, testes incrementais, programas de treinamento e eutanásia.

Figura 17. Peso dos ratos em todo o período de avaliações.

Figura 18. Carga externa diária das sessões de treinamento dos grupos submetidos aos modelos de treinamento.

Figura 19. Efeito de 4 semanas de treinamento de corrida sobre a Velocidade Máxima (Vmáx) atingida no teste incremental (TI).

Figura 20. Concentração de glicogênio no músculo sóleo dos quatro grupos experimentais após 5 semanas de intervenção.

Figura 21. Concentração de glicogênio no músculo EDL dos quatro grupos experimentais após 5 semanas de intervenção.

Figura 22. Concentração de glicogênio no fígado dos quatro grupos experimentais após 5 semanas de intervenção.

Figura 23. Conteúdo proteico de AMPK fosforilada no músculo sóleo dos quatro grupos experimentais após 5 semanas de intervenção. .56

Figura 24. Conteúdo proteico de citrato sintase no músculo sóleo dos quatro grupos experimentais após 5 semanas de intervenção.

Figura 25. Conteúdo proteico da GSK3$\beta$ no músculo sóleo dos quatro grupos experimentais após 5 semanas de intervenção. 
Figura 26. Conteúdo proteico da GSK3$\beta$ fosforilada no músculo sóleo dos quatro grupos experimentais após 5 semanas de intervenção.

Figura 27. Conteúdo proteico dos cinco complexos da fosforilação oxidativa (OXPHOS) no músculo sóleo dos quatro grupos experimentais após 5 semanas de intervenção. 


\section{RESUMO}

CARVALHO, Carlos Dellavechia de. Respostas fisiológicas e moleculares de três modelos de treinamento de corrida com cargas equiparadas em ratos Wistar. 2020. $96 \mathrm{f}$. Dissertação (Mestrado em Educação Física e Esporte) - Escola de Educação Física e Esporte de Ribeirão Preto, Universidade de São Paulo, Ribeirão Preto, 2020.

Poucos estudos verificaram as respostas fisiológicas e moleculares a partir da manipulação das variáveis volume e intensidade com equiparação das cargas dos treinamentos. O objetivo do presente estudo foi investigar as respostas fisiológicas e moleculares de ratos, submetidos a três modelos agudos e crônicos de treinamento de corrida, com diferentes relações entre volume e intensidade, mas com cargas equiparadas. Verificamos as respostas agudas (Estudo 1) de três sessões aguda de treinamento de corrida: $\mathrm{G}_{\mathrm{Z} 1}(\mathrm{n}=24$; intensidade abaixo do limiar anaeróbio obtido em teste incremental; volume $=43 \mathrm{~min}$, intensidade $=70 \% \mathrm{Lan}) ; \mathrm{G}_{\mathrm{Z} 2}(\mathrm{n}=24 ;$ intensidade de Lan; volume $=$ $31 \mathrm{~min}$, intensidade $=100 \%$ Lan $)$ e GZ3 $(n=24$; esforços supra-Lan; volume $=25 \mathrm{~min}$, intensidade $=120,4 \%$ Lan). Os animais neste experimento foram subdivididos em eutanasiados imediatamente $(n=6), 6(n=6), 12(n=6)$ e $24(n=6)$ horas após a sessão de exercício físico. Também verificamos as adaptações (Estudo 2) de programas de treinamento de 5 semanas com frequência semanal de 3 sessões baseados nas mesmas sessões (Z1, Z2 e Z3). Os resultados do Estudo 1 mostraram a supercompensão do glicogênio muscular entre 6 e 12 após o exercício e 24 após no fígado. O Estudo 2 mostrou que 5 semanas de treinamento de corrida em esteira baseados nas zonas 1, 2 e 3 de intensidade melhoraram o desempenho e aumentaram as concentrações de glicogênio no músculo sóleo. Nos dois experimentos não observamos alterações nas vias de sinalização a partir das análises das proteínas da via oxidadtiva. A partir dos resultados dos estudos 1 e 2 concluímos que a modulação da intensidade, no exercício de corrida em esteira, não altera a cinética das variáveis fisiológicas biomoleculares, no que diz respeito a respostas agudas e adaptações crônicas, desde as cargas estejam equiparadas.

Palavras-chaves: treinamento, isocarga, corrida 


\begin{abstract}
CARVALHO, Carlos Dellavechia de. Physiological and molecular responses of three models of running training with equalized loads in Wistar rats. 2020. 96 f. Dissertação (Mestrado em Educação Física e Esporte) - Escola de Educação Física e Esporte de Ribeirão Preto, Universidade de São Paulo, Ribeirão Preto, 2020.
\end{abstract}

Few studies analyzed the physiological responses from the manipulation of the variables volume and intensity with equalization of loads. The aim of the present study was to investigate the physiological and molecular responses of rats, submitted to three acute and chronic running training models, with different relations between volume and intensity, but with similar loads. We verified the acute responses (Study 1) of three acute running training sessions: $\mathrm{G}_{\mathrm{Z1}}(\mathrm{n}=24$; intensity below the anaerobic threshold (AnT) obtained in incremental test; volume $=43 \mathrm{~min}$, intensity $=70 \%$ AnT $) ; \mathrm{GZ}_{2}(\mathrm{n}=24 ;$ AnT intensity; volume $=31 \mathrm{~min}$, intensity $=100 \% \mathrm{AnT})$ and $\mathrm{G}_{\mathrm{z3}}(\mathrm{n}=24$; above AnT efforts; volume $=25 \mathrm{~min}$, intensity $=120.4 \%$ AnT). The animals in this experiment were subdivided into euthanized immediately $(n=6), 6(n=6), 12(n=6)$ and $24(n=6)$ hours after the physical exercise session. We also checked the adaptations (Study 2) of 5-week training programs with weekly frequency of three sessions based on the same sessions (Z1, Z2 and Z3). Results from Study 1 showed muscle glycogen supercompensation between 6 and 12 after exercise and 24 after in the liver. Study 2 showed that 5 weeks of treadmill running training based on intensity zones 1, 2, and 3 improved performance and increased glycogen concentrations in the soleus muscle. In both experiments we did not observe changes in the signaling pathways from the oxidative pathway proteins analysis. From the results of studies 1 and 2, we conclude that intensity modulation in treadmill running exercise does not change the kinetics of biomolecular physiological variables regarding acute responses and chronic adaptations, since the loads are equalized.

Keywords: training, isoloads, running 


\section{INTRODUÇÃO}

A busca pelos melhores modelos de treinamento ainda é uma questão que gera muita discussão, pois ainda não consenso sobre os melhores modelos, principalmente para atletas que competem em provas de longa duração. As diversidades metodológicas dos protocolos de treinamento sobre as variáveis, como volume, intensidade, frequência, complexidade, fazem com que as conclusões de estudos que comparam diferentes modelos de treinamento sejam imprecisas (De Araujo et al., 2015).

O paradigma vigente acerca dos modelos de periodização do treinamento é construído a partir do pressuposto de que parâmetros de carga mecânica aplicadas, diretamente ditam a magnitude das adaptações biológicas (Kiely, 2018), pois a partir da teoria geral da adaptação, proposta por Selye (1936) estas ocorrem apenas após a recuperação de algum stress fisiológico ao qual o organismo foi acometido (Cunanan et $a l ., 2018)$. O padrão qualitativo de respostas funcionais advindas de estresse fisiológicos, agudo e crônico, provocado pelo treinamento físico apresenta alta concordância com a curva da "Teoria Geral da Adaptação" (Cunanan et al., 2018). A partir desta afirmação as propostas de planejamento de programas de treinamento levam em consideração as variáveis que compõem a carga de treinamento (e. g., volume, intensidade, densidade, complexidade) pois sabe-se que a carga influencia diretamente na magnitude da resposta e seu controle deve ser feito ao comparar modelos agudos e crônicos de treinamento (Van Den Tillaar et al., 2011; Cunanan et al., 2018).

A prescrição de intensidades corretas de exercício desempenha um papel fundamental na busca por melhoria de desempenho, assim é comum que a utilização de "âncoras fisiológicas" para a prescrição principalmente de intensidades submáximas (Binder et al., 2008). A partir dos limiares fisiológicos (e. g., limiar anaeróbio (Lan), limiar ventilatório) é possível demarcar zonas de intensidade, nas quais as características do exercício mudam. Sob o aspecto fisiológico, com aumento da intensidade do exercício, dois limiares (ventilatórios ou lactacidêmicos) podem ser identificados, assim dois pontos de intersecção, demarcando três fases de demanda energética (i. e., zonas de intensidade) (Binder et al., 2008).

Considerando que: (i) diferentes modelos de treinamentos podem resultar similares respostas oxidativas na musculatura esquelética e de desempenho, (ii) os 
programas de treinamentos realizados predominantemente em intensidades próximas ao Lan parecem não ser mais adequado para adaptações aeróbias e de desempenho quando comparado aos programas de treinamentos realizados com baixa intensidade e elevado volume e que (iii) as respostas agudas da via de sinalização celular provenientes de diferentes modelos de treinamentos que utilizam a mesma carga de treinamento ("dose"), apesar de ser fundamental para o entendimento dos processos de estímulo e respostas provenientes do treinamento, ainda não foram investigados, o presente estudo estará empenhado em investigar as respostas fisiológicas e moleculares de três modelos de treinamento de corrida em ratos Wistar com diferentes relações entre volume e intensidade, mas com cargas equiparadas. 


\section{REVISÃO DA LITERATURA}

\subsection{MODELOS DE PERIODIZAÇÃO}

A periodização do treinamento consiste na divisão sistemática do tempo total de treinamento em períodos distintos a fim de fazer com que o atleta atinja o máximo de desempenho no momento desejado. Normalmente, esse período culmina com as principais competições de uma temporada. Embora esse modelo de treinamento tenha sido proposto e utilizado por atletas, recentemente Araujo et al. (2010) adaptaram o modelo de periodização para ratos durante exercício em natação. Pelo fato da periodização do treinamento compreender alterações constantes nas relações entre volume e intensidade do treinamento, a principal vantagem desse modelo parece ser a possibilidade de maximização do desempenho e o menor risco de supertreinamento, que é caracterizado por uma redução no desempenho por tempo prolongado (Araujo et al., 2010).

Apesar da predominância dos estímulos de treinamentos serem, de modo geral, dependente da especificidade da modalidade e da predominância energética dos esforços (aeróbio, anaeróbio alático e anaeróbio lático), observa-se em programas de treinamento periodizado uma alternância de estímulos de baixa, moderada e elevada intensidade (Issurin, 2010). Isso provavelmente ocorre pela dificuldade da realização de rotinas diárias e consecutivas de treinamento em alta intensidade (De Araujo et al., 2012). De modo semelhante, a realização diária e consecutiva de treinamentos com elevado volume, também tem sido questionado por muitos pesquisadores devido a elevada depleção de glicogênio muscular e por consequência, maior possibilidade de supertreinamento (Costill et al., 1991).

Especificamente com relação aos estímulos responsáveis pela melhora do desempenho aeróbio ainda há contradições na literatura com relação à estratégia mais adequada para que ocorram adaptações oxidativos da musculatura esquelética e por consequência, melhora do desempenho. Recentemente foi demonstrado que o treinamento intervalado de alta intensidade (Hight Intensity Interval Training, HIIT), pode promover adaptações oxidativas na musculatura esquelética similares ao treinamento aeróbio tradicional (Endurance Training; ET) (Gibala et al., 2006; Burgomaster et al., 2008; Gibala, 2009). 
Gibala et al. (2006) demonstram melhoras da atividade oxidativa da musculatura esquelética, por meio da quantificação da atividade da enzima citrado sintase (CS) e o tempo até a exaustão após seis sessões de treinamento realizado em máxima intensidade (allout), composto por 4-6 esforços de 30 segundos em ciclo ergômetro (Wingate), ou seja treinamento predominantemente anaeróbio, separados por intervalo de 4 minutos e frequência de 3 . semana ${ }^{-1}$.

Utilizando o mesmo protocolo, esses autores não encontraram diferença significativa entre as adaptações oxidativas provenientes do Treinamento Intervalado de Alta Intensidade (High Intensity Interval Training; HIIT) quando este foi comparado ao treinamento aeróbio tradicional (Endurance Training; ET), que foi composto por 90$120 \mathrm{~min}$ de esforço contínuo, intensidade de aproximadamente $65 \%$ do $\mathrm{VO}_{2}$ pico e frequência de 3.semana ${ }^{-1}$ (Gibala et al., 2006). No entanto, apesar dos significativos aumentos da $\mathrm{CS}$, esses autores não relataram alterações no $\mathrm{VO}_{2}$ pico em ambos os modelos de treinamento (ET e HIIT). Burgomaster et al. (2008), ao compararem os efeitos de seis semanas de HIIT com o treinamento de ET, constataram aumentos similares de peroxisome proliferator-activated receptor gamma coactivator 1-alpha (PGC1- $\alpha$ ) piruvato desidrogenase quinase (PDK), CS e $\mathrm{VO}_{2}$ pico [HIT (pré=41 \pm 2 , pós $=44 \pm 2 \mathrm{ml} \cdot \mathrm{kg}^{-1} \cdot \mathrm{min}^{-1}$ ), ET (pré=41 \pm 2 , pós $=45 \pm 2 \mathrm{ml} \cdot \mathrm{kg}^{-1} \cdot \mathrm{min}^{-1}$ )]. Em conjunto os resultados apresentados demonstraram a possibilidade do HIIT, mesmo baseado em treinamento predominantemente anaeróbio, melhorar capacidade oxidativa, potência aeróbia máxima e o desempenho de pessoas ativas, porém não atletas.

Recentemente Teixeira-Coelho et al. (2017) mostraram, em ratos Wistar, que a progressão de carga realizada através de aumento de intensidade foi mais efetiva, comparado ao aumento pelo volume, para aumentar o desempenho na corrida após 8 semanas de intervenção, mantendo as cargas equiparadas.

Durante décadas foi assumido que a intensidade "ideal" para o desenvolvimento da capacidade aeróbia era o treinamento realizado da intensidade de limiar anaeróbio, ou seja, intensidades próximas a intensidade da máxima fase estável de treinamento (Kindermann et al., 1979; Stegmann et al., 1981; Svedahl e Macintosh, 2003). No entanto, Beneke et al. (2011) em revisão de literatura relataram que não existem informações científicas de que o treinamento realizado na intensidade de máxima fase 
estável de lactato (MFEL) apresenta alguma vantagem para melhora da capacidade aeróbia em comparação aos demais modelos de treinamentos.

\subsection{ZONAS DE TREINAMENTO E MODELO DE TREINAMENTO POLARIZADO}

Convencionalmente as sessões de treinamento são classificadas a partir da relação do comportamento de variáveis fisiológicas (e. g., lactato, ventilação, dióxido de carbono $\left(\mathrm{CO}_{2}\right)$ ) e a intensidade de exercício. Considerando sessões de treinamento em que o objetivo é a melhora de parâmetros aeróbios a classificação é feita considerando três fases limitadas por limiares fisiológicos, sendo os mais usuais os limiares de lactato e ventilatórios. Na primeira fase, que corresponde baixas intensidades, aumentos de carga não resultam em aumentos nas concentrações sanguíneas de lactato [La] e aumentos lineares de consumo de oxigênio $\left(\mathrm{VO}_{2}\right), \mathrm{CO}_{2}$ e ventilação são observados. $\mathrm{Na}$ segunda fase passa a ser observado um aumento das [La] e aumentos de íon $\mathrm{H}^{+}$são tamponados por bicarbonato, resultando em aumentos de fração expiradas de $\mathrm{CO}_{2}$, resultando também em aumentos de ventilação, ambos em uma magnitude maior em comparação ao $\mathrm{VO}_{2}$, porém, e assim como na primeira, ainda se atinge estado estável das variáveis fisiológicas, quando a intensidade é constante. Na terceira fase mais pronunciados aumentos de [La], $\mathrm{CO}_{2}$ e ventilação são observados e não há estado estável de exercício (Binder et al., 2008). Estas três fases são também chamadas de zonas de treinamento.

Há também classificações para modelos crônicos de treinamento e uma série de estudos descritivos (Seiler e Kjerland, 2006; Arne e Eike, 2009) revelaram que atletas de elite optam por uma periodização do treinamento com uma distribuição "polarizada", ou seja, grande porcentagem (aproximadamente 75\%) do volume de treinamento é realizado na Zona 1 (Z1), ou seja, em baixa intensidade (>Limiar anaeróbio 1 ou $[\mathrm{La}]<2 \mathrm{mM}$ ), aproximadamente $15 \%$ na Zona 3 (Z3), ou seja, em intensidades superiores ao limiar anaeróbio 2 ([La] $>4 \mathrm{mM})$ e somente uma pequena quantidade do volume (aproximadamente 10\%) na Zona 2 (Z2), ou seja, em intensidades entre os limiares 1 e 2 ([La] entre 2 e $4 \mathrm{mM}$ ), apesar da intensidade dos eventos competitivos serem próximos ao limiar anaeróbio (Seiler e Kjerland, 2006; Arne e Eike, 2009; Yu et al., 2012; Neal et al., 2013). 
Seiler e Kjerland (2006) ao caracterizarem a distribuição das sessões durante o período pré-competitivo de esquiadores noruegueses bem-treinados de cross-country de nível júnior, constataram que esses atletas utilizaram um modelo de treinamento polarizado (75\% Z1, 5 - 10\% Z2 e 15 - 20\% em Z3). Arne e Eike (2009) ao analisarem a periodização de jovens remadores alemães, constataram no treinamento específico de remo, esses atletas apresentaram valores de $95 \%, 2 \%$ e $3 \%$ do volume de treinamento em Z1, Z2 e Z3 respectivamente e concluíram, portanto, também tratar-se de um modelo polarizado.

Esteve-Lanao et al. (2007) compararam o desempenho competitivo de esquiadores de cross-contry amadores em uma corrida simulada de 10,4 km que esses atletas foram divididos em dois grupos, em que houve diferença na distribuição das intensidades de treinamento, porém com a mesma carga total. Um grupo apresentou uma distribuição do volume de treinamento em que a predominância das intensidades foi realizada em Z1, enquanto que o outro treinou em Z2, porém igualmente em Z3. Esses autores mostraram que houve uma diferença no desempenho desses atletas em relação a situação pré-treinamento, mas não entre os grupos.

Yu et al. (2012) aplicaram um modelo de treinamento polarizado em patinadores chineses, homens e mulheres, os quais até então, treinavam a partir de um modelo de treinamento no Limiar, e verificaram melhora no desempenho de 500 e $1000 \mathrm{~m}$. Neal et al. (2013) também realizaram uma comparação dos dois modelos de treinamento, aplicados num grupo de ciclistas treinados que foram submetidos a um treinamento "polarizado" e verificaram aumentos significativos na capacidade aeróbia, potência pico e teste até a exaustão em comparação ao grupo que treinou com uma distribuição “baseado no Limiar”. Em contradição, Muñoz et al. (2014) não encontraram diferenças significativas no desempenho em corrida de $10 \mathrm{~km}$ entre dois grupos de corredores recreacionais submetidos a esses dois modelos de treinamento (polarizado vs limiar) e concluíram que ambos os modelos resultaram em aumentos significativos de desempenho.

A explicação para a suposta superioridade do modelo de treinamento polarizado em comparação aos demais, em atletas de alto nível, fundamenta-se em uma menor ativação simpática, determinado por meio da variabilidade da frequência cardíaca, com o 
treinamento realizado predominante com elevado volume e intensidade inferior em Z1. Os autores têm argumentado que pelo fato dos atletas necessitarem de uma elevada carga de treinamento, que de modo geral tem sido assumida como o produto do volume pela intensidade, é mais "seguro" atingir essas elevadas cargas por meio do aumento do volume em detrimento da intensidade, mesmo para os atletas que competem em provas em que as intensidades são próximas a intensidade de Z2 (Seiler et al., 2007).

Apesar dos resultados citados anteriormente apresentarem uma tendência em considerar o modelo de treinamento polarizado, como sendo mais efetivo, principalmente em modalidades com características de resistências aeróbia (Arne e Eike, 2009; Yu et al., 2012), provavelmente devido às dificuldades metodológicas relacionadas ao controle e manipulação dos estímulos de treinamento, inviabilidade de realizar coletas de tecido muscular em atletas pertencentes a diferentes modalidades esportivas, os estudos que investigaram as respostas fisiológicas e moleculares dos treinamentos realizados exclusivamente em Z1, Z2 e Z3 ainda são limitados.

\subsection{SESSÕES AGUDAS DE EXERCÍCIO, DINÂMICA DE RECUPERAÇÃO E METABOLISMO DA GLICOSE}

A partir da teoria geral da adaptação, proposta por Selye (1936), quando o organismo é submetido a uma situação de stress (e. g., exercício físico), o nível de adaptação sofre um decréscimo que se estende enquanto esse stress perdura. Após o estímulo e durante o período de recuperação o nível de adaptação retorna ao nível inicial, podendo até superar este nível (Cunanan et al., 2018).

O glicogênio representa a fonte primária de combustível para manutenção de homeostase de adenosina trifosfato (ATP) e, portanto, para disponibilidade energética durante sessões de exercício de intensidade moderada à intensa (Casey et al., 2000; Jentjens e Jeukendrup, 2003; Hearris et al., 2018; Takahashi et al., 2019) e os níveis musculares de glicogênio representam um fator determinante para o desempenho (Takahashi et al., 2019). E corroborando com a teoria geral da adaptação, após um exercício pode-se observar uma diminuição dos estoques de glicogênio (i. e., depleção), seguida de um aumento deste substrato durante o período de recuperação do esforço, 
podendo superar os níveis prévios (Jentjens e Jeukendrup, 2003; Raja et al., 2004; Hearris et al., 2018).

O fenômeno da "supercompensação" do glicogênio muscular, que foi observado pela primeira vez em humanos por Bergström e Hultman (1966), é atribuído à ativação da enzima glicogênio sintase e ao aumento da sensibilidade à insulina que perdura por algum tempo após o exercício (Nakatani et al., 1997; Greiwe et al., 1999). Além disso, também é geralmente aceito que além do conteúdo muscular, a depleção dos estoques hepáticos de glicogênio representa um dos principais fatores relacionados à fadiga, proveniente de um exercício de endurance (Hearris et al., 2018).

Após um exercício, e com adequada ingestão de carboidratos (que deve ser realizada tanto anterior ao exercício quanto após), o metabolismo do glicogênio transita da fase catabólica para anabólica (Bruce et al., 2001; Hearris et al., 2018). A síntese do glicogênio após o exercício ocorre em duas fases; inicialmente ocorre uma fase rápida que independe da presença de insulina e, a seguir, ocorre a fase mais lenta que depende da atividade da insulina (Jentjens e Jeukendrup, 2003). Takahashi et al. (2017) compararam em camundongos uma dieta rica em gorduras a dieta padrão rica em carboidratos, e verificaram maiores concentrações de glicogênio e consequentemente maior supercompensação deste substrato para o grupo que ingeriu a dieta padrão e Matsunaga et al. (2018) ao compararem três dietas ministradas anteriormente uma sessão aguda de exercício mostraram, em camundongos, que tanto a dieta exclusivamente constituída de glicose, quanto dietas que combinam glicose e uma mistura de aminoácidos promovem a recuperação do glicogênio depletado durante o exercício, porém o mesmo não ocorreu para o grupo que ingeriu a dieta que combinava glicose e caseína, e os autores hipotetizaram que a explicação para esse ocorrido foi o maior gasto energético observado para esse grupo durante o período de recuperação. Lambert et al. (1997) verificaram em modelo animal que as enzimas glicogênio sintase e fosforilase têm um papel importante nesta transição no metabolismo da glicose, de modo que a primeira tem sua atividade aumentada, e a outra diminuída, durante o período de recuperação de exercício de alta intensidade ( 3 minutos de natação atado a um peso adicional, equivalente a $9 \%$ do peso corporal). Bruce et al. (2001) também mostraram em ratos, que a disponibilidade de carboidratos após um exercício de depleção de glicogênio resultando na 
supercompensação (i. e., aumento nos níveis de glicogênio em comparação ao estado basal) deste substrato, mesmo na situação de resistência à insulina.

Existem vários fatores que regulam o uso de substratos energéticos durante o exercício, como intensidade, volume e status de treinamento do praticante (Hearris et al., 2018). A progressão do exercício moderado a intenso leva a um aumento do metabolismo de carboidratos (glicogenólise muscular e hepática e consumo de glicose) para a ressíntese de ATP, com uma consequente redução da oxidação lipídica (Loon et al., 2001; Gonzalez et al., 2016). Neste contexto, a disponibilidade de glicose para o tecido muscular ativo aumenta como resultado do aumento da taxa de glicogenólise hepática (Trimmer et al., 2002; Fuller et al., 2019). Além disso, sabe-se que o processo de gliconeogênese hepática, que também auxilia na manutenção da glicose, aumenta imediatamente após o exercício e o glucagon tem um papel fundamental neste processo (Fuller et al., 2019).

Adan et al. (1997) mostraram que, após a exaustão proveniente de um exercício de alta intensidade, os processos de depleção dos estoques de glicogênio muscular, do aumento de liberação de glicose muscular e do acúmulo de lactato ocorrem em simultâneo, indicando uma relação entre estes fenômenos, o que ressalta a importância da glicose na manutenção de um exercício de elevada intensidade. O lactato, que por sua vez, tem um papel importante nos processos de restituição dos estoques de glicogênio, principalmente após esforços de alta intensidade, em que ocorre acúmulo deste metabólito, pois representa uma importante fonte de carbono nesta situação (Raja et al., 2004). Entretanto, Raja et al. (2004) mostraram, em ratos Wistar, que a recuperação dos estoques de glicogênio muscular, após em exercício de alta intensidade, não é limitada pela quantidade de lactato acumulado, mesmo em jejum após o esforço.

Conforme relatado anteriormente, os estoques de glicogênio muscular desempenham papel importante no aporte energético durante uma sessão aguda de exercício de alta intensidade (Raja et al., 2008). Sendo assim, a recuperação dos estoques depletados durante um exercício ocorre, sobre condições favoráveis, preferencialmente em fibras de contração rápida (Raja et al., 2008). E, como mostrado por Sano et al. (2012) uma sessão aguda de natação de alta intensidade e curta duração ( 8 x 20 segundos; 18\% do peso corporal), em condições favoráveis de consumo de carboidrato, causa a 
supercompensação do glicogênio de forma similar ao que ocorre com um exercício de alto volume (3 horas sem carga adicional).

Portanto, o entendimento da cinética de depleção e recuperação do glicogênio, tanto muscular quanto hepático, é determinante para a determinação da capacidade de realização de exercício de baixa a alta intensidade. Contudo ainda não está claro como a modulação das variáveis que compõem uma sessão de exercício alteram a cinética deste substrato.

\subsection{EXERCÍCIO AERÓBIO E RESPOSTAS BIOMOLECULARES}

As contrações musculares provenientes de exercício físico, resultam em um aumento das concentrações de adenosina monofosfato (AMP) musculares, e este aumento resulta em aumento da atividade da proteína quinase ativada por AMP (AMPK) que, sensível ao desequilíbrio energético (i. e., aumento das razões AMP/ATP e ADP/ATP), é responsável pela manutenção da homeostase energética (Rasmussen et al., 1998; Ruderman et al., 2003; Winder et al., 2006; Saleem et al., 2013; Kjøbsted et al., 2018; Rezaee et al., 2019). A AMPK atua nos processos de transporte de glicose e oxidação de ácidos graxos e na supressão da atividade da glicogênio sintase e de síntese proteica (Kjøbsted et al., 2018).

Rasmussen et al. (1998) verificaram, em modelo animal, aumento do conteúdo de AMPK após dois modelos de exercício, de moderada e alta intensidade, respectivamente, concomitante a diminuições do conteúdo de glicogênio e das enzimas malonyl-CoA e acetyl-CoA carboxilase. Assim evidências apontam que a AMPK tem sua atividade aumentada após um exercício físico (Koopman et al., 2006) e regula os níveis de enzimas relacionadas a aumento da oxidação de gorduras para manutenção da homeostase da glicose (Rasmussen et al., 1998; Ruderman et al., 2003; Andersson et al., 2005; Pagano et al., 2014; Fritzen et al., 2015). Estudos recentes mostraram em camundongos, aumento na fosforilação (Pagano et al., 2014) e no conteúdo proteico (Saleem et al., 2013) de AMPK em resposta a uma sessão de exercício de baixa intensidade. Fritzen et al. (2015) mostraram, em camundongos que a AMPK regula o metabolismo muscular após o exercício, inibindo o complexo da piruvato desidrogenase quinase (PDK) e 
consequentemente a oxidação de glicose, subsequentemente criando condições para a aumento da oxidação de ácidos graxos.

Tem sido demonstrado ainda que a atividade da AMPK aumenta de maneira intensidade-dependente após um exercício (Koshinaka et al., 2009) em ratos (Rasmussen e Winder, 1997; Musi et al., 2001) e humanos (Fujii et al., 2000; Wojtaszewski et al., 2000; Chen et al., 2003). Koshinaka et al. (2009) mostraram que ratos que realizaram um exercício de alta intensidade apresentaram maior ativação da AMPK em comparação a um grupo que realizou um exercício de baixa intensidade e longa duração, contudo estes mesmos modelos de exercício apresentaram a mesma resposta no aumento da responsividade à insulina e do consumo de glicose após o exercício.

Apesar disso, foi mostrado por Jørgensen et al. (2005) que a ativação induzida pelo exercício de enzimas metabólicas investigadas em camundongos não foi prejudicada nos músculos $\alpha 1$ - ou $\alpha 2$-AMPK knock-out, indicando que a AMPK não é necessariamente essencial para a ativação dos processos regulatórios do metabolismo de glicose ativados pelo exercício.

É plausível considerar, e já foi mostrado, que a atividade da AMPK no hipotálamo teria participação no controle do apetite (Minokoshi et al., 2004). Porém ainda não consenso sobre essa regulação após um exercício, pois Andersson et al. (2005) verificaram, em modelo animal, os processos de regulação do apetite ocorrendo após 1 hora de exercício de corrida, sem alterações na atividade da AMPK.

De modo semelhante a AMPK atua na regulação do PGC1- $\alpha$ que, pertence a uma família de coativadores de transcrição que interage diretamente com fatores de transcrição, regulando a expressão e decodificação de proteínas mitocondriais, ou seja, o PGC1- $\alpha$ é considerado o "regulador mestre" da biogênese mitocondrial (Wende et al., 2007; Laursen, 2010; Rezaee et al., 2019) e atua em vários processos metabólicos relacionados à fosforilação oxidativa, oxidação de ácidos graxos, consumo de glicose, angiogênese, aumento de capilarização e aumento na expressão de enzimas oxidativas (Wende et al., 2007; Kiilerich et al., 2010; Oe et al., 2011; Safdar et al., 2011; Koltai et al., 2012; Ringholm et al., 2013; Halling et al., 2016; Karlsson et al., 2018).

Foi constatado em modelo animal, por Wende et al. (2007), que o PGC1- $\alpha$ atua no aumento dos estoques de glicogênio por meio de vários mecanismos (e. g., captação 
de glicose, supressão do fluxo glicolítico, e inibição da expressão da glicogênio fosforilase). Assim, o PGC1- $\alpha$ é um crítico regulador nos estoques energéticos musculares; atua na regulação da enzima piruvato desidrogenase (PDH) em paralelo com proteínas mitocondriais oxidativas (Kiilerich et al., 2010). Foi mostrado, em camundongos, que uma sessão de exercício aeróbio aumenta a expressão e o conteúdo de PGC1- $\alpha$, promovendo a biogênese mitocondrial, atuando como regulador central de respostas adaptativas ao exercício pela regulação da expressão de genes metabólicos (Safdar et al., 2011; Saleem et al., 2013; Halling et al., 2016). A via do PGC1- $\alpha$, ativado pela AMPK diminui progressivamente sua atividade com o avanço da idade, porém (Koltai et al., 2012) mostraram em modelo animal, que o exercício é capaz de atenuar esse efeito deletério da idade sobre esta via. Neste sentido, Vechetti-Junior et al. (2015) mostraram em ratos Wistar idosos, que o PGC1- $\alpha$ ativado pelo exercício aeróbio atua na regeneração muscular após um período de indução à atrofia muscular, através da inibição do sistema ubiquitina proteassoma relacionado à atrofia.

O exercício ainda aumenta a capacidade do organismo em oxidar glicose, o que é sugerido por evidências que apontam aumento da atividade da CS nesta situação, de modo que a CS é considerada um marcador de capacidade oxidativa e de atividade mitocondrial, além de regulador central destes processos (Chou et al., 2005; Koulmann et al., 2017; De Brito Vieira et al., 2018), e ainda Koulmann et al. (2017) mostraram uma associação entre os aumentos da CS e de PGC1- $\alpha$, que por sua vez, segundo estes mesmos autores, está relacionado com melhora de fenótipos do ponto de vista tanto contrátil, quanto metabólico.

Sabe-se que o fígado através dos processos de glicogenólise e gliconeogênese, atua auxiliando na manutenção dos níveis sanguíneos de glicose (Knudsen et al., 2015). Knudsen et al. (2015) mostraram, em camundongos, diminuição da AMPK imediatamente após uma sessão aguda de uma hora de corrida em esteira, do fígado destes animais e ainda afirmam que estes achados sugerem que no tecido hepático, o piruvato derivado do lactato produzido, seria o principal substrato a ser oxidado em detrimento aos ácidos graxos.

Portanto, o exercício aeróbio agudo é responsável pela ativação de diversas enzimas de vias de sinalização relacionadas ao metabolismo da glicose, que cronicamente estão relacionadas às adaptações provenientes de programas de treinamento físico. 


\subsection{SESSÃO AGUDA DE EXERCÍCIO E REGULAÇÃO NO TRANSPORTE DE GLICOSE}

O exercício aumenta a absorção de glicose pelo músculo esquelético e consequentemente a disponibilidade deste substrato para fibras musculares em atividade, que se dá a partir da translocação dos transportadores de glicose tipos 1 e 4 (GLUT-1 e principalmente GLUT-4), mediada pela atividade da AMPK (Kido et al., 2016) e a fosforilação realizada predominantemente pela hexoquinase, que é uma enzima que tem sua atividade significativamente aumentada em resposta ao treinamento aeróbio (O'doherty et al., 1994). O'doherty et al. (1994) mostraram em modelo animal que uma sessão aguda (90 minutos) de exercício de corrida em esteira aumentou a expressão e a atividade da hexoquinase nos músculos sóleo e gastrocnêmio, após o término do exercício e também verificaram que as alterações induzidas pelo exercício são dependentes do tipo de fibra.

O transportador de glicose regulado pela insulina, em que o GLUT-4 é considerado o principal responsável pelo transporte de glicose induzido pelo exercício (Ryder et al., 1999; Chou et al., 2005), além do que o conteúdo normal de GLUT-4 é suficiente para aumentar o consumo de glicose pelo músculo durante um exercício (Fueger et al., 2004). É consenso que uma sessão aguda de exercício aumenta a expressão de GLUT-4 muscular e também que há correlação positiva entre o conteúdo proteico de GLUT-4 e os estoques de glicogênio (Jentjens e Jeukendrup, 2003).

Foi mostrado, em modelo animal, 16 horas após 2 vezes de 3 horas de exercício de natação, aumento no conteúdo de glicogênio na expressão e atividade do GLUT-4, com maior magnitude de resposta quando carboidratos foi fornecido em comparação ao seu controle que não ingeriu alimento após o exercício (Kuo, C.-H. et al., 1999) e em comparação com tempos anteriores (0, 1,5 e 5 horas) (Kuo, C. et al., 1999). Ryder et al. (1999) mostraram em modelo animal a importância do GLUT-4 no transporte de glicose e na restituição dos estoques depletados de glicogênio muscular após um exercício prolongado (i. e., 3 horas) de natação.

Foi mostrado também por Chiu et al. (2005) que a atividade do GLUT-4 tem um papel importante na regulação do metabolismo de glicose no músculo cardíaco. Neste experimento em modelo animal, os autores associaram um aumento da expressão e no 
conteúdo de GLUT-4, com a diminuição do glicogênio no músculo cardíaco, após um exercício seguido de um período de exposição à hipóxia.

Ainda por Chou et al. (2005) foi evidenciado que as concentrações intramusculares de glicogênio desempenham um papel fundamental na regulação da captação de glicose. Neste estudo foi verificado em modelo animal, que uma sobrecarga de glicogênio induzida de maneira exógena inibe a expressão do GLUT-4, suprimindo o transporte de glicose. Ainda foi mostrado por Ikeda et al. (2016) em camundongos que uma sessão aguda de exercício (90 minutos de corrida em esteira) aumenta a sensibilidade à insulina e a expressão de GLUT-4 no músculo esquelético, associando estes fenômenos a um concomitante aumento da proteína interleucina 6.

Outro fator que pode influenciar na magnitude da atividade do transporte de glicose é o estado de treinamento, pois o treinamento físico induz várias adaptações a nível muscular que podem contribuir para aumento da sensibilidade à insulina, incluindo aumentos no conteúdo de GLUT-4, na sensibilidade à insulina e no fluxo sanguíneo (Jentjens e Jeukendrup, 2003). Tais adaptações favorecem a captação de glicose e consequentemente aumentar a síntese de glicogênio muscular (Jentjens e Jeukendrup, 2003).

Portanto o exercício agudo aeróbio promove a translocação dos transportadores de glicose (principalmente o GLUT-4) amentando a disponibilidade deste substrato para o tecido muscular em atividade. Isto cronicamente, após um período de treinamento físico, melhora a eficiência no transporte e utilização da glicose pelo metabolismo energético.

\subsection{MODELOS DE TREINAMENTO FÍSICO E ADAPTAÇÕES BIOMOLECULARES}

Esses estudos demonstraram que diferentes modelos de treinamento (ET e HIT) resultam em aumento da densidade mitocondrial da musculatura esquelética por meio de complexas vias de sinalização celular. Dentre elas destacam-se a presença prolongada de cálcio intramuscular, como o que ocorre durante o treinamento contínuo de alta duração e alteração do estado energético celular (diminuição da razão ATP/AMP e de glicogênio muscular), como o que ocorre durante o HIIT (Handschin, 2010; Laursen, 2010). A 
propósito, do ponto de vista bioenergético foi recentemente mostrado por Fuller et al. (2019), em camundongos, que 6 semanas de exercício de corrida em esteira em baixa intensidade aumenta os conteúdos musculares e hepáticos de glicogênio e diminui o acúmulo de triacilglicerídeos hepáticos nestes mesmos tecidos.

As elevadas concentrações de cálcio na musculatura esquelética, durante contrações prolongadas como as que ocorrem durante o ET, ativam a enzima cálciocalmodulina kinase $(\mathrm{CaMK})$, que por sua vez fosforila a proteína quinase ativada por AMP (AMPK). Além disso, a AMPK é uma proteína composta subunidades sensíveis a alterações do estado energético induzidas pelo exercício (Winder et al., 2006; Rezaee et al., 2019). Foi mostrado por Rezaee et al. (2019) associação entre inibição da AMPK e perda de peso em ratos com doença de Parkinson, comparados a animais saudáveis e submetidos a um treinamento físico. Outro estímulo importante é a alteração do estado energético celular, decorrente de alterações na concentração de ATP e AMP, como o que ocorre durante o HIIT. Tem sido demonstrado que o aumento do AMP que, assim como a CaMK, também fosforila a enzima AMPK, ativa a PGC1- $\alpha$, aumenta a biogênese mitocondrial e por consequência, potencializa a capacidade de gerar ATP aerobiamente (Coffey e Hawley, 2007; Hawley, 2009). Sabe-se que o ET, realizado tanto de forma aguda quanto crônica, aumenta a transcrição, o mRNA, a expressão e por consequência o conteúdo proteico de PGC1- $\alpha$ (Holloszy, 2011).

Os resultados provenientes dos trabalhos que investigaram o ET e HIIT juntamente com a apresentação de algumas vias de sinalização celular que explicam as respostas similares entre ET e HIIT, verificadas por alguns autores, relacionadas às adaptações oxidativas, três considerações são necessárias.

A primeira é que a maioria dos estudos que demonstraram adaptações oxidativas (CS, citocromo oxidase, PCG1- $\alpha$, além de outros) similares com a utilização do HIIT em comparação ao treinamento de ET investigaram pessoas ativas, porém não atletas (Burgomaster et al., 2005; Gibala et al., 2006; Burgomaster et al., 2008). Além disso, somente Burgomaster et al. (2008) demonstraram melhoras similares do $\mathrm{VO}_{2}$ pico com HIIT, baseado em esforços predominantemente anaeróbios, em comparação ao ET.

Somente recentemente De Araujo et al. (2015) compararam os efeitos de dois modelos de treinamentos, um contínuo e outro intermitente, mas com cargas idênticas 
durante 8 semanas em ratos Wistar no exercício de natação. Esses pesquisadores encontraram um maior aumento nas concentrações de glicogênio muscular, nos músculos sóleo e gastrocnêmio, tanto de forma aguda quanto crônica, no grupo intervalado em comparação ao grupo contínuo. Todavia encontraram uma melhor resposta do Limiar anaeróbio no grupo contínuo (pré = 19,59 $\pm 5,39 \mathrm{~m} \cdot \mathrm{min}^{-1} ; 4^{\mathrm{a}}$ semana $=20,20 \pm 5,05 \mathrm{~m} \cdot \mathrm{min}^{-}$ ${ }^{1}$ ) em relação ao grupo intervalado (pré $=19,15 \pm 5,59 \mathrm{~m} \cdot \mathrm{min}^{-1} ; 4^{\mathrm{a}}$ semana $=17,39 \pm$ $\left.4,92 \mathrm{~m} \cdot \mathrm{min}^{-1}\right)$, nas primeiras quatro semanas de treinamento, porém estes ganhos não se mantiveram até o fim do programa, devido, segundo os autores, à monotonia do treinamento.

A segunda relaciona-se aos estudos que investigaram modelos de treinamentos com atletas (recreacionais e de alto nível). Esses estudos têm demonstrado que o modelo polarizado tem se apresentado superior em comparação aos treinamentos predominantemente com elevado volume e baixa intensidade, moderado volume e moderada intensidade e reduzido volume e alta intensidade na indução de melhoras da potência aeróbia máxima (Stöggl e Sperlich, 2014). No entanto a comparação das adaptações das vias de sinalização celular desses modelos de treinamento com o HIIT e o treinamento realizado na intensidade de Lan ainda não foram realizados. Finalmente, a terceira diz respeito à necessidade de equiparação das cargas de treinamento para realização de estudos dessa natureza devido à dificuldade de estabelecimento da "dose" de treinamento necessária para que tais adaptações ocorram.

Significativas associações têm sido encontradas entre CS e volume mitocondrial da musculatura esquelética após programas de treinamento. Consequentemente, a CS tem sido frequentemente utilizada como um biomarcador indireto de adaptação oxidativa (Vigelsø et al., 2014). Embora o aumento concomitante da CS e do $\mathrm{VO}_{2}$ pico, após diferentes modelos de treinamento sejam frequentemente demonstrados em diferentes estudos, somente recentemente foi demonstrado em revisão sistemática, significativas correlações entre alteração percentual do $\mathrm{VO}_{2}$ pico e CS com o treinamento (ET + HIIT) $(\mathrm{r}=0,81)$, ET $(\mathrm{r}=0,42)$ mas não entre CS e HIIT $(\mathrm{r}=0,29)$ (Vigels $\emptyset$ et al., 2014). Esses autores sugerem que o HIIT pode não estimular biogênese mitocondrial com a mesma magnitude que o ET. Desse modo, a "dose" de treinamento necessária para que as adaptações sejam desencadeadas (independentemente da via de sinalização celular) ainda não são conhecidas. 


\section{OBJETIVO}

\subsection{OBJETIVO GERAL}

Investigar as respostas fisiológicas e moleculares de ratos, submetidos a três modelos agudos e crônicos de treinamento de corrida, com diferentes relações entre volume e intensidade, mas com cargas equiparadas.

\subsection{OBJETIVOS ESPECÍFICOS}

Investigar a cinética de recuperação de variáveis fisiológicas e moleculares de ratos Wistar, submetidos a três sessões agudas de treinamento de corrida, com diferentes relações entre volume e intensidade, mas com cargas equiparadas.

Investigar as respostas fisiológicas e moleculares de ratos Wistar Hannover, submetidos a três modelos crônicos de 5 semanas de treinamento de corrida, com diferentes relações entre volume e intensidade, mas com cargas equiparadas. 


\section{FLUXOGRAMA DOS PROCEDIMENTOS}

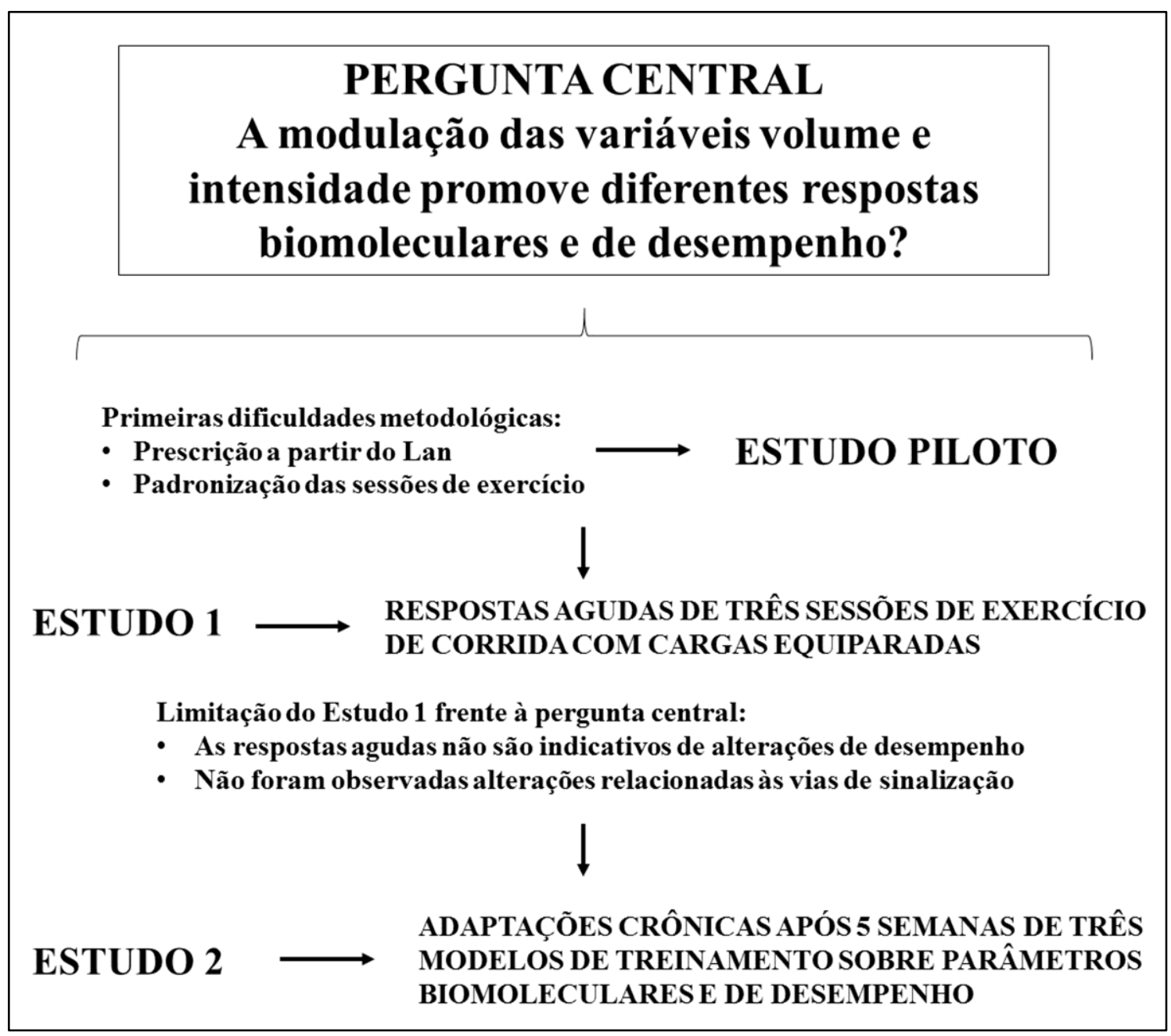

Figura 1. Fluxograma dos procedimentos e experimentos que compõem a presente dissertação. Lan = Limiar anaeróbio. 


\section{ESTUDO PILOTO}

\subsection{JUSTIFICAIVA E OBJETIVO}

O estudo piloto foi necessário para a padronização das avaliações e das técnicas utilizadas para a extração muscular. Além disso, as sessões de treinamento também precisavam ser padronizadas. Portanto o objetivo do presente estudo piloto foi testar a aplicabilidade da sessão de treinamento supra-limiar prescrita a partir dos parâmetros Limiar anaeróbio e Velocidade Máxima de corrida.

\subsection{METODOLOGIA}

\subsubsection{Animais}

Foram utilizados quatro ratos Wistar provenientes do Biotério Central do Campus da USP de Ribeirão Preto. Durante todo o experimento, os animais foram mantidos em gaiolas coletivas, em ciclo claro/escuro de 12/12 horas. Todos os animais receberam ração comercial e água ad libitum. Neste estudo e nos estudos subsequentes foi realizada seleção de ratos para que fossem incluídos nos estudos apenas os ratos corredores.

\subsubsection{Desenho experimental}

Todos os procedimentos (treinamentos e avaliações) foram realizados em esteira rolante e os animais foram adaptados ao exercício durante 5 dias, correndo 10 min.dia ${ }^{-1}$ em intensidade entre 8 e 20m. $\mathrm{min}^{-1} .72$ horas após o período de adaptação, os animais foram submetidos ao teste incremental para a tentativa de determinação do Lan e após 48 horas foram submetidos à sessão de treinamento supra-limiar que deveria ser prescrita a partir do Lan, porém a partir da impossibilidade desta prescrição, as tentativas de aplicação das sessões se deram a partir da intensidade prescrita a partir da Velocidade máxima de corrida (Vmáx), obtida no teste incremental.

\subsubsection{Teste incremental (TI) para determinação do limiar anaeróbio (Lan) e da Velocidade máxima de corrida (Vmáx)}

Para determinação do Limiar anaeróbio (Lan) foi utilizado o protocolo padronizado recentemente em nosso laboratório (Serrano, 2014). Nesse protocolo os animais foram submetidos a um teste incremental com velocidade inicial de $8 \mathrm{~m} \cdot \mathrm{min}^{-1} \mathrm{e}$ 
com incremento de $3 \mathrm{~m} \cdot \mathrm{min}^{-1}$ a cada 3 minutos. Coletas de amostras sanguíneas foram realizadas durante a condição de repouso e imediatamente após cada estágio. Através da inspeção visual, dois avaliadores experientes determinaram independentemente a velocidade de limiar anaeróbio (VLan) como o primeiro ponto de inflexão da curva lactato-velocidade (Kindermann et al., 1979), de modo que esta intensidade seria usada para prescrição das sessões de treinamento. A velocidade máxima de corrida (Vmáx) atingida no teste foi registrada e ajustada considerando o tempo de permanência no último estágio como proposto por Kuipers et al. (1985) para ciclistas, e esta variável foi também utilizada para prescrição das sessões de treinamento.

\subsubsection{Coleta e análise de amostras sanguíneas}

Durante o Teste Incremental amostras de sangue $(25 \mu \mathrm{L})$ foram coletadas, em repouso e ao final de cada estágio, em capilares de vidro previamente calibrados com heparina, da extremidade distal da cauda dos animais e colocadas em microtubos contendo $50 \mu \mathrm{L}$ de fluoreto de sódio ( $\mathrm{NaF} 1 \%$ ), homogeneizadas e mantidas a $-4^{\circ} \mathrm{C}$. As concentrações sanguíneas de lactato [La] foram determinadas em Lactímetro Eletroquímico Yellow Spring Instruments (YSI), modelo 1500 Sport.

\subsubsection{Sessões agudas de treinamento}

Seriam utilizadas as seguintes sessões agudas: treinamento abaixo do Lan (Gz1; volume $=43 \mathrm{~min} ;$ Intensidade $=70 \% \mathrm{Lan})$, na intensidade de $\mathrm{Lan}\left(\mathrm{G}_{\mathrm{Z} 2} ;\right.$ volume $=31 \mathrm{~min}$; Intensidade $=100 \%$ Lan $)$ e supra-Lan $\left(G_{z 3}\right.$; volume $=25 \mathrm{~min}$; Intensidade $=120,4 \%$ Lan $)$. $\mathrm{O}$ treinamento do $\mathrm{G}_{\mathrm{Z} 3}$ foi realizado de modo intervalado que foi composto por 5 esforços de 5 minutos separados por 2,5 min de intervalo passivo, caracterizando, portanto, um modelo de treinamento intervalado de alta intensidade (HIIT).

Apesar das sessões de treinamentos realizadas por $\mathrm{G}_{\mathrm{Z} 1} \mathrm{G}_{\mathrm{Z} 2}$ e $\mathrm{G}_{\mathrm{Z} 3}$ apresentarem diferentes relações entre o volume e a intensidade, as cargas dos treinamentos, ou seja, o impulso do treinamento (TRIMP) foram equiparadas em 3100 u.a. O TRIMP foi assumido como o produto do volume ( $\mathrm{v}$; min) pela intensidade de corrida, relativa ao Lan (\%Lan) $($ TRIMP = v.\%Lan), conforme sugerido por Araújo et al. (2010), inicialmente para exercício de natação (Figura 2). 


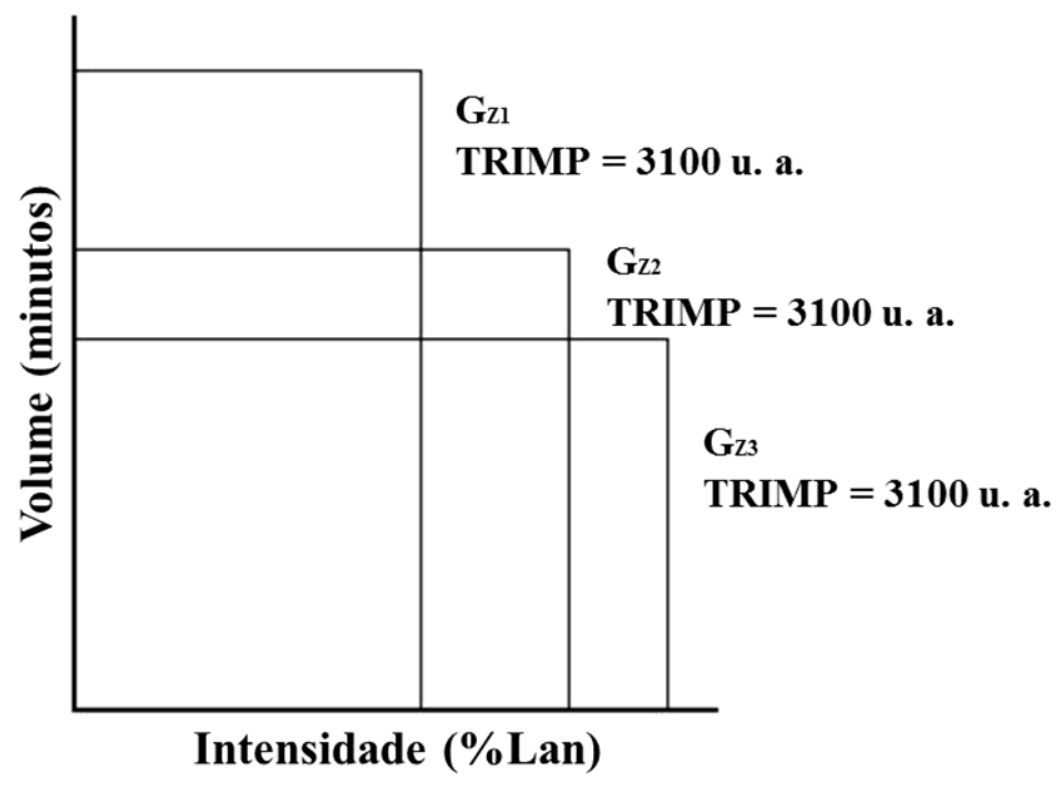

Figura 2. Representação esquemática da relação entre volume e intensidade, expressa em unidades arbitrárias (u. a.), que foram utilizadas para as composições das sessões dos treinamentos realizados abaixo (Z1), na intensidade de limiar anaeróbio (Z2) e acima do limiar anaeróbio (Z3).

\subsubsection{Adequação metodológica}

A partir dos resultados observados durante o teste incremental, consideramos que a prescrição das sessões agudas de treinamento por meio do Lan, seria um risco para as próximas etapas do presente projeto. Desse modo, buscamos padronizar as sessões de treinamento em Z1, Z2 e Z3 a partir da Vmáx. Assim, foram realizadas tentativas para que os animais completassem as sessões de treinamento, mantendo a carga equalizada entre as zonas de treinamento. Para isso, tendo em vista a maior intensidade, a sessão em Z3 foi padronizada primeiramente, direcionando a quantificação das cargas relativas às outras zonas de treinamento.

\subsection{RESULTADOS}

\subsubsection{Teste incremental}

No plano de trabalho inicial, o teste incremental foi proposto para a determinação do Lan, possibilitando a prescrição das sessões de treinamento em Z1, Z2 e Z3. Todos os 
ratos foram capazes de completar ao menos cinco estágios, indicando que a velocidade inicial $\left(8 \mathrm{~m} \cdot \mathrm{min}^{-1}\right)$ e os incrementos $\left(3 \mathrm{~m} \cdot \mathrm{min}^{-1}\right)$ foram prescritos de maneira satisfatória.

Entretanto, as [La] não apresentaram o comportamento esperado, impossibilitando a determinação do Lan de maneira fidedigna (i. e., aumento abrupto da relação intensidade $v s$ [La]). Verificamos um baixo percentual de sucesso na determinação do Lan (i. e., 25\%). A Figura 3 demonstra o comportamento das [La] durante o teste incremental para cada rato. Além disso, elevadas [La] foram observadas no repouso $(2,29 \pm 0,51 \mathrm{mM})$, o que pode ter sido ocasionado pela transferência do animal da gaiola para a esteira. Desse modo, em todas as avaliações do presente projeto, os ratos permaneceram 10 min na esteira sem realizar qualquer atividade.
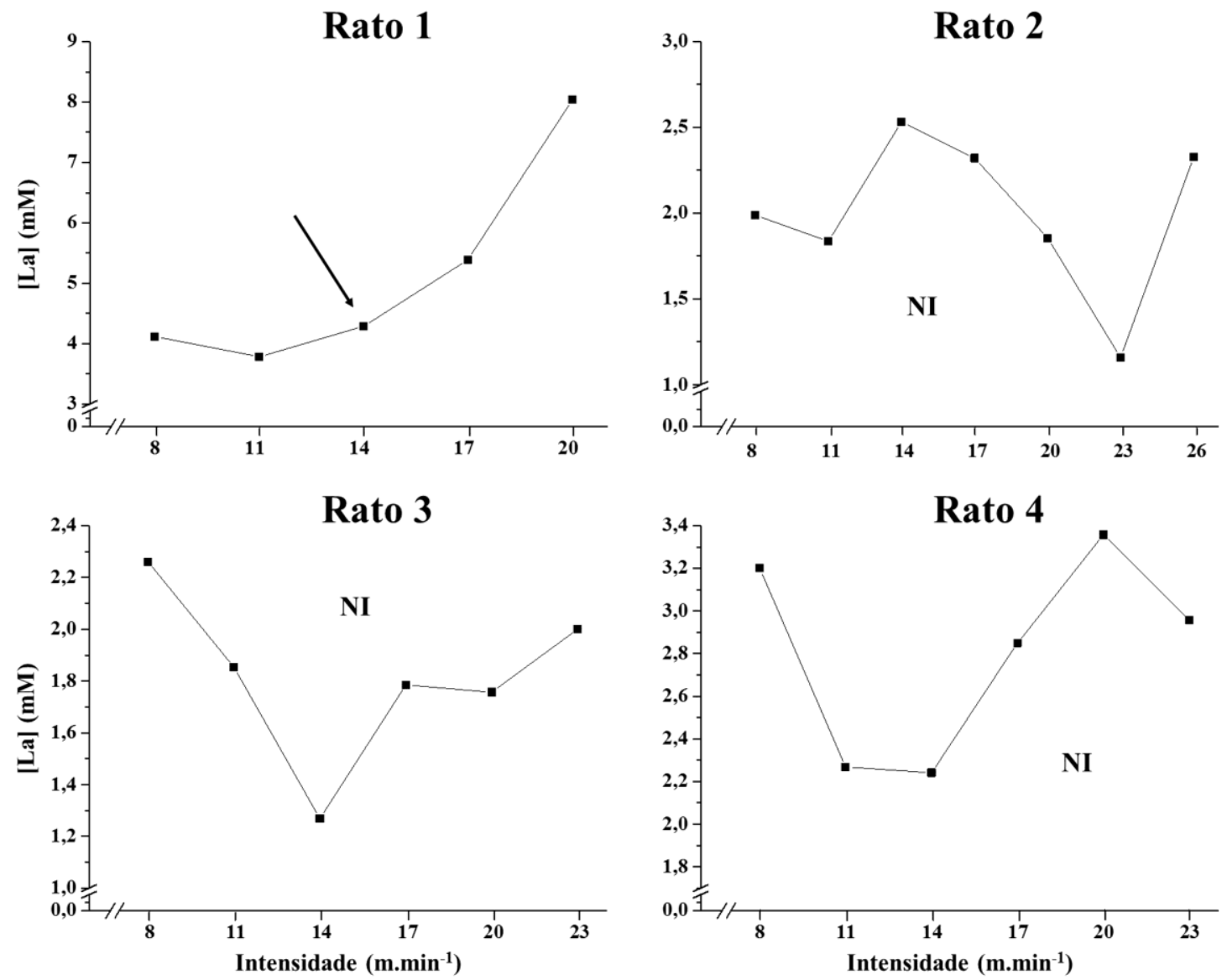

Figura 3. Comportamento das concentrações sanguíneas de lactato ([La]) durante o teste incremental. A determinação do limiar anaeróbio (Lan) de maneira fidedigna foi possível apenas para um rato (indicado pela flecha). $\mathrm{NI}=$ Lan não identificado. 


\subsubsection{Tentativa 1 de aplicação da sessão em Z3}

Dois animais realizaram a sessão de treinamento em Z3 prescrita a partir da Vmáx, que foi composta por cinco esforços de $300 \mathrm{~s}$ separados por $150 \mathrm{~s}$ de intervalo passivo. A intensidade foi correspondente a 100\% da Vmáx. Neste modelo de sessão, embora um animal tenha terminado todos os esforços $\left(\right.$ Vmáx $=20,42 \mathrm{~m} \cdot \mathrm{min}^{-1}$ ), os avaliadores aplicaram muitos estímulos (i. e., leve jato de ar na porção posterior do animal) desde o primeiro minuto de esforço. O segundo animal (Vmáx $=26,34 \mathrm{~m} \cdot \mathrm{min}^{-1}$ ) lesionou os membros posteriores.

\subsubsection{Tentativa 2 de aplicação da sessão em $Z 3$}

Diferentemente da Tentativa 1, dois ratos foram submetidos a cinco esforços de 320 segundos separados por 160 segundos de intervalo passivo. Agora a intensidade da sessão foi relativa a $90 \%$ da Vmáx. Neste modelo de sessão, os dois ratos completaram todos os esforços $\left(90 \%\right.$ da Vmáx $\left.=18,78 \pm 2,1 \mathrm{~m} \cdot \mathrm{min}^{-1}\right)$ e os estímulos foram dados apenas na segunda metade do último esforço. Desse modo, o exercício teve duração de 1600 segundos (26,7 minutos), levando a uma carga equivalente a 2400 u.a.

\subsection{CONCLUSÕES E ALTERAÇÕES PARA AS PRÓXIMAS ETAPAS}

A partir dos resultados obtidos neste estudo piloto é possível observar a dificuldade na determinação do Lan em modelo animal (i. e., primeiro ponto de inflexão da curva lactato-velocidade). Desse modo, acreditamos que o comportamento do lactato sanguíneo durante o teste incremental não foi um parâmetro adequado para prescrição do treinamento nestes animais.

Com base nos resultados apresentados anteriormente, realizamos a prescrição das sessões de treinamento utilizando a Vmáx. Optamos por testar a prescrição do treinamento em Z3, por se tratar da sessão com maior intensidade e, portanto, aquela com maior probabilidade dos animais entrarem em exaustão antes do termino. A Tentativa 1 demonstrou que a intensidade relativa a $100 \%$ da Vmáx foi pouco tolerada pelos animais, aumentando a probabilidade de os animais entrarem em exaustão sem completar a sessão e/ou apresentarem lesão. A partir disso, a Tentativa 2 foi prescrita com uma intensidade relativa a $90 \%$ da Vmáx, o que demonstrou os melhores resultados. 
Desse modo, para as próximas etapas, as sessões em Z3 foram aplicadas por meio de cinco esforços de 320 segundos separados por 160 segundos de intervalo passivo e intensidade relativa a 90\% da Vmáx. Esta sessão apresenta uma carga de 2400 u. a. (i. e., produto entre a intensidade (\%Vmáx) e o tempo de esforço (min)). Assim, para que as cargas sejam idênticas entre as zonas de treinamento, as intensidades e durações das sessões em Z1 e Z2 foram ajustadas para 2400 u. a. A Tabela 1 demonstra a prescrição das zonas de treinamento aplicada nas próximas etapas do presente projeto de pesquisa.

Tabela 1. Caracterização das sessões de treinamento em baixa (Z1), moderada (Z2) e alta (Z3) intensidade.

\begin{tabular}{cccc}
\hline & TE (min) & INT (\%Vmáx) & TRIMP \\
\hline $\mathrm{Z} 1$ & 48 & 50 & 2400 \\
$\mathrm{Z} 2$ & 32 & 75 & 2400 \\
$\mathrm{Z3}$ & 26,6 & 90 & 2400 \\
\hline
\end{tabular}

TE: tempo de esforço; INT: intensidade relativa a máxima velocidade no teste incremental; Vmáx = velocidade máxima de corrida; TRIMP: impulso de treinamento (carga dada pelo produto entre TE e a INT). 


\section{ESTUDO 1}

\subsection{OBJETIVO}

O objetivo do presente estudo foi investigar as respostas fisiológicas e moleculares de ratos Wistar, submetidos a três sessões agudas de treinamento, com diferentes relações entre volume e intensidade, mas com cargas equiparadas.

\subsection{METODOLOGIA}

\subsubsection{Animais}

Oitenta e um ratos da linhagem Wistar com 60 dias de idade, provenientes do Biotério Central da PUSP, com 89,1 \pm 5,4 gramas (peso no momento da aquisição dos animais). Durante todo o experimento, os animais foram mantidos em gaiolas coletivas, não excedendo quatro ratos por gaiola, em ciclo claro/escuro de 12/12 horas. Os experimentos foram realizados no período da manhã, pelos mesmos pesquisadores que faziam a manutenção dos animais nas gaiolas. Todos os animais receberam ração comercial (NUVILAB) e água ad libitum. Foi realizado o controle da ingestão de ração dos animais, através da pesagem realizada diariamente antes de cada procedimento. Todos os procedimentos do presente estudo foram submetidos e aprovados pelo Comitê de Ética e pesquisa no Uso de Animais da Escola de Educação Física e Esportes de Ribeirão Preto (protocolo ${ }^{\circ}$ 2018.5.31.90.5). Nove corresponderam à linha de base $\left(\mathrm{G}_{\mathrm{Base}}\right)$. Os demais foram divididos aleatoriamente em três grupos, treinamento sub-limiar $\left(\mathrm{G}_{\mathrm{Z1}} ; \mathrm{n}=24\right)$, treinamento na intensidade relativa ao limiar anaeróbio $\left(\mathrm{G}_{\mathrm{Z} 2} ; \mathrm{n}=24\right)$ e treinamento supra limiar $\left(\mathrm{G}_{\mathrm{Z} 3} ; \mathrm{n}=24\right)$.

\subsubsection{Desenho experimental}

Todos os procedimentos (treinamentos e avaliações) foram realizados em esteira rolante e os animais foram adaptados ao exercício durante 5 dias, correndo $10 \mathrm{~min}$. dia $^{-1}$ em intensidades entre 8 e $20 \mathrm{~m} \cdot \mathrm{min}^{-1}$. Ao final do período de adaptação os animais foram submetidos a um teste incremental para prescrição individual das intensidades das sessões de treinamento (sessão 5.2.3). Após o teste incremental realizado com todos os animais,

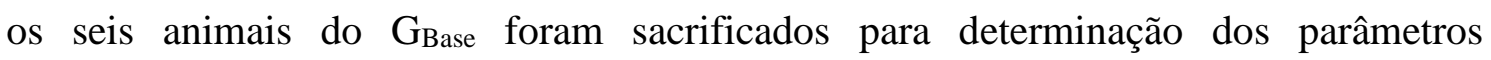


correspondentes a linha de base. Após a sessão aguda de treinamento $\left(\mathrm{G}_{\mathrm{Z} 1}, \mathrm{G}_{\mathrm{Z} 2}\right.$ e $\left.\mathrm{G}_{\mathrm{Z} 3}\right)$, seis animais de cada grupo foram sacrificados imediatamente ( $\mathrm{t} 0$ ) após, seis (t6), doze (t12) e 24 horas (t24) às suas respectivas sessões de treinamento (Figura 4).

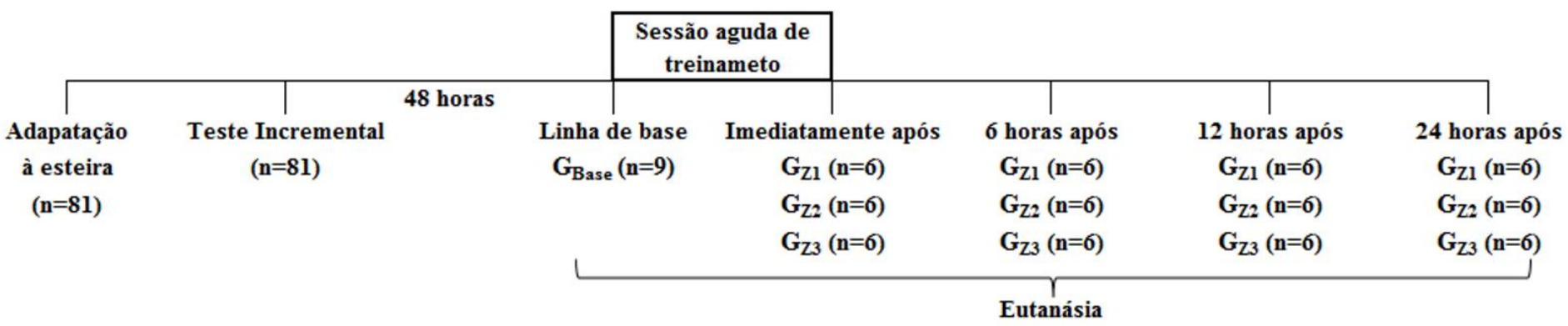

Figura 4. Representação esquemática dos procedimentos experimentais que envolveram a adaptação com todos os animais ao ergômetro, testes incrementais ( $\mathrm{G}_{\text {Base, }}, \mathrm{G}_{\mathrm{Z} 1}, \mathrm{G}_{\mathrm{Z} 2} \mathrm{e}$ $\mathrm{G}_{\mathrm{Z} 3}$ ), sessões agudas experimentais de treinamento e momentos de eutanásia. Gase: Animais que foram sacrificados para estimativa dos parâmetros correspondentes a linha de base; $\mathrm{G}_{\mathrm{Z1}}$ : Treinamento caraterizado por baixa intensidade e elevado volume; $\mathrm{G}_{\mathrm{Z2}}$ : Treinamento caraterizado por moderada intensidade e moderado volume; Gz3: Treinamento caraterizado por alta intensidade e reduzido volume.

\subsubsection{Teste incremental (TI) para determinação da Velocidade máxima de corrida} (Vmáx)

Para determinação da Velocidade máxima de corrida (Vmáx) foi utilizado o protocolo padronizado recentemente em nosso laboratório (Serrano, 2014). Nesse protocolo os animais foram submetidos a um teste incremental com velocidade inicial de $8 \mathrm{~m} \cdot \mathrm{min}^{-1}$ e com incremento de $3 \mathrm{~m} \cdot \mathrm{min}^{-1}$ a cada 3 minutos. A Vmáx atingida no teste foi registrada e ajustada considerando o tempo de permanência no último estágio como proposto por Kuipers et al. (1985) para ciclistas, e esta variável foi também utilizada para prescrição das sessões de treinamento.

\subsubsection{Sessões agudas e quantificação das cargas dos treinamentos}


As sessões de treinamento foram realizadas $48 \mathrm{~h}$ após o teste incremental. Os animais foram divididos primeiramente conforme a sessão, sendo posteriormente determinado o momento da eutanásia. Este processo foi realizado de maneira randomizada, sendo realizado um sorteio no início dos procedimentos.

Os grupos realizaram as sessões de treinamento em baixa (i. e., Z1) $\left(\mathrm{G}_{\mathrm{Z} 1}\right.$; volume $=48$ minutos; Intensidade $=50 \%$ da Vmáx), moderada (i. e., Z2) $\left(\mathrm{G}_{22}\right.$; volume = 32 minutos; Intensidade $=75 \%$ da Vmáx) e alta intensidade (i. e., Z3) $\left(G_{z 3}\right.$; volume $=26$ minutos e 40 segundos; Intensidade $=90 \%$ da Vmáx). $O \mathrm{G}_{Z 3}$ realizou a sessão de treinamento de modo intervalado, sendo composta por cinco esforços de 320 segundos separados por 160 segundos de intervalo passivo caracterizando, portanto, um modelo de treinamento intervalado de alta intensidade (HIIT). As alterações em relação ao proposto no projeto foram em função dos resultados do estudo piloto.

Apesar das sessões de treinamentos realizadas por $\mathrm{G}_{\mathrm{Z} 1}, \mathrm{G}_{\mathrm{Z} 2}$ e $\mathrm{G}_{\mathrm{Z} 3}$ apresentarem diferentes relações entre o volume e a intensidade, as cargas dos treinamentos, ou seja, o impulso do treinamento (TRIMP) foram equiparadas em 2400 u. a. O TRIMP foi assumido como o produto do volume (v; min) pela intensidade de corrida, relativa à Vmáx (\%Vmáx) (TRIMP = v.\%Vmáx), conforme adaptado de Araújo et al. (2010), inicialmente para exercício de natação (Figura 5).

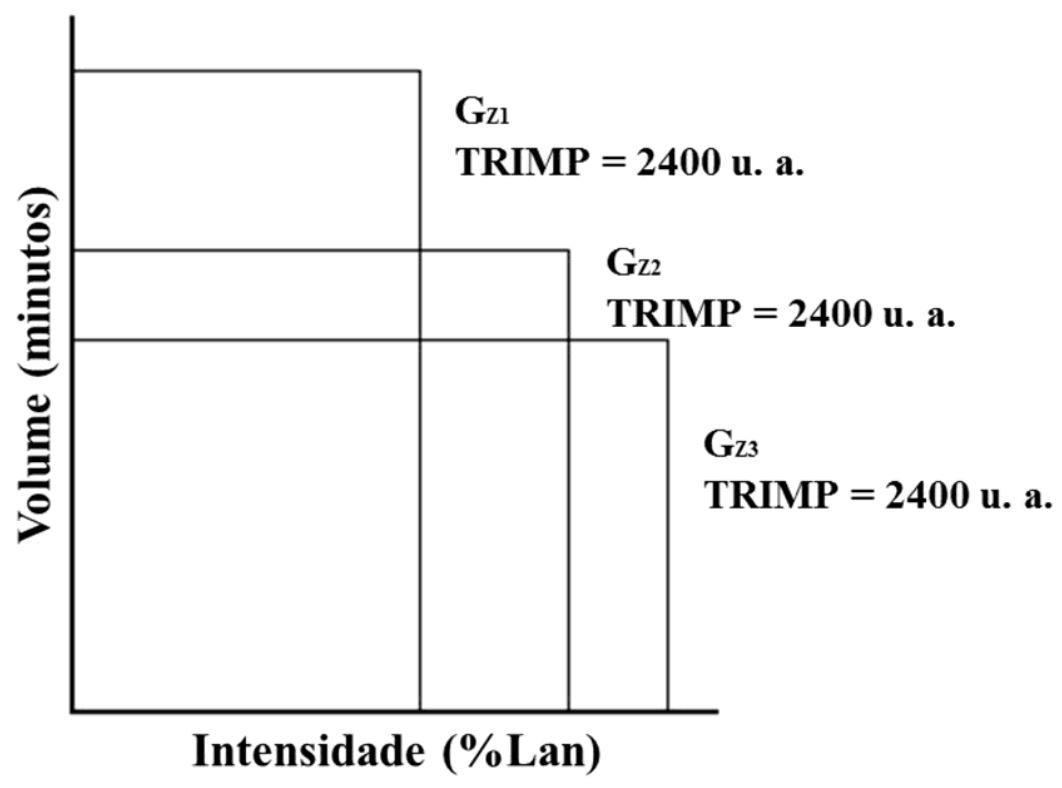


Figura 5. Representação esquemática da relação entre volume e intensidade, expressa em unidades arbitrárias (u.a.), que foram utilizadas para as composições das sessões dos treinamentos realizados abaixo (Z1), na intensidade de limiar anaeróbio (Z2) e acima do limiar anaeróbio (Z3).

Todos os estímulos de exercício foram aplicados de maneira individual e monitorados pelo mesmo pesquisador que realizou as sessões de familiarização e o teste incremental. Para caracterização dos estímulos, amostras de sangue $(25 \mu \mathrm{L})$ foram coletadas da extremidade distal da cauda dos animais para a determinação das concentrações de lactato ([La]) (YSI-2300; Yellow Springs Instruments ${ }^{\circledR}$, Ohio, USA). Estes procedimentos foram realizados imediatamente antes ao exercício, após $50 \%$ do volume proposto e imediatamente após o término do exercício. Para cada estímulo de exercício a taxa de acúmulo de lactato foi calculada pela equação: Taxa de acúmulo de lactato $=([$ La $]$ pico $-[$ La $]$ repouso $)$. volume $^{-1}$.

\subsubsection{Extração do músculo esquelético}

Antes (pré), imediatamente, seis, 12 e 24 horas após as sessões agudas de treinamento, seis animais de cada grupo $\left(\mathrm{G}_{\mathrm{z} 1}, \mathrm{G}_{\mathrm{z} 2}\right.$ e $\left.\mathrm{G}_{\mathrm{z} 3}\right)$ foram anestesiados através da administração intraperitoneal de xilazina $(10 \mathrm{mg} / \mathrm{kg}$ peso corporal) e quetamina (100 $\mathrm{mg} / \mathrm{kg}$ peso corporal) misturadas na mesma seringa. O controle da anestesia foi avaliado pela perda do reflexo podal (Pauli et al., 2008). Posteriormente, músculos sóleo, gastrocnêmio e EDL (extensor digitorum longus) e o fígado foram retirados para serem e armazenados a $-80^{\circ} \mathrm{C}$ para análise subsequente dos conteúdos e ativação das proteínas pela técnica de immunoblotting.

\subsubsection{Estimativa do Glicogênio muscular}

Para determinação da concentração dos músculos glicogênio dos músculos sóleo, gastrocnêmico e EDL foram utilizadas frações pesando entre 25-23mg, retiradas imediatamente após o sacrifício e foram digeridas em banho a 100/c em 0,5 mL de KOH $1 \mathrm{~N}$ durante 20 minutos. Foram adicionadas $20 \mu \mathrm{L}$ de solução saturada de $\mathrm{Na}_{2} \mathrm{SO}_{4}$ e o glicogênio foi precipitado através das duas passagens de $2,5 \mathrm{~mL}$ de etanol a quente, seguida de centrifugação, em $4 \mathrm{~mL}$ de água e a determinação colorimétrica realizada em 
$1 \mathrm{mM}$ de extrato, $20 \mu \mathrm{L}$ de fenol a $80 \%$ e $2,0 \mathrm{~mL}$ de ácido sulfúrico concentrado, após fervura de 15 minutos. A absorbância foi medida em espectrofotômetro 490nm. Soluções conhecidas de glicose foram utilizadas para curva de calibração (Dubois et al., 1956; Araujo et al., 2010).

\subsubsection{Immunoblotting}

Para a determinação do conteúdo de proteínas por Western blot os tecidos foram homogeneizados em tampão RIPA $50 \mathrm{mM}$ de Tris- $\mathrm{HCl}(\mathrm{pH} \mathrm{7,4)}$ contendo $150 \mathrm{mM}$ de $\mathrm{NaCl} ; 1 \mathrm{mM}$ de EDTA; $1 \%$ de Triton X-100; 0,1\% de SDS; $5 \mu \mathrm{g} / \mathrm{ml}$ de aprotinina; $1 \mathrm{mM}$ de PMSF; $10 \mathrm{mM}$ de ortovanadato de sódio; $100 \mathrm{mM}$ de NaF; $10 \mathrm{mM}$ de pirofosfofato de sódio; $10 \mathrm{uM}$ de tricostatina $\mathrm{A} ; 5 \mathrm{mM}$ de Nicotinamida. O homogenado foi centrifugado a 17.000 g por 20 minutos a $4^{\circ} \mathrm{C}$ e o sobrenadante foi separado para a realização da eletroforese e dosagem de proteínas pelo método de Lowry (Classics Lowry et al., 1951). Aos homogenados foi adicionado tampão da amostra (20\% de glicerol, $125 \mathrm{mM}$ de Tris$\mathrm{HCl}, 4 \%$ de SDS, 100mM de ditiotreitol, 0,02\% de azul de bromofenol, $\mathrm{pH} 6,8$ ) na proporção 1:4. Antes da realização da eletroforese, as amostras foram fervidas a $100^{\circ} \mathrm{C}$ por 5 minutos para a desnaturação das proteínas. Após a eletroforese, as proteínas foram transferidas do gel para membrana de nitrocelulose utilizando tampão (48mM de Tris, $39 \mathrm{mM}$ de glicina, SDS $10 \%$ e $20 \%$ de metanol) em um sistema semiseco por 30 minutos sob a voltagem fixa de 20 volts, à temperatura ambiente. (BioRad Trans-Blot SD Cell, EUA) (Towbin et al., 1979). Após o término da transferência, a membrana foi submetida a immunoblot. O bloqueio da membrana foi feito pela incubação por 1 hora, sob agitação, à temperatura ambiente em solução de leite desnatado em pó 5\%, diluído em solução TBS-T (20mM Tris-HCl; $160 \mathrm{mM}$ de $\mathrm{NaCl}$ e $0,1 \%$ Tween 20). A membrana foi então incubada overnight a $4^{\circ} \mathrm{C}$ sob agitação com anticorpos primários específicos (antiAMPK $\alpha$, p-AMPK $\alpha$ e anti- $\beta$-actina) diluídos em solução de TBS-T contendo 2,5\% de albumina bovina e $0,01 \%$ de azida sódica. No dia seguinte, a incubação com o anticorpo secundário foi feita por 1 hora à temperatura ambiente. As membranas foram reveladas em fotodocumentador (BioRad) utilizando kit de quimiluminescência amplificada (ECL, Amersham). As bandas reveladas foram fotografadas e quantificadas por densitometria utilizando o software Image Lab (BioRad). Após a quantificação densitométrica das proteínas. Os resultados foram expressos pela relação entre as densidades obtidas para a 
proteína de interesse e da proteína normalizadora, utilizada como controle de aplicação, conforme indicado em cada resultado.

\subsubsection{Análise estatística}

Os dados são apresentados em média \pm desvio padrão e variação percentual. Para verificar se os dados apresentam distribuição normal foi utilizado o teste de Shapiro-Wilk (IBM SPSS Statistics 20, São Paulo, SP). A comparação do conteúdo de glicogênio muscular e hepático entre os grupos e os momentos de eutanásia foi realizada por meio da Análise de Variância Two-Way, seguido quando necessário pelo teste Post-hoc de Fisher (Statistica 7.0® Statsoft, Tulsa, OK). Em todos os casos, o nível de significância foi estabelecido em $\mathrm{p}<0,05$

\subsection{RESULTADOS}

Foram necessários 90 ratos para a seleção de 81 animais corredores que compuseram o presente estudo, evidenciando um baixo índice de rejeição a partir do processo de seleção dos animais. A massa corporal dos ratos durante todo o monitoramento e o consumo de ração não foram diferentes entre os grupos $(p>0,05)$ (Figura 6). 

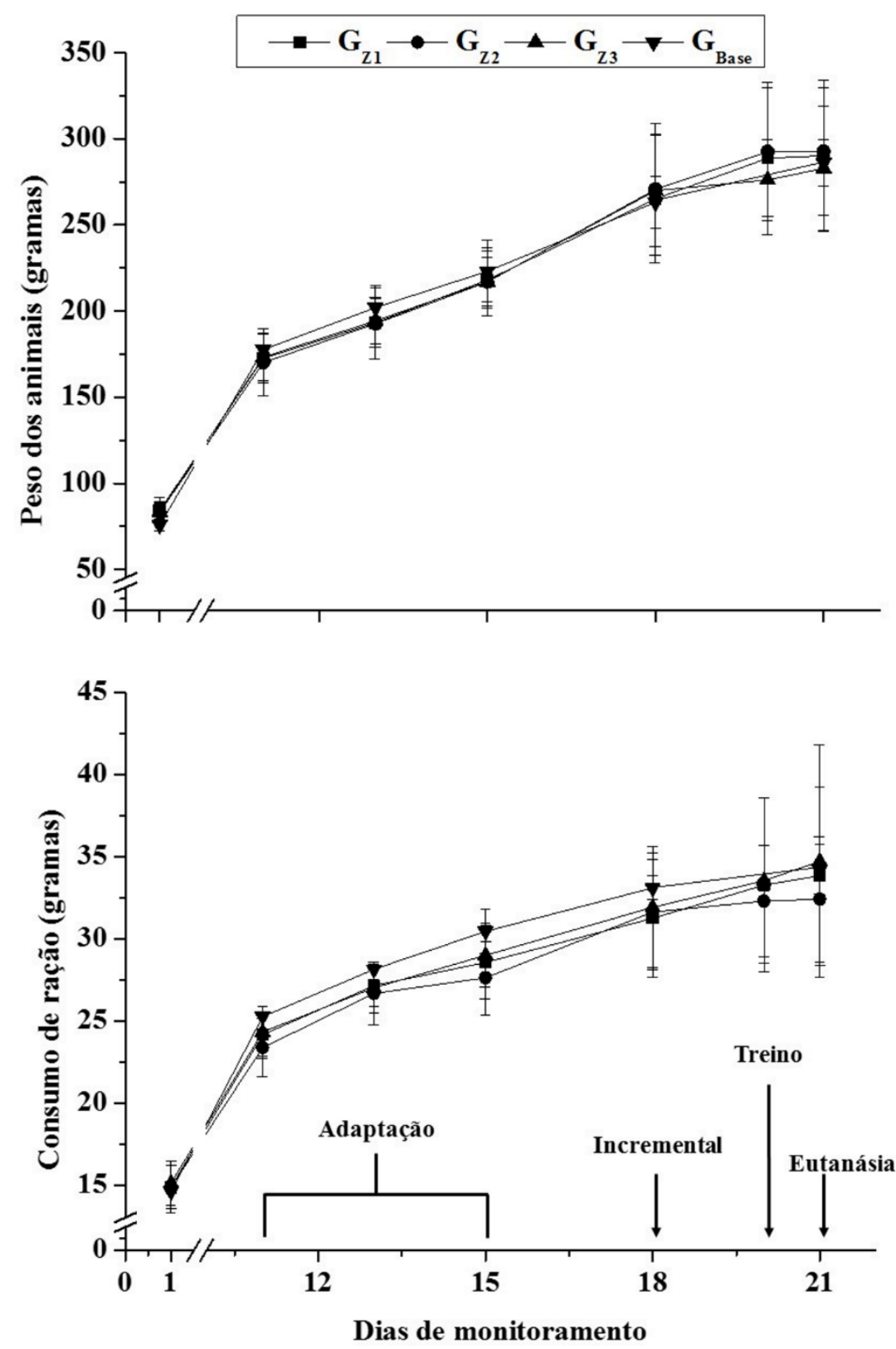

Figura 6. Massa corporal dos ratos e do consumo de ração referentes a todo o período de avaliações. $\mathrm{G}_{\mathrm{Z} 1}=$ treinamento sub-limiar; $\mathrm{G}_{\mathrm{Z} 2}=$ treinamento na intensidade relativa ao limiar anaeróbio; $\mathrm{G}_{\mathrm{Z} 3}=$ treinamento supra limiar; $\mathrm{G}_{\mathrm{Base}}=$ grupo linha de base.

\subsubsection{Caracterização das sessões de treinamento}

A taxa acúmulo de lactato calculado foi diferente nas três sessões na comparação entre si $(\mathrm{p}<0,05)$ (Figura 7). 


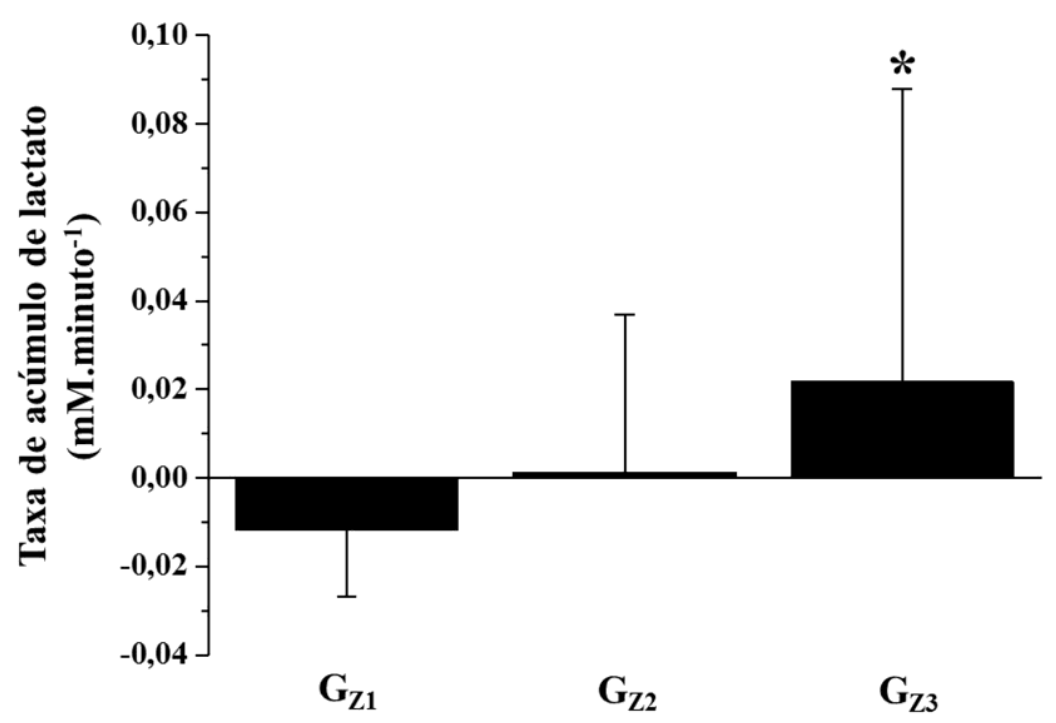

Figura 7. Caracterização das sessões de treinamento através da taxa de acúmulo de lactato. * = diferença significativa em comparação com $\mathrm{G}_{\mathrm{Z} 1}$; \# diferença significativa em comparação com o Gz2.

\subsubsection{Eutanásia e extração dos tecidos}

O peso dos ratos no dia da eutanásia, não foi diferente entre os grupos ( $p>0,05)$ (Figura 6). O consumo de ração 48h antes do sacrifício também não foi diferente entre os grupos ( $p>0,05)$ (Figura 6). Os tempos de eutanásia em relação a sessão de treinamento nos diferentes grupos está apresentado na Figura 8. Uma diferença de no máximo 20 min foi observada entre o horário previsto e o de eutanásia, sendo explicado por variações nos efeitos da anestesia (e. g., necessidade de uma dose adicional). A Figura 9 demonstra os pesos relativos aos músculos e da porção do fígado extraída nos diferentes grupos. Não foram observadas diferenças significativas entre os grupos para os pesos de tecido extraído ( $p>0,05)$. 


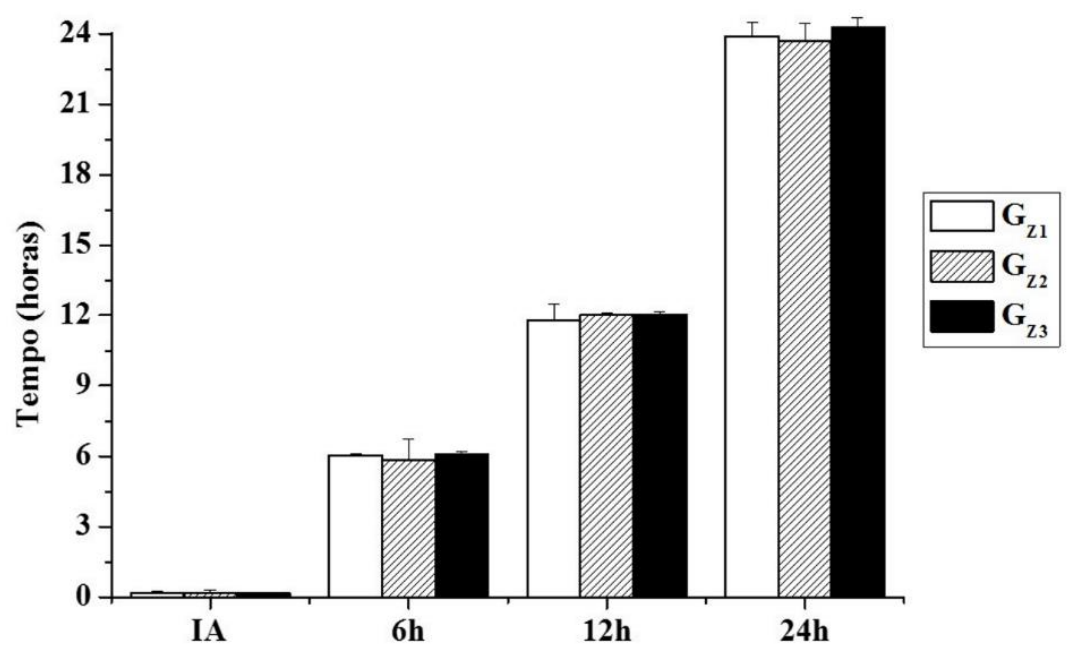

Figura 8. Tempo da eutanásia em relação à sessão de treinamento para os diferentes grupos e diferentes momentos de eutanásia. $\mathrm{IA}=$ imediatamente após; $\mathrm{G}_{\mathrm{Z} 1}=$ treinamento sub-limiar; $\mathrm{G}_{\mathrm{Z} 2}=$ treinamento na intensidade relativa ao limiar anaeróbio; $\mathrm{G}_{\mathrm{Z} 3}=$ treinamento supra limiar; \# = diferença estatística em relação ao grupo imediatamente após.
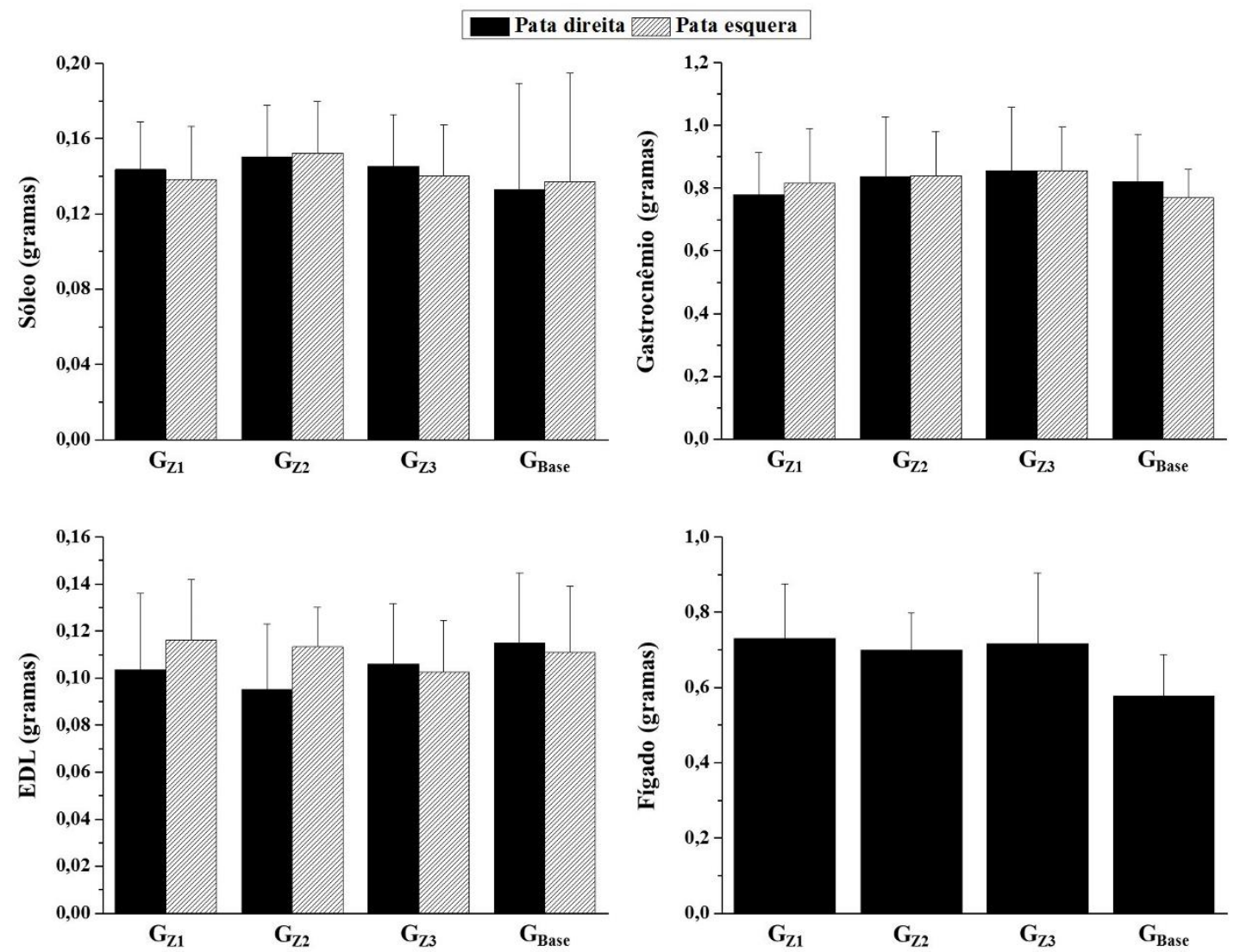
Figura 9. Peso dos tecidos extraídos durante a eutanásia nos diferentes grupos. $\mathrm{G}_{\mathrm{Base}}=$ grupo linha de base; $\mathrm{G}_{\mathrm{Z} 1}=$ treinamento sub-limiar; $\mathrm{G}_{\mathrm{Z} 2}=$ treinamento na intensidade relativa ao limiar anaeróbio; $\mathrm{G}_{\mathrm{Z} 3}=$ treinamento supra limiar.

\subsubsection{Estimativa do Glicogênio muscular e hepático}

No músculo sóleo, as [Glic] foram maiores em t6 e t12 em comparação com $\mathrm{G}_{\text {Base, }}$, t0 e t24 para $\mathrm{G}_{Z 1}, \mathrm{G}_{\mathrm{Z} 2}$ e $\mathrm{G}_{\mathrm{Z} 3}(\mathrm{p}<0,024)$ e em t24 foram menores em comparação com $\mathrm{t} 12$ apenas para $\mathrm{G}_{\mathrm{Z3}}(\mathrm{p}=0,038)$ (Fig. 10A). Na comparação das três sessões, as [Glic] foram maiores em t6 e t12 em comparação com $G_{\text {Base, }}$ t0 e t24 (p <0,022) (Fig. 10B). 

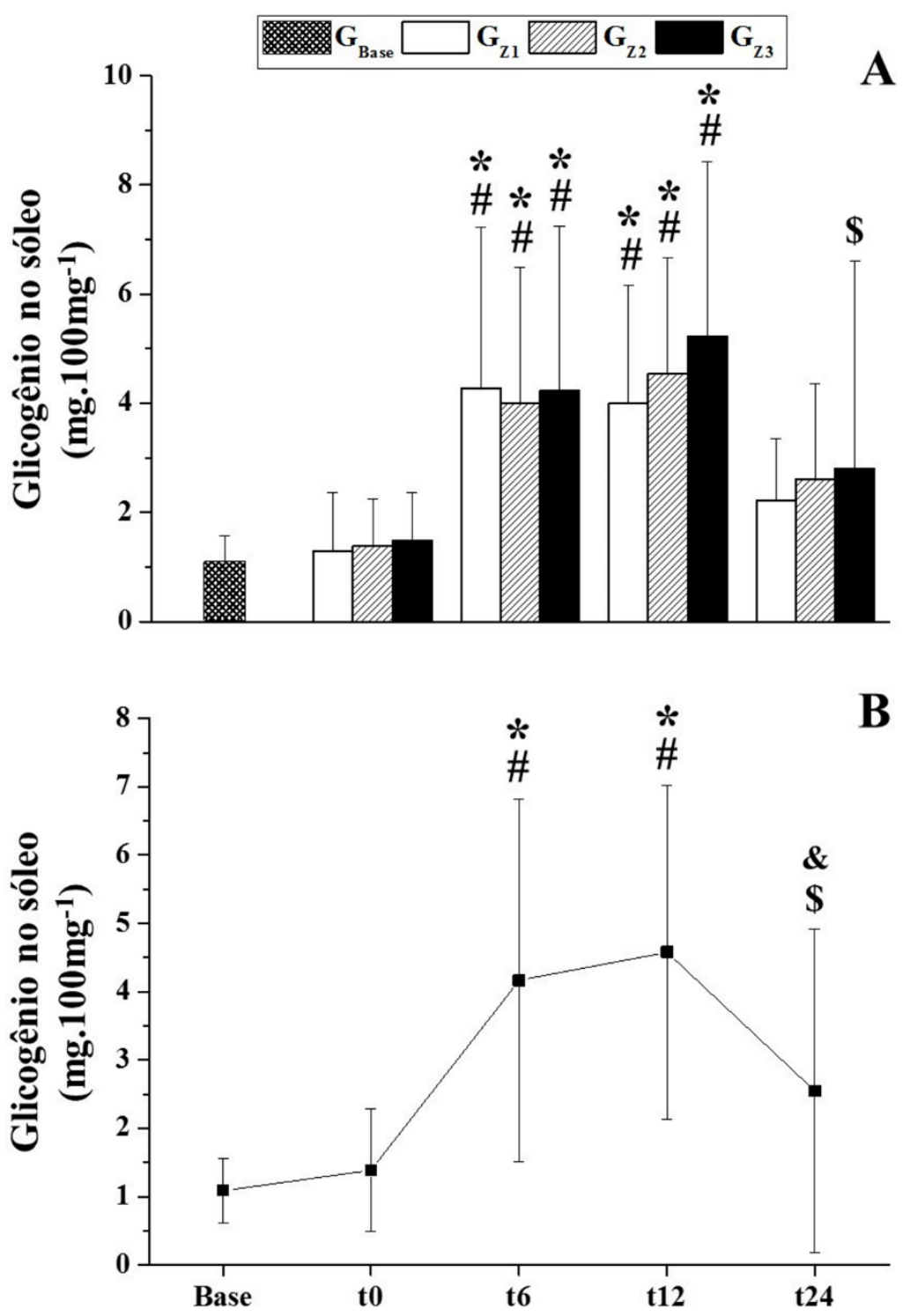

Figura 10. Cinética de depleção e recuperação do glicogênio no músculo sóleo e comparação entre as sessões de treinamento. $\mathrm{G}_{\mathrm{Base}}=$ grupo linha de base; $\mathrm{G}_{\mathrm{Z} 1}=$ treinamento sub-limiar; $\mathrm{G}_{\mathrm{Z} 2}=$ treinamento na intensidade relativa ao limiar anaeróbio; $\mathrm{G}_{\mathrm{Z3}}=$ treinamento supra limiar; t0 = eutanásia imediatamente após a sessão aguda de treinamento; t6 = eutanásia 6 horas após a sessão aguda de treinamento; t12 = eutanásia 12 horas após a sessão aguda de treinamento; t24 = eutanásia 24 horas após a sessão aguda de treinamento; $\mathrm{A}=$ comparação entre as sessões; $\mathrm{B}=$ média das três sessões $*=$ diferença estatística em relação ao grupo controle; \# = diferença estatística em relação ao grupo imediatamente após; \$ = diferença estatística em relação ao grupo 12 horas. 

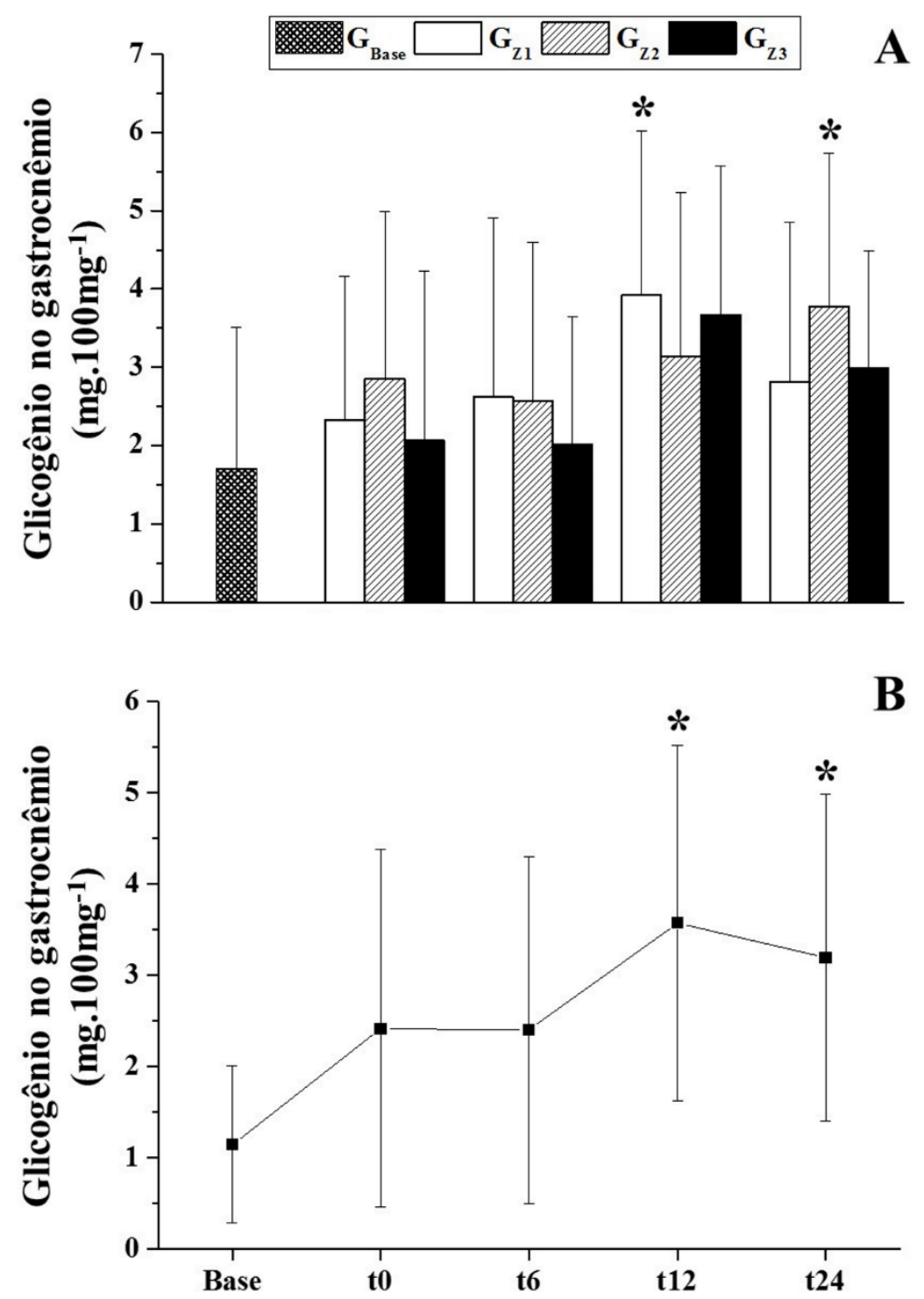

Figura 11. Cinética de depleção e recuperação do glicogênio no músculo gastrocnêmio e comparação entre as sessões de treinamento. $\mathrm{G}_{\mathrm{Base}}=$ grupo linha de base; $\mathrm{G}_{\mathrm{Z} 1}=$ treinamento sub-limiar; $\mathrm{G}_{\mathrm{Z} 2}=$ treinamento na intensidade relativa ao limiar anaeróbio; $\mathrm{G}_{\mathrm{Z} 3}=$ treinamento supra limiar; $\mathrm{t} 0$ = eutanásia imediatamente após a sessão aguda de treinamento; t6 = eutanásia 6 horas após a sessão aguda de treinamento; t12 = eutanásia 12 horas após a sessão aguda de treinamento; t24 = eutanásia 24 horas após a sessão aguda de treinamento; $\mathrm{A}=$ comparação entre as sessões; $\mathrm{B}=$ média das três sessões $*=$ diferença estatística em relação ao grupo controle. 
No músculo EDL, a [Glic] foi maior apenas em t6 em comparação com $\mathrm{G}_{\text {Base }}$ e t0 em Gz1 (p <0,046) (Fig. 12A). Na comparação das três sessões, a [Glic] foi maior em t6 em comparação com $G_{\text {Base, }}$ t0 e t24 e maior em t12 em comparação com t0 ( $\left.p<0,038\right)$ (fig. 12B).
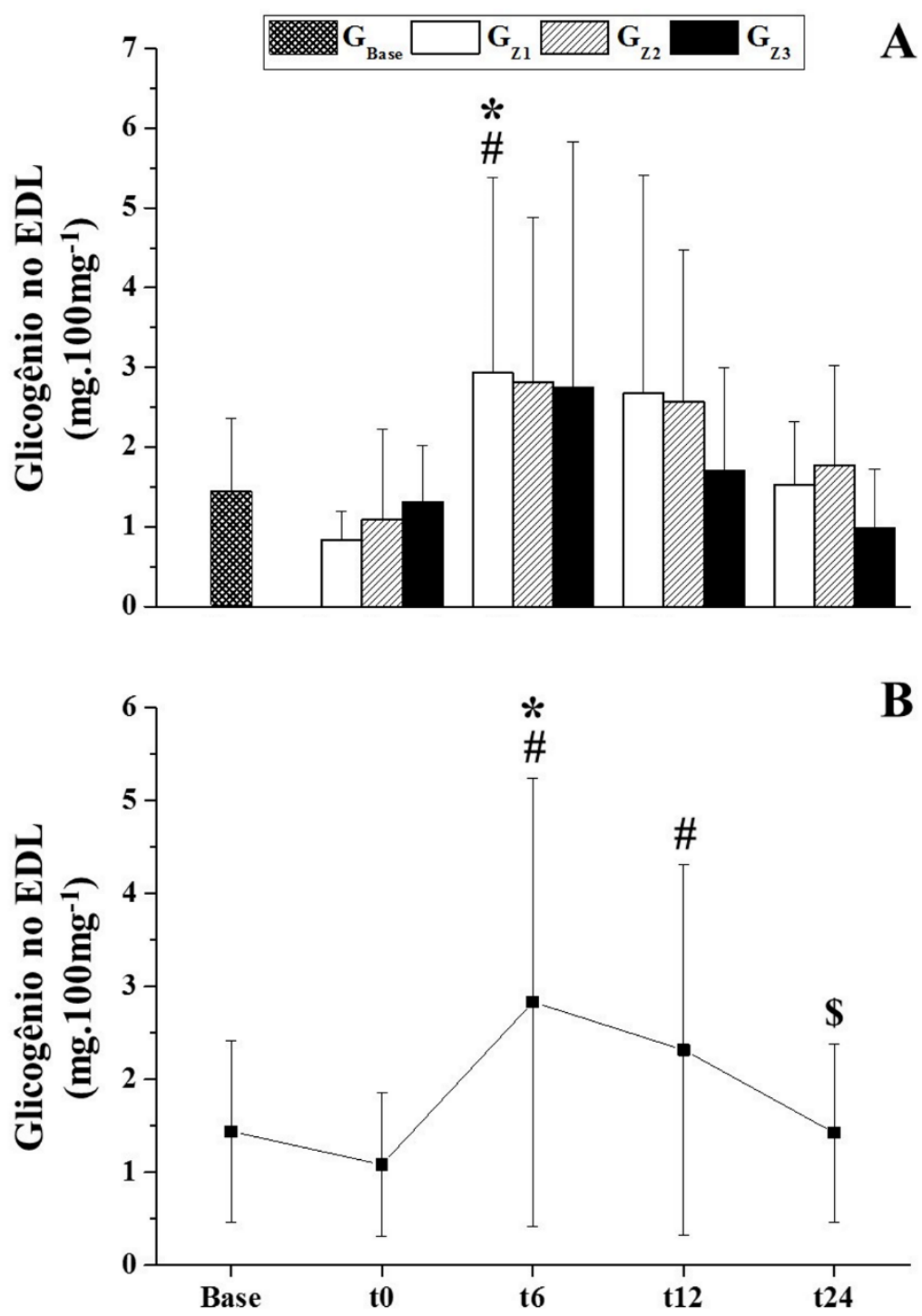

Figura 12. Cinética de depleção e recuperação do glicogênio no músculo EDL (extensor digitorum longus) e comparação entre as sessões de treinamento. $\mathrm{G}_{\mathrm{Base}}=$ grupo linha de base; $\mathrm{G}_{\mathrm{Z} 1}=$ treinamento sub-limiar; $\mathrm{G}_{\mathrm{Z} 2}=$ treinamento na intensidade relativa ao limiar anaeróbio; $\mathrm{G}_{\mathrm{Z} 3}=$ treinamento supra limiar; $\mathrm{t} 0$ = eutanásia imediatamente após a sessão aguda de treinamento; t6 = eutanásia 6 horas após a sessão aguda de treinamento; 12 = eutanásia 12 horas após a sessão aguda de treinamento; t24 = eutanásia 24 horas após a 
sessão aguda de treinamento; $\mathrm{A}=$ comparação entre as sessões; $\mathrm{B}=$ média das três sessões * = diferença estatística em relação ao grupo controle; \# = diferença estatística em relação ao grupo imediatamente após.

No fígado, a [Glic] foi menor em t6 em comparação com $\mathrm{G}_{\text {Base }}$ apenas para $\mathrm{G}_{\mathrm{Z} 3} \mathrm{e}$ foi maior em t24 em comparação com $\mathrm{G}_{\mathrm{Base}}$, $\mathrm{t} 0$, t6 e t12 para $\mathrm{G}_{\mathrm{Z} 1}, \mathrm{G}_{\mathrm{Z} 2}$ e $\mathrm{G}_{\mathrm{Z} 3}$ (p <0,032) (Fig. 13A). Na comparação das três sessões, os [Glic] foram menores em t6 em comparação com $\mathrm{G}_{\mathrm{Base}}, \mathrm{t} 0$ e $\mathrm{t} 12$ ( $\mathrm{p}<0,028$ ) e mais altos em $\mathrm{t} 24$ em comparação com $\mathrm{G}_{\mathrm{Base}}$, t0, t6 e t12 (p <0,001) (Fig. 13B).

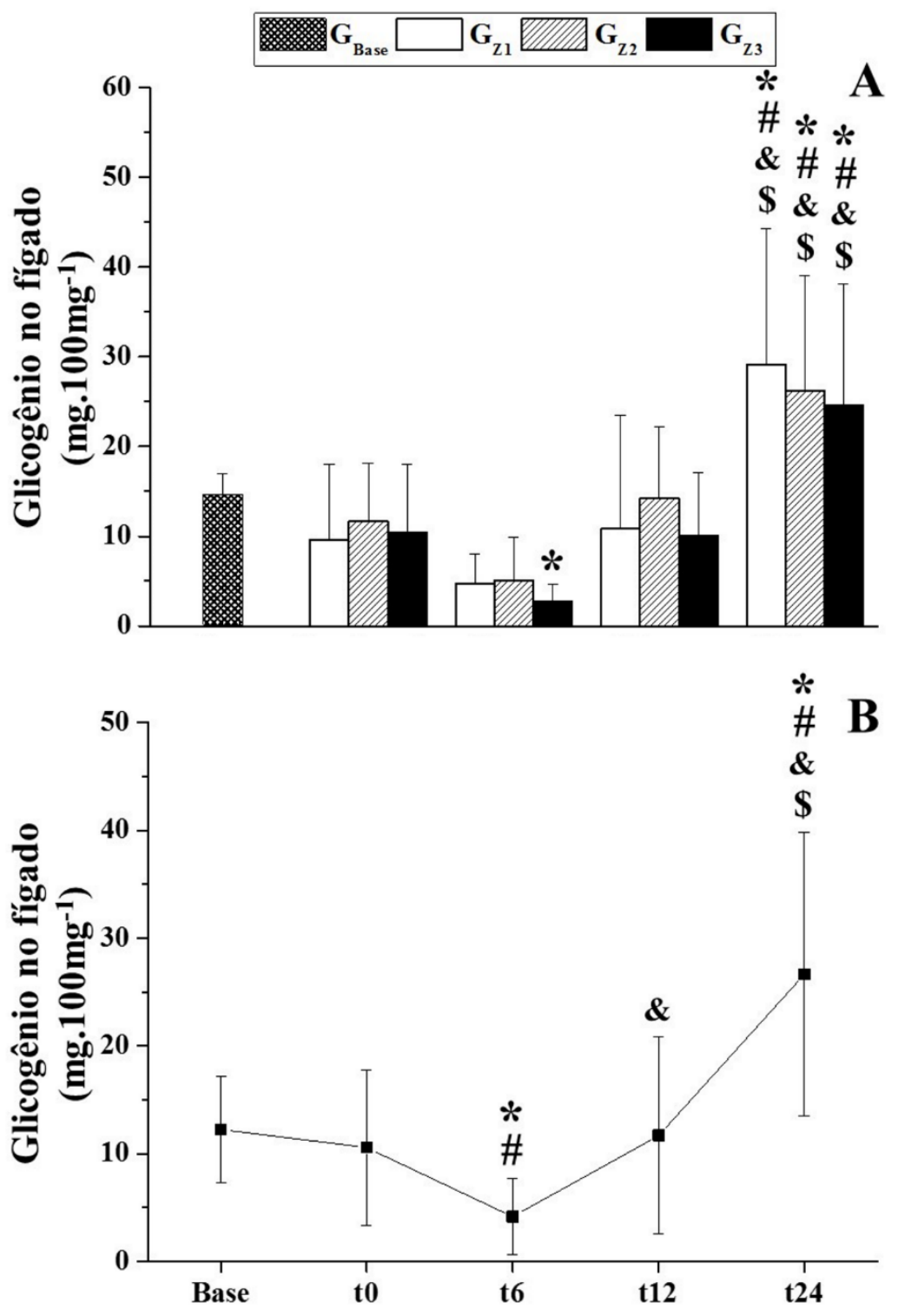


Figura 13. Cinética de depleção e recuperação do glicogênio no fígado e comparação entre as sessões de treinamento. $\mathrm{G}_{\mathrm{Base}}=$ grupo linha de base; $\mathrm{G}_{\mathrm{Z} 1}=$ treinamento sublimiar; $\mathrm{G}_{\mathrm{Z} 2}=$ treinamento na intensidade relativa ao limiar anaeróbio; $\mathrm{G}_{\mathrm{Z} 3}=$ treinamento supra limiar; t $0=$ eutanásia imediatamente após a sessão aguda de treinamento; t6 = eutanásia 6 horas após a sessão aguda de treinamento; t12 = eutanásia 12 horas após a sessão aguda de treinamento; t24 = eutanásia 24 horas após a sessão aguda de treinamento; $\mathrm{A}=$ comparação entre as sessões; $\mathrm{B}=$ média das três sessões * = diferença estatística em relação ao grupo controle; \# = diferença estatística em relação ao grupo imediatamente após; $\&=$ diferença estatística em relação ao grupo 6 horas; $\$=$ diferença estatística em relação ao grupo 12 horas.

A Figura 14 mostra a comparação da variação percentual em relação à linha de base dos músculos sóleo e EDL e do fígado. A variação percentual em t6 foi diferente entre os três tecidos ( $<$ <.001); em 112 para o sóleo comparado aos outros tecidos ( $p$ $<0.001)$ e em t24 para o EDL comparado aos outros tecidos ( $\mathrm{p}<0.009)$.

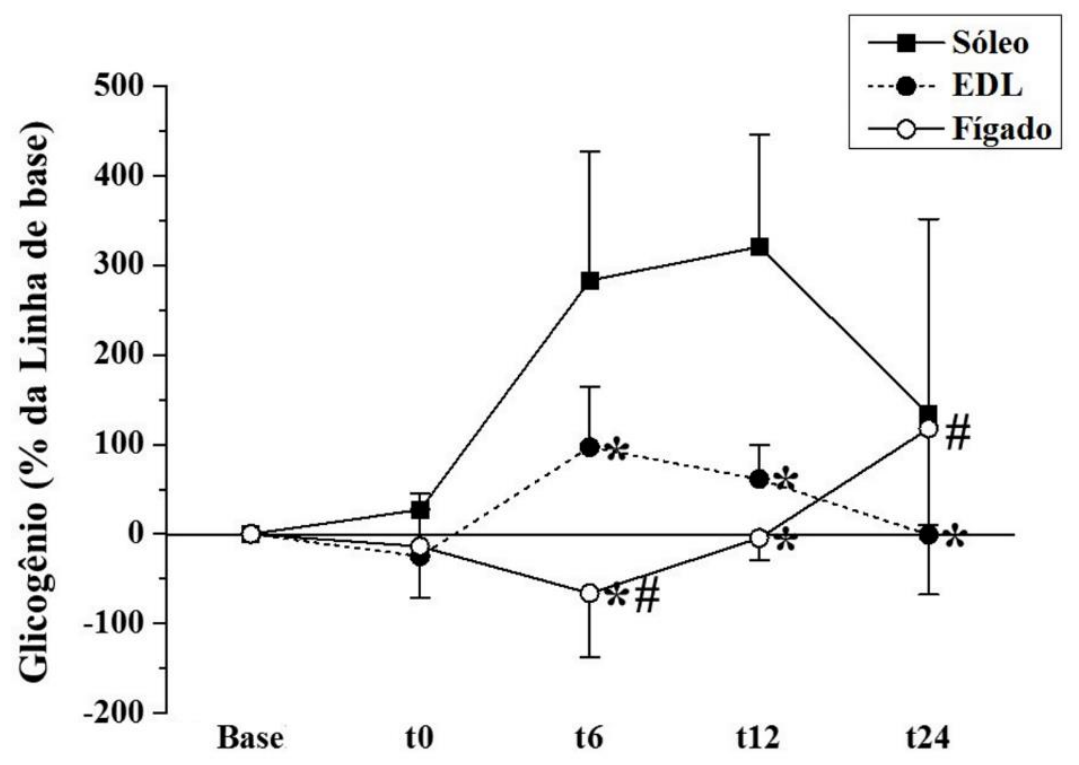

Figura 14. Comparação da variação percentual da cinética de depleção e recuperação do glicogênio nos músculos sóleo e EDL e no fígado. t0 = eutanásia imediatamente após a sessão aguda de treinamento; t6 = eutanásia 6 horas após a sessão aguda de treinamento; t12 = eutanásia 12 horas após a sessão aguda de treinamento; t24 = eutanásia 24 horas 
após a sessão aguda de treinamento; * = diferença estatística em relação ao músculo sóleo; \# = diferença estatística em relação ao músculo EDL.

\subsubsection{Conteúdo e atividade da AMPK}

Não foram encontradas diferenças no conteúdo proteico (Figura 15A), na proteína fosforilada (Figura 15B) e na atividade dada pela razão entre as duas (Figura 15C) para todos grupos $(\mathrm{p}<0,05)$.
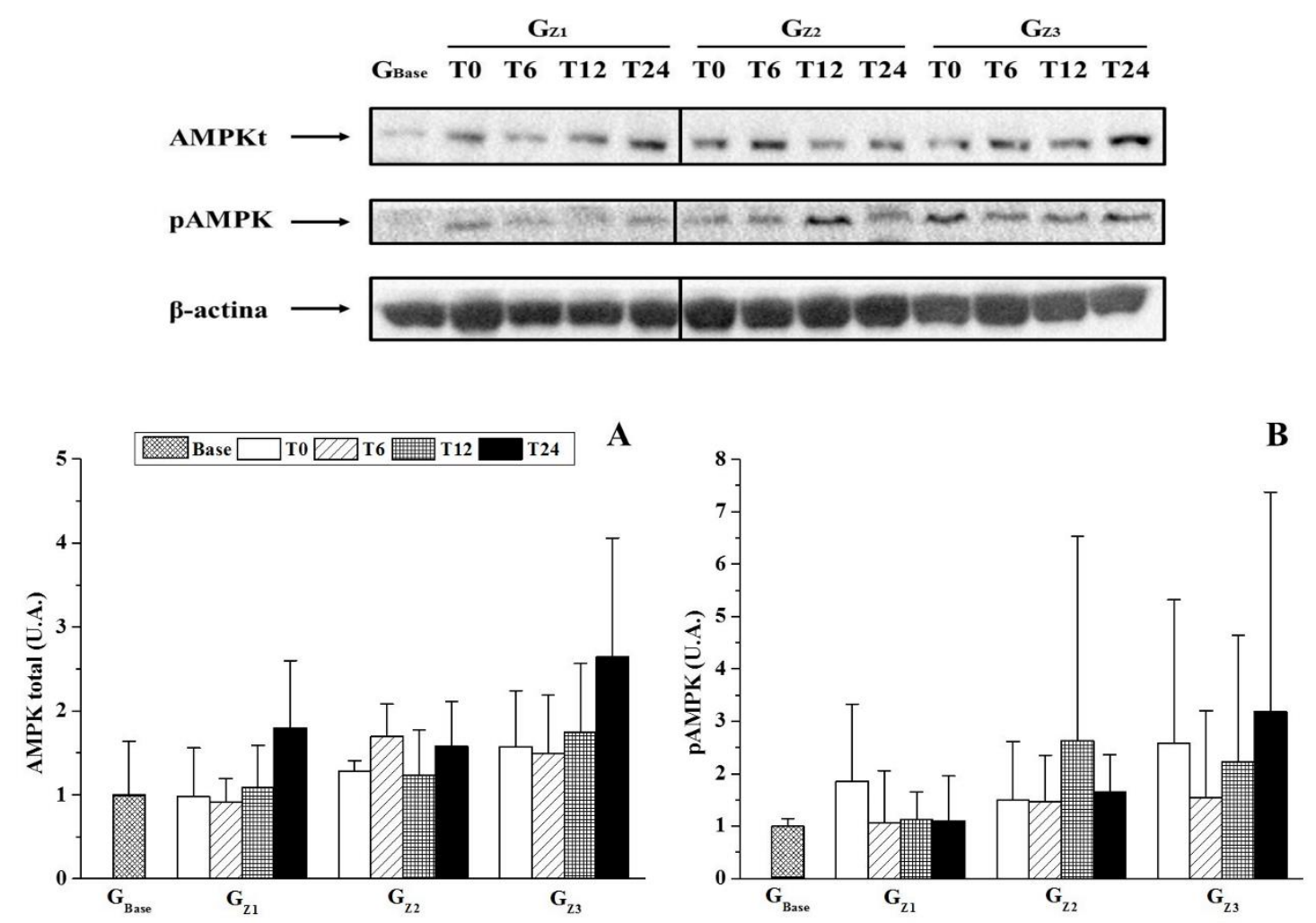

Figura 15. Conteúdo proteico total (A) e da proteína fosforilada (B) de AMPK no músculo sóleo. $\mathrm{G}_{\mathrm{Base}}=$ grupo linha de base; $\mathrm{G}_{\mathrm{Z} 1}=$ treinamento sub-limiar; $\mathrm{G}_{\mathrm{Z} 2}=$ treinamento na intensidade relativa ao limiar anaeróbio; $\mathrm{G}_{\mathrm{Z3}}=$ treinamento supra limiar; $\mathrm{T} 0$ = animais sacrificados imediatamente após o exercício; $\mathrm{T} 6$ = animais sacrificados 6 horas após o exercício; T12 = animais sacrificados 12 horas após o exercício; T24 = animais sacrificados 24 horas após o exercício. 


\subsubsection{Inferências sobre os resultados}

A partir dos resultados obtidos, pode-se concluir que os ajustes realizados com base nos resultados do estudo piloto, proporcionaram intensidades toleráveis nas diferentes sessões de treinamento, dado pelo alto índice de rejeição durante a seleção de ratos corredores. Desse modo, os objetivos do presente projeto foram mantidos, permitindo a investigação das respostas fisiológicas agudas induzidas por sessões de baixa (Z1), moderada (Z2) e alta intensidade (Z3).

Os resultados demonstram que a randomização dos animais nas diferentes zonas e nos diferentes momentos de eutanásia, foi eficaz na homogeneização dos grupos. Adicionalmente, o peso dos animais e o consumo de ração durante o delineamento, demonstram que as avaliações e a eutanásia estão ocorrendo em um estado nutricional similar (Figura 5).

Além disso, o procedimento de extração dos tecidos foi realizado conforme o planejamento inicial (Figura 8) e também não houve diferença no peso dos tecidos extraídos entre os grupos (Figura 9).

As [Glic] analisadas do músculo gastrocnêmio apresentaram grande variação entre para todos os grupos (coeficiente de variação: $Z 1=73,53 ; Z 2=69,56 ; Z 3=72,65$ ), portanto apesar das diferenças estatisticamente significativas encontradas nos momentos 12 e 24 horas após a sessão aguda, optamos por não incluir esses resultados em futuras publicações pela não confiabilidade que temos a partir de conclusões provenientes destes resultados em específico. Por esse motivo, também optamos em não discutir esses resultados neste documento.

\subsection{DISCUSSÃO}

No presente estudo, testamos a hipótese de que sessões de treinamento induziriam o fenômeno de supercompensação de glicogênio em todos os tecidos analisados, com diferentes respostas entre os músculos e para o fígado. Considerando que as três sessões agudas têm a mesma carga de treinamento (i. e., 2.400 u. a.), agrupamos as [Glic] das três sessões em um mesmo grupo para cada tecido, a fim de verificar a influência da carga na modulação das [Glic]. Não verificamos a depleção de glicogênio em nenhum dos tecidos 
analisados imediatamente após o exercício, mas observamos a supercompensação desse substrato, que ocorreu entre 6 e 12 horas após o estímulo de exercício, com maior magnitude de resposta no músculo sóleo, enquanto em o tecido hepático ocorreu apenas 24 após o exercício.

Um fator que pode influenciar o metabolismo do glicogênio é a ingestão calórica antes e após o exercício (Hearris et al., 2018). No presente estudo, não encontramos diferença na ingestão diária de alimento entre os grupos em nenhum momento, o que garante que as diferenças encontradas resultam apenas da manipulação dos estímulos de exercício e dos tecidos analisados. Além disso, encontramos diferenças significativas na taxa de acúmulo de lactato entre os grupos Z1 e Z3, indicando que o estresse fisiológico induzido pelo exercício aumentou de modo concomitante à intensidade do estímulo.

É importante destacar que ainda não há consenso na literatura sobre o conteúdo de glicogênio muscular em diferentes tipos de fibras musculares (Hearris et al., 2018). A partir de técnicas histoquímicas realizadas em homens, foi relatado que não há diferença nas [Glic] entre as fibras do tipo I e do tipo II (Essén e Henriksson, 1974; Stellingwerff et al., 2007). No entanto, a partir da quantificação bioquímica também em homens (medida mais quantitativa), a [Glic] parece ser maior em fibras do tipo II em comparação com fibras do tipo I (Tsintzas et al., 1995; 1996). No presente estudo, não encontramos

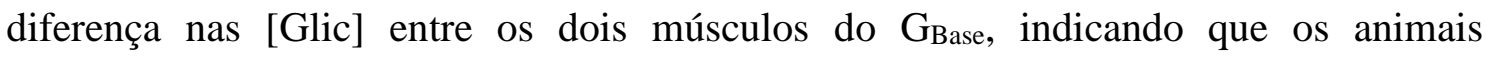
apresentaram quantidades semelhantes deste substrato em músculos com diferentes composições de fibras.

Evidências indicam que a depleção de glicogênio como resultado de exercício físico ocorre primeiro nas fibras do tipo I (oxidativas) e, à medida que o exercício se estende, a depleção de glicogênio ocorre progressivamente também nas fibras do tipo II (glicolíticas) (Gollnick et al., 1974). Portanto, espera-se que a supercompensação de glicogênio seja maior nas fibras do tipo I. Entretanto, no presente estudo, a depleção de glicogênio não foi observada nos músculos analisados imediatamente após as sessões, mas as [Glic] no sóleo foram maiores que no EDL 6 horas após as sessões, indicando que em diferentes músculos a modulação de intensidade não altera a cinética de depleção, mas a recuperação e supercompensação de glicogênio, desde que a carga seja equalizada entre as diferentes sessões de exercício. 
Na comparação entre os músculos, a variação percentual do glicogênio apresentou uma supercompensação mais acentuada 6 horas após as sessões no músculo sóleo em relação ao EDL. Assim, observamos que o tecido muscular mais responsivo às sessões de treinamento é o de fibras do tipo I (i. e., o músculo sóleo no presente estudo), o que é esperado considerando que o metabolismo predominante nos esforços do presente estudo foi o aeróbio. Uma possível explicação para esse achado pode ser a atividade dos transportadores de glicose através da membrana celular, especialmente a translocação do GLUT-4 do citosol para o sarcolema (Fueger et al., 2005) e também da fosforilação intracelular da enzima hexoquinase (Baldwin et al., 1973; Röckl et al., 2007), que desempenha um papel importante na modulação do consumo de glicose pelo exercício físico estimulado pelo músculo (Fueger et al., 2005), mais acentuadamente em tecidos com fibras do tipo I (Baldwin et al., 1973; Röckl et al., 2007).

No fígado, ao contrário do tecido muscular, a depleção de glicogênio foi observada 6 horas após a sessão. Conlee et al. (1987) observaram a depleção de glicogênio hepático imediatamente após o término de uma sessão de exercício de natação de 90 minutos em ratos. Provavelmente, não observamos no presente estudo a depleção após o exercício devido à duração das sessões que não ultrapassaram 48 minutos (Z1). Além disso, o fenômeno da supercompensação foi observado 24 horas após a sessão para todas as sessões, o que é esperado, considerando a depleção de [Glic] em t6.

Sabe-se que os processos de glicogenólise hepática e síntese de glicogênio muscular ocorrem simultaneamente (Gonzalez et al., 2016). Portanto, acredita-se que esses processos ocorram simultaneamente durante o período de recuperação da sessão de exercício físico. No presente estudo, considerando a comparação de todas as sessões, observou-se depleção hepática das [Glic] 6 horas após, que é o mesmo momento em foram encontradas as maiores [Glic] nos músculos sóleo e EDL, evidenciando uma provável associação entre esses achados, reforçada pela diferença significativa entre a variação percentual do fígado e os tecidos musculares 6 horas após as sessões de treinamento.

De acordo com a teoria geral de adaptação atualmente aceita e proposta por Selye (1936), a supercompensação de substratos energéticos deve ocorrer somente após sua depleção induzida por algum estresse fisiológico (Cunanan et al., 2018), mas no presente 
estudo observamos que o exercício não causou depleção de [Glic], provavelmente devido ao fato de os animais não terem atingido a exaustão (Ørtenblad et al., 2013; Areta e Hopkins, 2018), mas ocorreu o fenômeno de supercompensação de glicogênio.

Uma possível explicação para os achados do presente estudo seria a ativação da AMPK aumentada no período de recuperação levando a aumento nas [Glic], pois baixos níveis de glicogênio muscular estão relacionados com aumento da atividade da AMPK (Kjøbsted et al., 2018), que por sua vez colabora no processo de síntese de glicogênio. No presente estudo não foram observadas alterações no conteúdo de AMPK (proteína total e da proteína fosforilada) no músculo sóleo. Como não observamos depleção no conteúdo muscular de glicogênio logo após as sessões de exercício é plausível que alterações na atividade da AMPK também não sejam observadas.

Os resultados apresentados anteriormente podem ser explicados a partir de duas hipóteses: i) o lactato produzido durante o exercício foi convertido em glicose e depois em glicogênio, pois sabe-se que isso pode ocorrer em situações de baixo nível de glicogênio (Fournier et al., 2004), mas isso é apenas especulação, uma vez que não observamos elevadas [La] após o término das sessões $(\mathrm{Z} 1=1,28 \pm 0,28 ; \mathrm{Z} 2=1,82 \pm 1,02 \mathrm{e}$ $\mathrm{Z} 3=2,57 \pm 1,61)$; ii) o exercício foi estímulo suficiente para a ativação da glicogênio sintase e aliado ao consumo de alimentos ad libitum após o exercício (Doering et al., 2019) causou um aumento nas [Glic] após a ingestão de fontes de carboidratos após o exercício, corroborando com Nakatani et al. (1997), demonstrou que em modelo animal, aumento da atividade de GS após o exercício de natação, sem depleção de [Glic] e um subsequente aumento de glicogênio entre 4 e 48 horas após o exercício e iii). Este último corrobora com Hingst et al. (2018) que demonstraram a glicogênio sintase é um reguladores-chave da supercompensação de glicogênio após um único estímulo de exercício no músculo esquelético do homem e do camundongo.

Embora a extrapolação de modelos animais para a fisiologia humana seja limitada, os resultados do presente estudo apontam para uma diferenciação de recuperação das [Glic] de acordo com o músculo estudado e não pela intensidade realizada, o que parece estar relacionado às diferentes distribuições de fibras (i. e., tipo I, predominante em sóleo e tipo II, predominante em EDL), enquanto que, no tecido hepático, a supercompensação 
de glicogênio é observada apenas mais tarde em comparação ao tecido muscular, de modo que a glicogenólise hepática pode estar relacionada à síntese de glicogênio muscular.

Destacamos como limitações do presente estudo a não mensuração da glicemia durante o experimento e também o fato de que o controle da ingestão alimentar não ter sido realizado individualmente. Assim, não foi possível relacionar a depleção de glicogênio e a cinética de recuperação com o exercício associado ao estado nutricional.

\subsection{CONCLUSÃO}

A depleção de glicogênio muscular e hepática e a cinética de recuperação não parecem ser moduladas pela intensidade do exercício quando a carga é equalizada, mas os efeitos são diferentes nos diferentes tecidos. Os processos de glicogenólise hepática e síntese de glicogênio muscular parecem estar relacionados. 


\section{ESTUDO 2}

\subsection{OBJETIVO}

O objetivo do presente estudo foi investigar as respostas fisiológicas e moleculares de ratos Wistar Hannover, submetidos a três modelos crônicos de 5 semanas de treinamento, com diferentes relações entre volume e intensidade, mas com cargas equiparadas.

\subsection{METODOLOGIA}

\subsubsection{Animais}

Vinte e quatro ratos da linhagem Wistar Hannover com 60 dias de idade, provenientes do Biotério Central da PUSP, com 188,8 \pm 16,8 gramas (peso no momento da aquisição dos animais). Durante todo o experimento, os animais foram mantidos em gaiolas coletivas, não excedendo quatro ratos por gaiola, em ciclo claro/escuro de 12/12 horas. Os experimentos foram realizados no período da manhã, pelos mesmos pesquisadores que faziam a manutenção dos animais nas gaiolas. Todos os animais receberam ração comercial (NUVILAB) e água ad libitum. Foi realizado o controle da ingestão de ração dos animais, através da pesagem realizada diariamente antes de cada procedimento. Todos os procedimentos do presente estudo foram submetidos e aprovados pelo Comitê de Ética e pesquisa no Uso de Animais da Escola de Educação Física e Esportes de Ribeirão Preto (protocolo $n^{\circ}$ 2018.5.31.90.5). Os animais foram divididos aleatoriamente em quatro grupos: controle, treinamento em baixa intensidade $(Z 1 ; n=6)$, treinamento em moderada intensidade $(\mathrm{Z} 2 ; \mathrm{n}=6)$ e treinamento em alta intensidade ( $\mathrm{Z} 3$; $n=6)$.

\subsubsection{Desenho experimental}

Todos os procedimentos (treinamentos e avaliações) foram realizados em esteira rolante e os animais foram adaptados ao exercício durante 5 dias, correndo $10 \mathrm{~min}$. dia $^{-1}$ em intensidades entre 8 e $20 \mathrm{~m} \cdot \mathrm{min}^{-1}$. Todos os procedimentos foram realizados no período da manhã. Ao final do período de adaptação os animais foram submetidos a um teste incremental para prescrição individual das intensidades das sessões de treinamento (sessão 5.2.3). Os animais foram divididos aleatoriamente em quatro grupos: grupo 
controle $(n=6)$; grupo treinamento de baixa intensidade $(Z 1 ; n=6)$; grupo treinamento de moderada intensidade $(Z 2 ; n=6)$ e grupo treinamento de alta intensidade $(Z 3 ; n=6)$. Após o teste incremental os animais iniciaram os protocolos de treinamento que teve a duração de 5 semanas. 48 após a sexta (2 semanas) e décima segunda (4 semanas) sessões de treinamento os animais realizaram novamente o teste incremental para reajuste da intensidade de treino e para avaliação de desempenho (Figura 16). Após o último teste incremental, os animais foram submetidos a mais uma semana de treinamento para minimizar uma possível influência deste teste nas respostas biomoleculares posteriormente analisadas. As sessões utilizadas para compor os programas de treinamento foram exatamente as mesmas padronizadas no Estudo Piloto e utilizadas no Estudo 1 (Tabela 1).

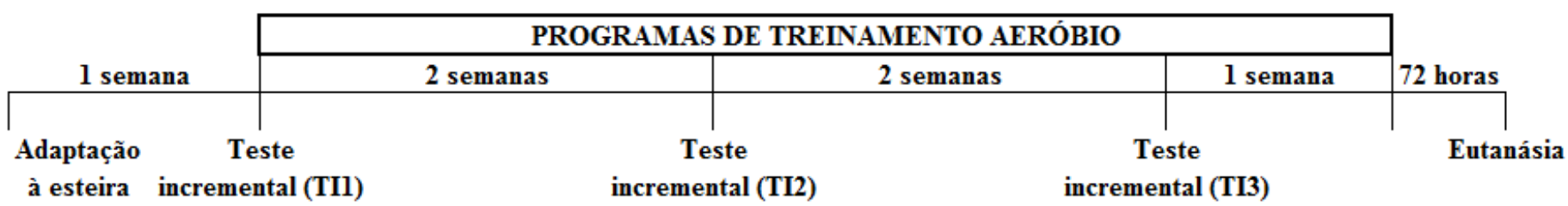

Figura 16. Cronograma de aplicação de avaliações que incluem adaptação à esteira, testes incrementais, programas de treinamento e eutanásia. TI = teste incremental.

\subsubsection{Programas de treinamento}

Os animais foram submetidos a 3 modelos (Z1, Z2 e Z3) de 5 semanas de treinamento de corrida com uma frequência de 3 vezes por semanas totalizando 15 sessões. A carga das sessões de treinamento foi equiparada entre as sessões (i. e., $2400 \mathrm{u}$. a.) (Tabela 2). 
Tabela 2. Variáveis que compõem as sessões de treinamento prescritas.

\begin{tabular}{ccccc}
\hline Grupos & Volume & Intensidade & Frequência & Carga \\
\hline Z1 & 48 minutos & $50 \%$ da Vmáx & 3 vezes por semana & 2400 u. a. \\
Z2 & 32 minutos & $75 \%$ da Vmáx & 3 vezes por semana & 2400 u. a. \\
Z3 & 5 x 5,33 minutos & $90 \%$ da Vmáx & 3 vezes por semana & 2400 u. a. \\
\hline
\end{tabular}

$\mathrm{Z1}$ = grupo treinamento de baixa intensidade; $\mathrm{Z2}$ = grupo treinamento de moderada intensidade; Z3 = grupo treinamento de alta intensidade; Vmáx = velocidade máxima de corrida; u. a. = unidades arbitrárias.

Foram realizados ajustes das cargas de acordo com os testes incrementais que foram aplicados anteriormente às semanas 1,3 e 5 , com o objetivo de adequar o estado de treinamento dos animais à carga proposta.

\subsubsection{Extração do músculo esquelético}

Setenta e duas horas após a última sessão de treinamento, seis animais de cada grupo (controle, Z1, Z2 e Z3) foram anestesiados através da administração intraperitoneal de xilazina (10 mg/kg peso corporal) e quetamina (100 mg/kg peso corporal) misturadas na mesma seringa. O controle da anestesia foi avaliado pela perda do reflexo podal (Pauli et al., 2008). Posteriormente, músculos sóleo, e EDL (extensor digitorum longus) e o fígado foram retirados para serem e armazenados a $-80^{\circ} \mathrm{C}$ para análise subsequente dos conteúdos e ativação das proteínas pela técnica de immunoblotting. Também foi armazenado o sangue total dos animais para posterior análise das concentrações séricas de insulina.

\subsubsection{Estimativa do Glicogênio muscular}

Para determinação da concentração dos músculos glicogênio dos músculos sóleo, gastrocnêmico e EDL foram utilizadas frações pesando entre 25-23mg, retiradas imediatamente após o sacrifício e foram digeridas em banho a 100/c em 0,5 mL de KOH 
$1 \mathrm{~N}$ durante 20 minutos. Foram adicionadas $20 \mu \mathrm{L}$ de solução saturada de $\mathrm{Na}_{2} \mathrm{SO}_{4}$ e o glicogênio foi precipitado através das duas passagens de $2,5 \mathrm{~mL}$ de etanol a quente, seguida de centrifugação, em $4 \mathrm{~mL}$ de água e a determinação colorimétrica realizada em $1 \mathrm{mM}$ de extrato, $20 \mu \mathrm{L}$ de fenol a $80 \%$ e $2,0 \mathrm{~mL}$ de ácido sulfúrico concentrado, após fervura de 15 minutos. A absorbância foi medida em espectrofotômetro 490nm. Soluções conhecidas de glicose foram utilizadas para curva de calibração (Dubois et al., 1956; Araujo et al., 2010).

\subsubsection{Immunoblotting}

Para a determinação do conteúdo de proteínas por western blot os tecidos foram homogeneizados em tampão RIPA $50 \mathrm{mM}$ de Tris- $\mathrm{HCl}(\mathrm{pH} 7,4)$ contendo $150 \mathrm{mM}$ de $\mathrm{NaCl} ; 1 \mathrm{mM}$ de EDTA; $1 \%$ de Triton X-100; 0,1\% de SDS; $5 \mu \mathrm{g} / \mathrm{ml}$ de aprotinina; $1 \mathrm{mM}$ de PMSF; $10 \mathrm{mM}$ de ortovanadato de sódio; $100 \mathrm{mM}$ de NaF; $10 \mathrm{mM}$ de pirofosfofato de sódio; $10 \mathrm{uM}$ de tricostatina $\mathrm{A} ; 5 \mathrm{mM}$ de Nicotinamida. $\mathrm{O}$ homogenado foi centrifugado a $17.000 \mathrm{~g}$ por 20 minutos a $4^{\circ} \mathrm{C}$ e o sobrenadante foi separado para a realização da eletroforese e dosagem de proteínas pelo método de Lowry (Classics Lowry et al., 1951). Aos homogenados foi adicionado tampão da amostra (20\% de glicerol, $125 \mathrm{mM}$ de Tris$\mathrm{HCl}, 4 \%$ de SDS, 100mM de ditiotreitol, 0,02\% de azul de bromofenol, $\mathrm{pH}$ 6,8) na proporção 1:4. Antes da realização da eletroforese, as amostras foram fervidas a $100^{\circ} \mathrm{C}$ por 5 minutos para a desnaturação das proteínas. 23 após a eletroforese, as proteínas foram transferidas do gel para membrana de nitrocelulose utilizando tampão (48mM de Tris, 39mM de glicina, SDS $10 \%$ e $20 \%$ de metanol) em um sistema semiseco por 30 minutos sob a voltagem fixa de 20 volts, à temperatura ambiente. (BioRad Trans-Blot SD Cell, EUA) (Towbin et al., 1979). Após o término da transferência, a membrana foi submetida a immunoblot. O bloqueio da membrana foi feito pela incubação por 1 hora, sob agitação, à temperatura ambiente em solução de leite desnatado em pó 5\%, diluído em solução TBS-T (20mM Tris-HCl; $160 \mathrm{mM}$ de $\mathrm{NaCl}$ e $0,1 \%$ Tween 20). A membrana foi então incubada overnight a $4^{\circ} \mathrm{C}$ sob agitação com anticorpos primários específicos (anti-p-AMPK $\alpha$, anti-citrato sintase, anti-GSK3 $\beta$, anti-pGSK3 $\beta$, anti-OXPHOS e anti- $\beta$ actina) diluídos em solução de TBS-T contendo 2,5\% de albumina bovina e 0,01\% de azida sódica. No dia seguinte, a incubação com o anticorpo secundário foi feita por 1 hora à temperatura ambiente. As membranas foram reveladas em fotodocumentador (BioRad) utilizando kit de quimiluminescência amplificada (ECL, Amersham). As bandas 
reveladas foram fotografadas e quantificadas por densitometria utilizando o software Image Lab (BioRad). Após a quantificação densitométrica das proteínas. Os resultados foram expressos pela relação entre as densidades obtidas para a proteína de interesse e da proteína normalizadora, utilizada como controle de aplicação, conforme indicado em cada resultado.

\subsubsection{Análise estatística}

Os dados estão expressos em média \pm desvio padrão, com exceção dos dados de carga externa e desempenho no teste incremental que estão expressos em mediana e intervalo interquartil. A normalidade dos dados foi testada através do teste de ShapiroWilk. A comparação do conteúdo de glicogênio muscular e hepático e do conteúdo das proteínas entre os grupos foi realizada por meio da Análise de Variância One-Way, seguido quando necessário pelo teste Post-hoc de Tukey (Statistica 7.0® Statsoft, Tulsa, OK). Em todos os casos, o nível de significância foi estabelecido em p $<0,05$.

\subsection{RESULTADOS}

\subsubsection{Desenho experimental}

Todos os ratos finalizaram todas as 15 sessões de treinamento propostas. Os pesos dos ratos durante todo o monitoramento, não foram diferentes entre os grupos $(p>0,05)$ (Figura 17). 


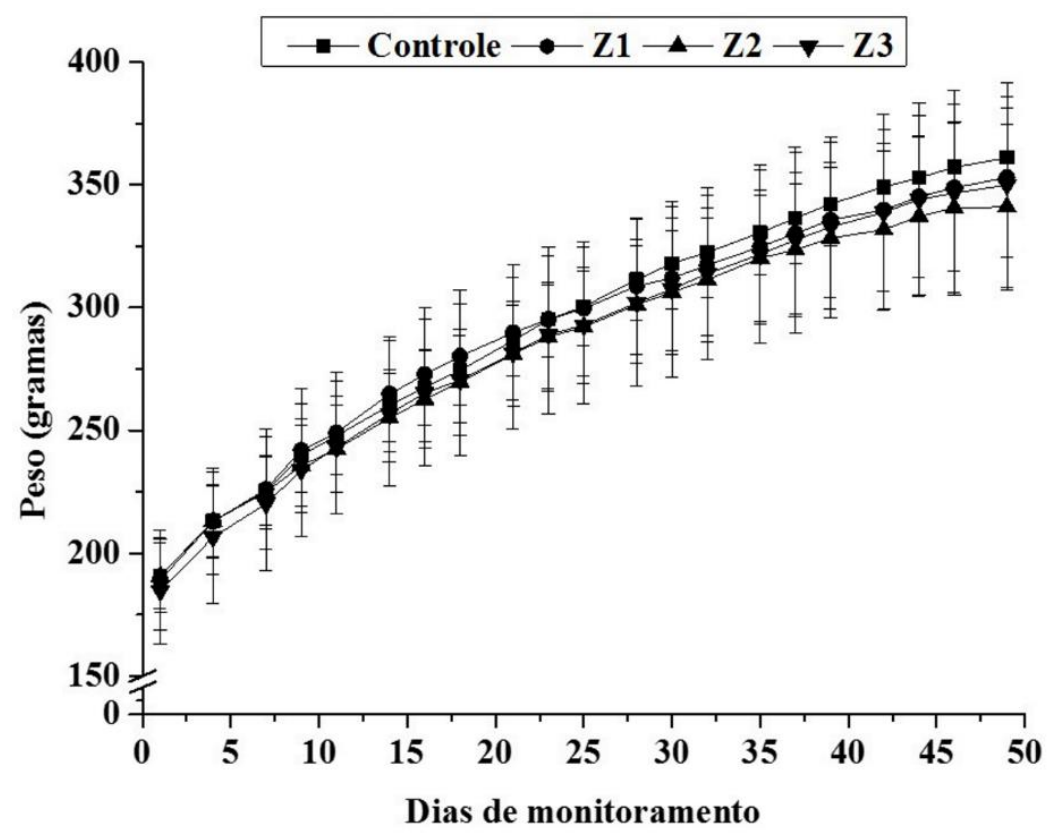

Figura 17. Peso dos ratos em todo o período de avaliações. $Z 1$ = grupo treinamento de baixa intensidade; $\mathrm{Z2}$ = grupo treinamento de moderada intensidade; $\mathrm{Z3}$ = grupo treinamento de alta intensidade.

Todos os animais $(\mathrm{n}=18)$ submetidos aos modelos de treinamento completaram a totalidade das sessões de treinamento propostas. Não houve diferença na carga externa diária dos animais ( $p>0,376$ ), que foi calculada pelo produto do volume pela intensidade individual de cada animal. A intensidade foi ajustada a partir dos resultados dos testes incrementais, assim a carga de treino aumentou sendo que na $5^{a}$ semana os animais treinaram com uma carga significativamente maior que nas primeiras duas semanas $(\mathrm{p}<0,029)$ (Figura 18). 


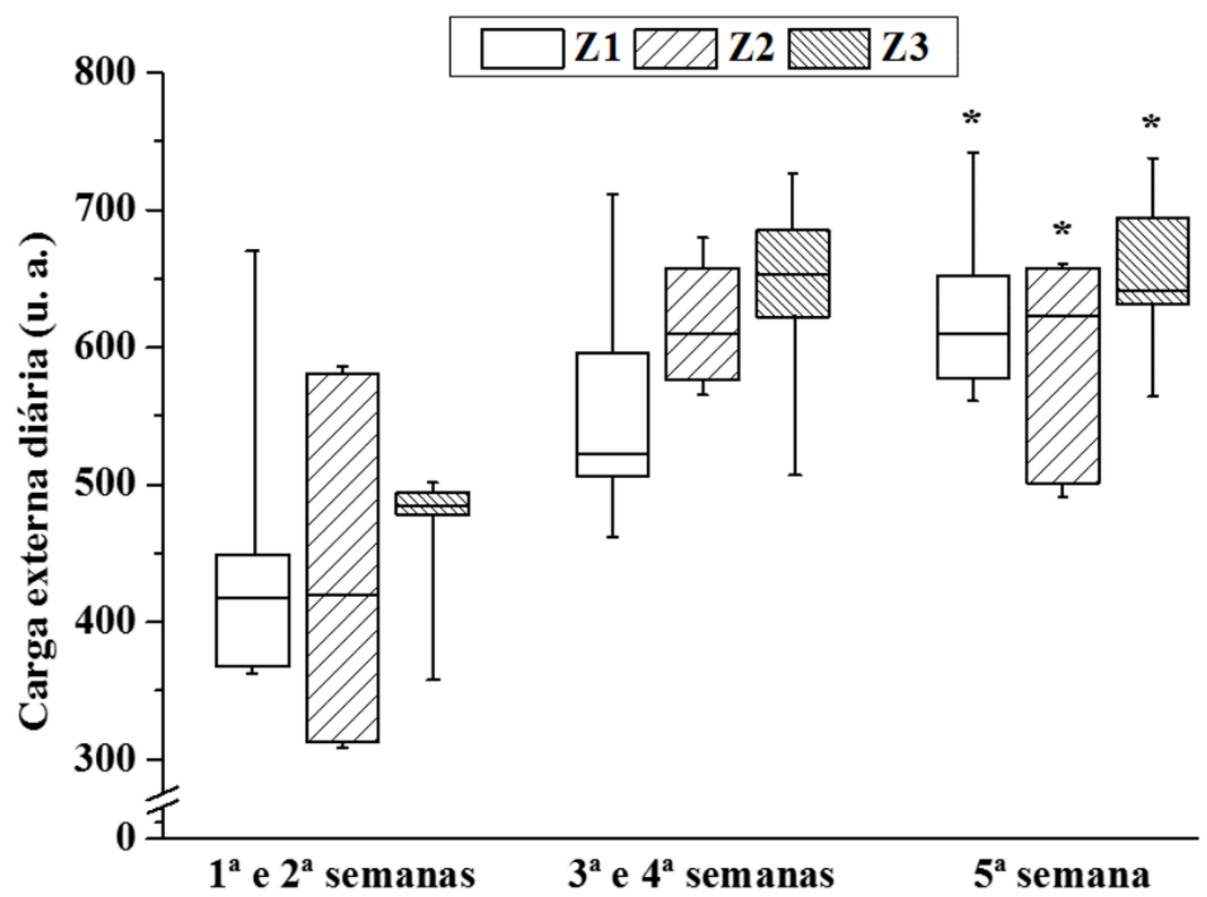

Figura 18. Carga externa diária das sessões de treinamento dos grupos submetidos aos modelos de treinamento. $\mathrm{Z} 1$ = grupo treinamento de baixa intensidade; $\mathrm{Z} 2$ = grupo treinamento de moderada intensidade; $\mathrm{Z3}$ = grupo treinamento de alta intensidade.

\subsubsection{Efeito de 4 semanas sobre o desempenho no teste incremental}

O grupo controle não apresentou diferença na Vmáx entre os três testes incrementais ( $\mathrm{p}=0,311$ ) (Figura 19). A Vmáx foi maior no TI3 em comparação ao TI1, para os grupos $Z 1(p=0,002), Z 2(p=0,012)$ e $Z 3(p=0,028)$ (Figura 19). 


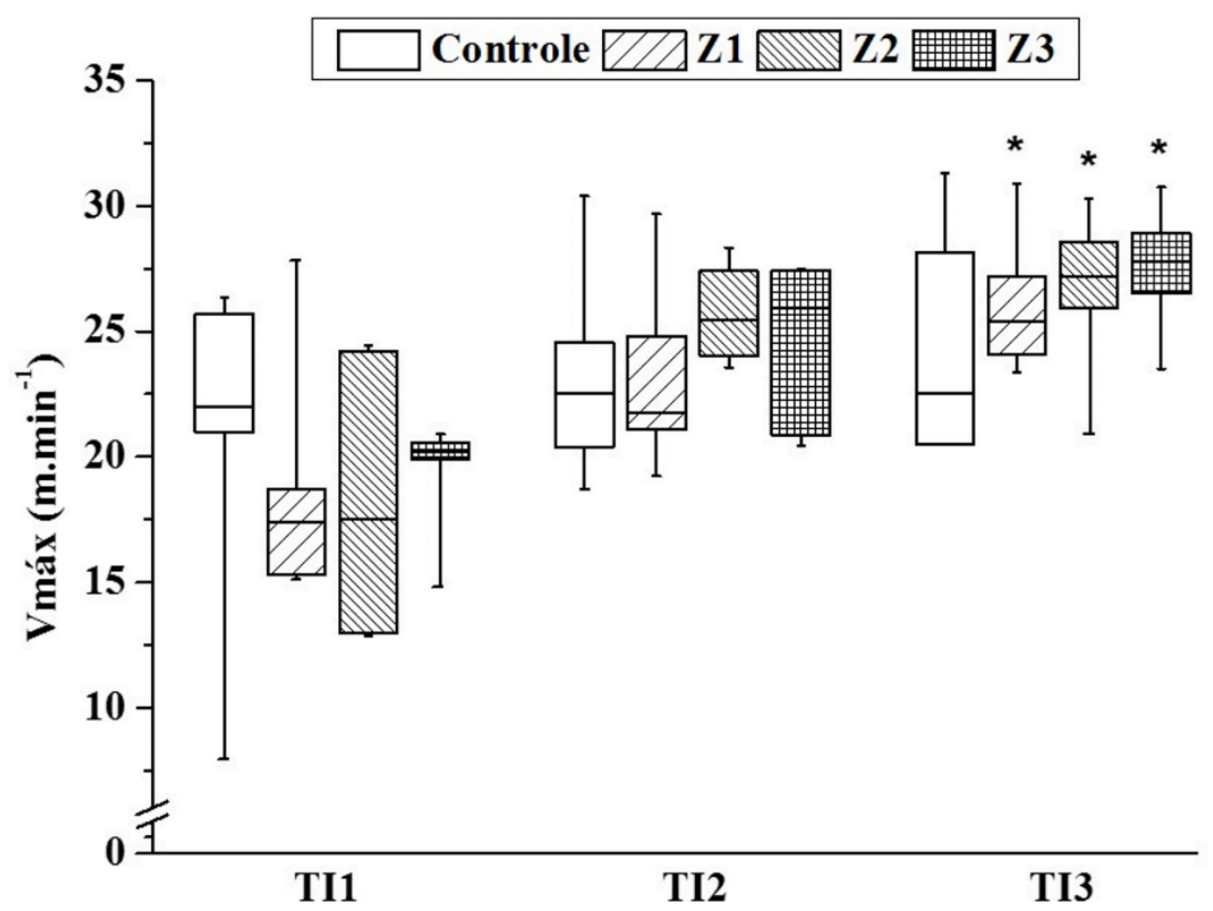

Figura 19. Efeito de 4 semanas de treinamento de corrida sobre a Velocidade Máxima (Vmáx) atingida no teste incremental (TI). Z1 = grupo treinamento de baixa intensidade; $\mathrm{Z} 2$ = grupo treinamento de moderada intensidade; $\mathrm{Z} 3$ = grupo treinamento de alta intensidade; $*$ = diferença estatisticamente significativa em comparação à TI1 $(\mathrm{p}<0,05)$.

\subsubsection{Estimativa do glicogênio muscular e hepático}

No músculo sóleo as [Glic] foram maiores para os três grupos submetidos aos programas de treinamento (i. e., Z1, Z2 e Z3) em comparação ao grupo controle $(p<0,034)$ (Figura 20). 


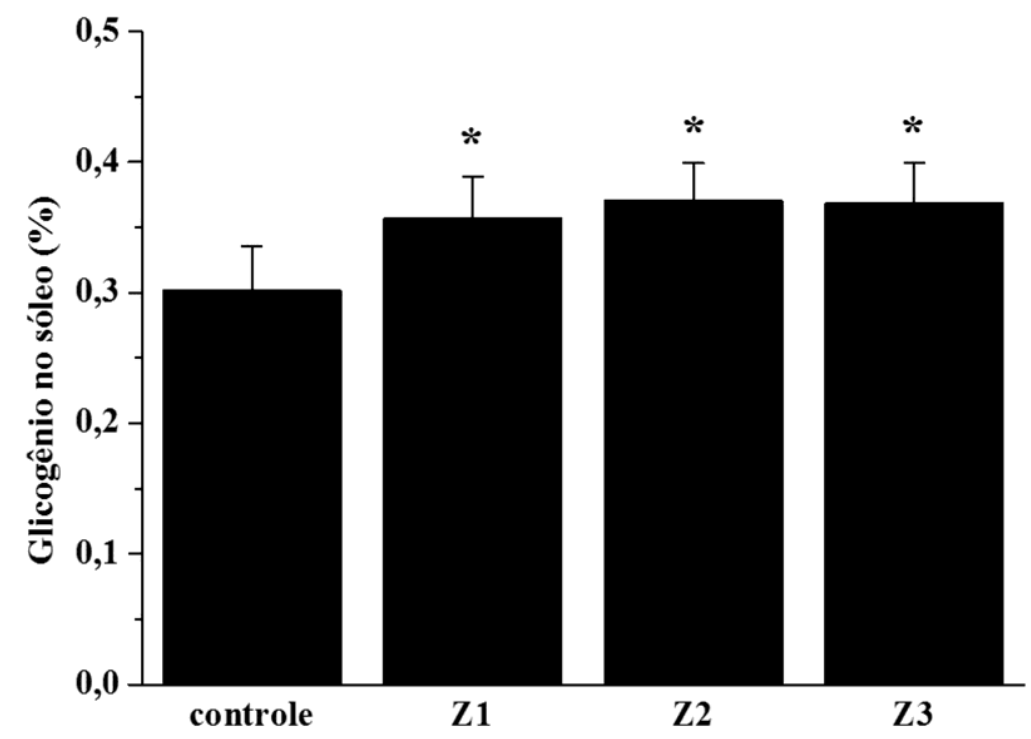

Figura 20. Concentração de glicogênio no músculo sóleo dos quatro grupos experimentais após 5 semanas de intervenção. $\mathrm{Z1}$ = grupo treinamento em baixa intensidade; $\mathrm{Z} 2$ = grupo treinamento em moderada intensidade; $\mathrm{Z} 3$ = grupo treinamento em alta intensidade; $*$ = diferença significativa em comparação ao grupo controle.

No músculo EDL as [Glic] foram menores apenas para o grupo Z3 em comparação com o grupo controle $(\mathrm{p}=0,021)$ (Figura 21$)$.

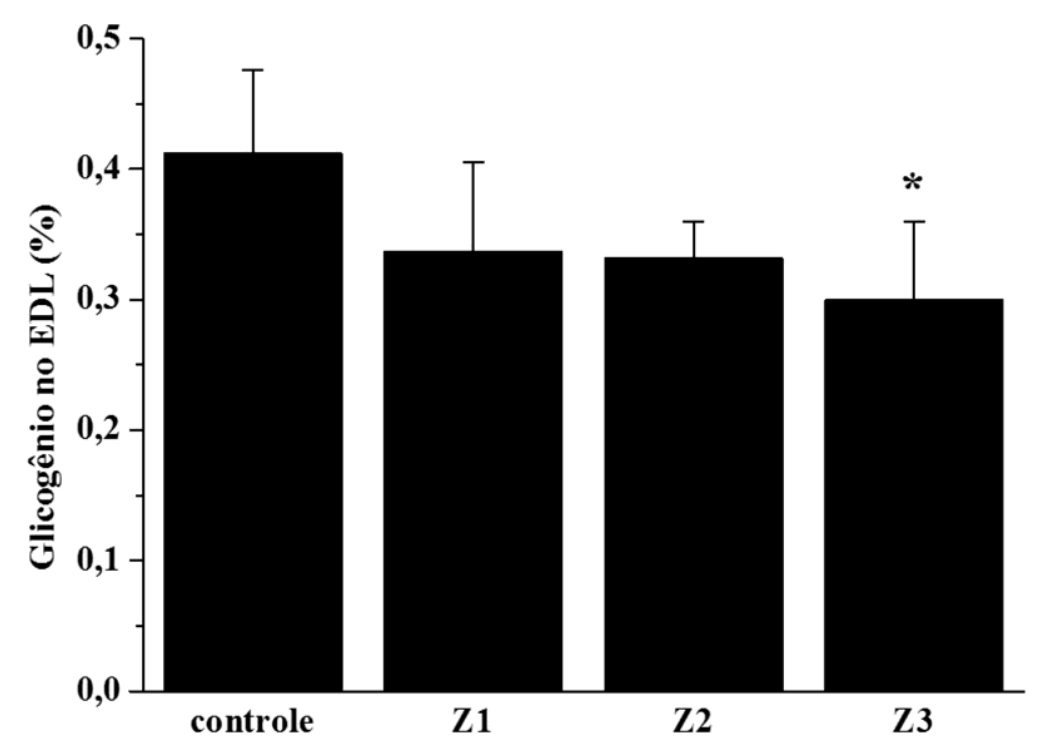

Figura 21. Concentração de glicogênio no músculo EDL dos quatro grupos experimentais após 5 semanas de intervenção. $\mathrm{Z1}$ = grupo treinamento em baixa 
intensidade; Z2 = grupo treinamento em moderada intensidade; Z3 = grupo treinamento em alta intensidade; * = diferença significativa em comparação ao grupo controle.

Não foram encontradas diferenças significativas no glicogênio hepático entre os grupos experimentais ( $\mathrm{p}>0,05)$ (Figura 22).

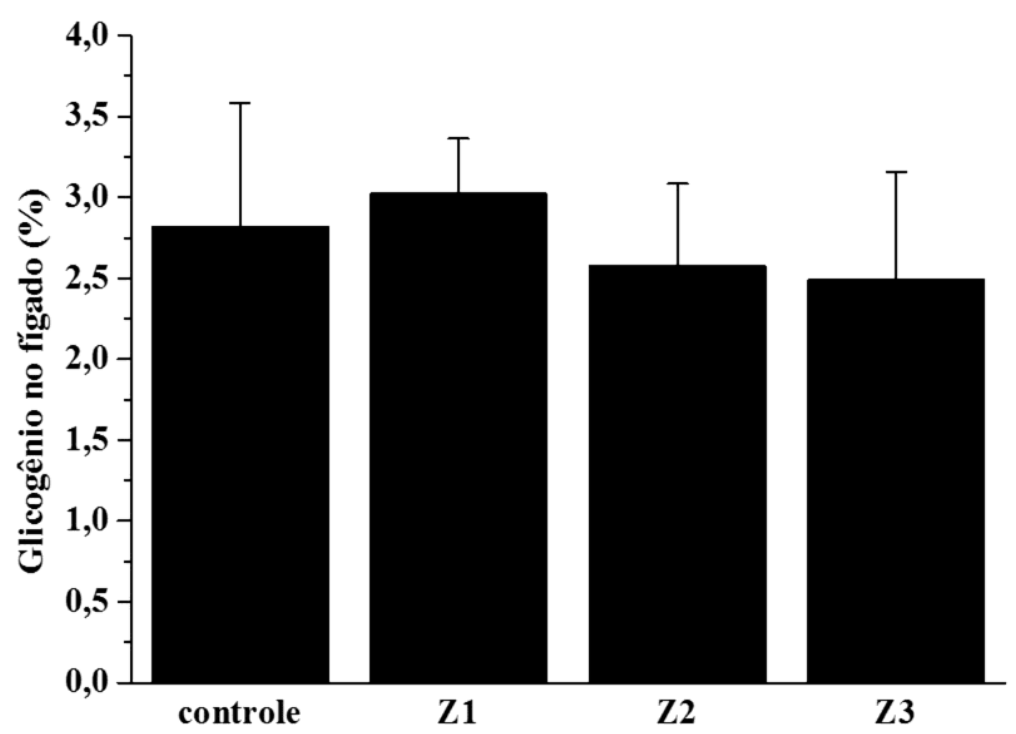

Figura 22. Concentração de glicogênio no fígado dos quatro grupos experimentais após 5 semanas de intervenção. $\mathrm{Z} 1$ = grupo treinamento em baixa intensidade; $\mathrm{Z} 2$ = grupo treinamento em moderada intensidade; $\mathrm{Z} 3$ = grupo treinamento em alta intensidade.

\subsubsection{Conteúdo proteico no músculo sóleo}

Não foram encontradas diferenças significativas no conteúdo proteico da pAMPK (Figura 23), da CS (Figura 24) e dos complexos da fosforilação oxidativa (OXPHOS) (Figura 27) ( $>>0,05)$. O conteúdo proteico da GSK3 $\beta$ (Figura 25) e da pGSK3 $\beta$ (Figura 26) foram maiores apenas no grupo $\mathrm{Z} 2$ em comparação ao grupo controle $(p<0,05)$. 

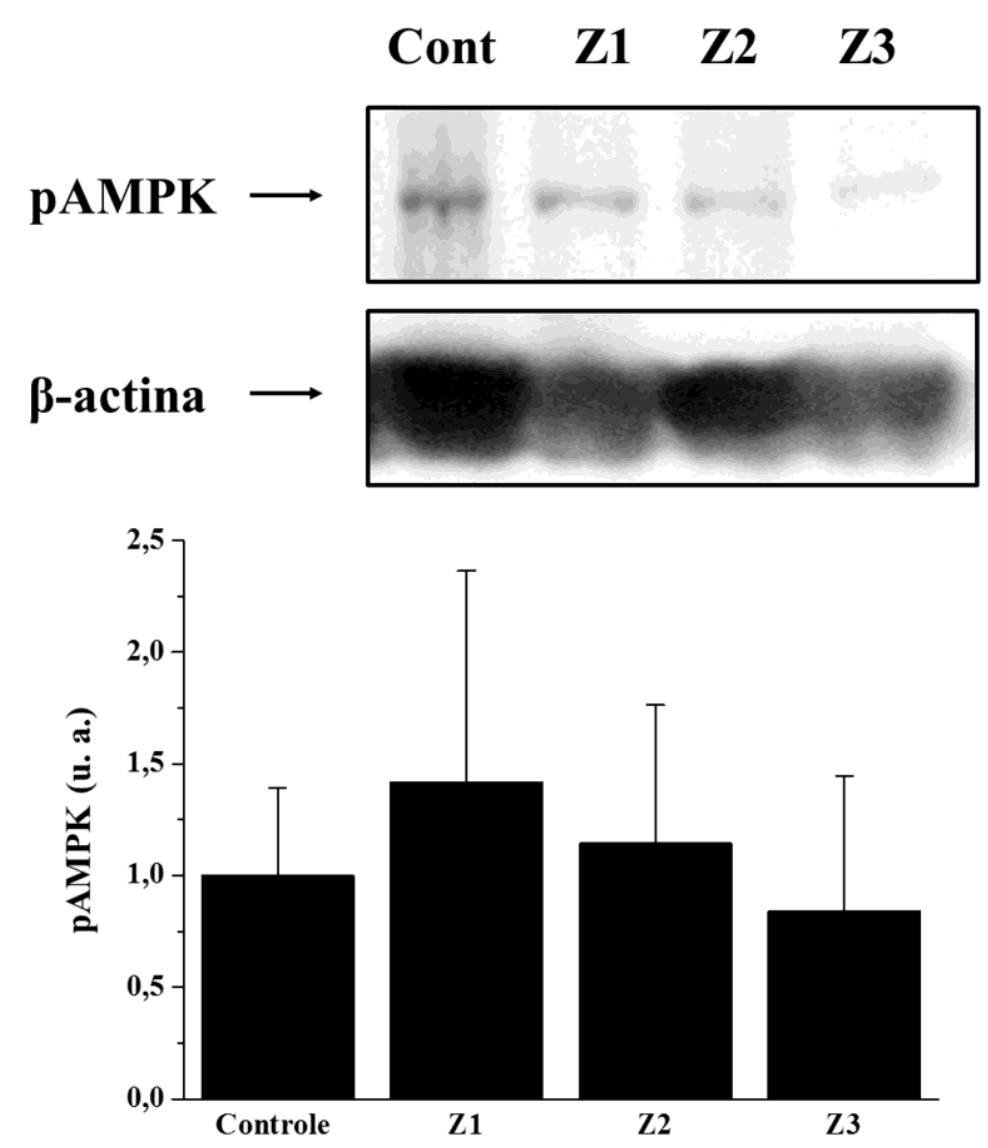

Figura 23. Conteúdo proteico de AMPK fosforilada no músculo sóleo dos quatro grupos experimentais após 5 semanas de intervenção. $\mathrm{Z1}$ = grupo treinamento em baixa intensidade; $\mathrm{Z2}$ = grupo treinamento em moderada intensidade; $\mathrm{Z3}$ = grupo treinamento em alta intensidade. 

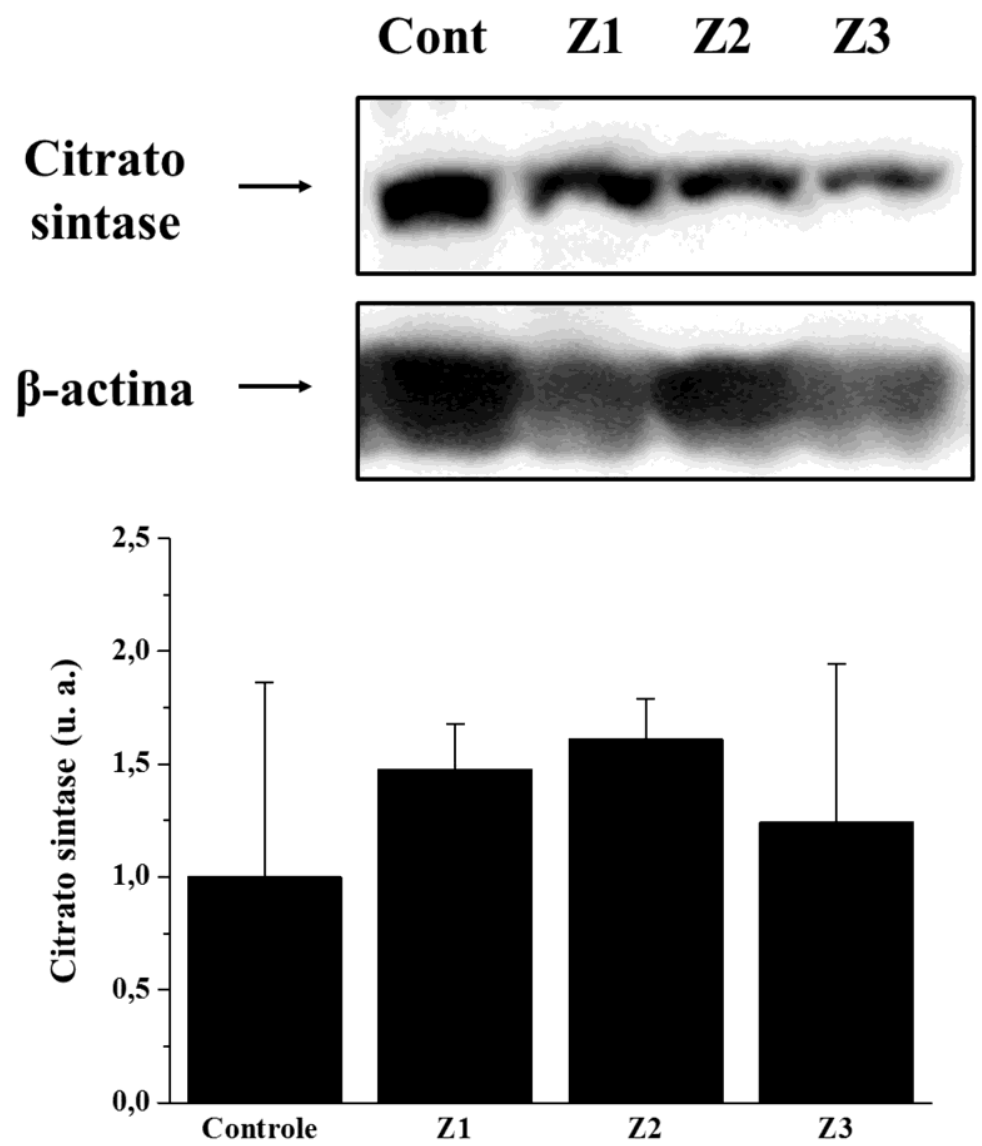

Figura 24. Conteúdo proteico de citrato sintase no músculo sóleo dos quatro grupos experimentais após 5 semanas de intervenção. $\mathrm{Z1}$ = grupo treinamento em baixa intensidade; Z2 = grupo treinamento em moderada intensidade; Z3 = grupo treinamento em alta intensidade. 

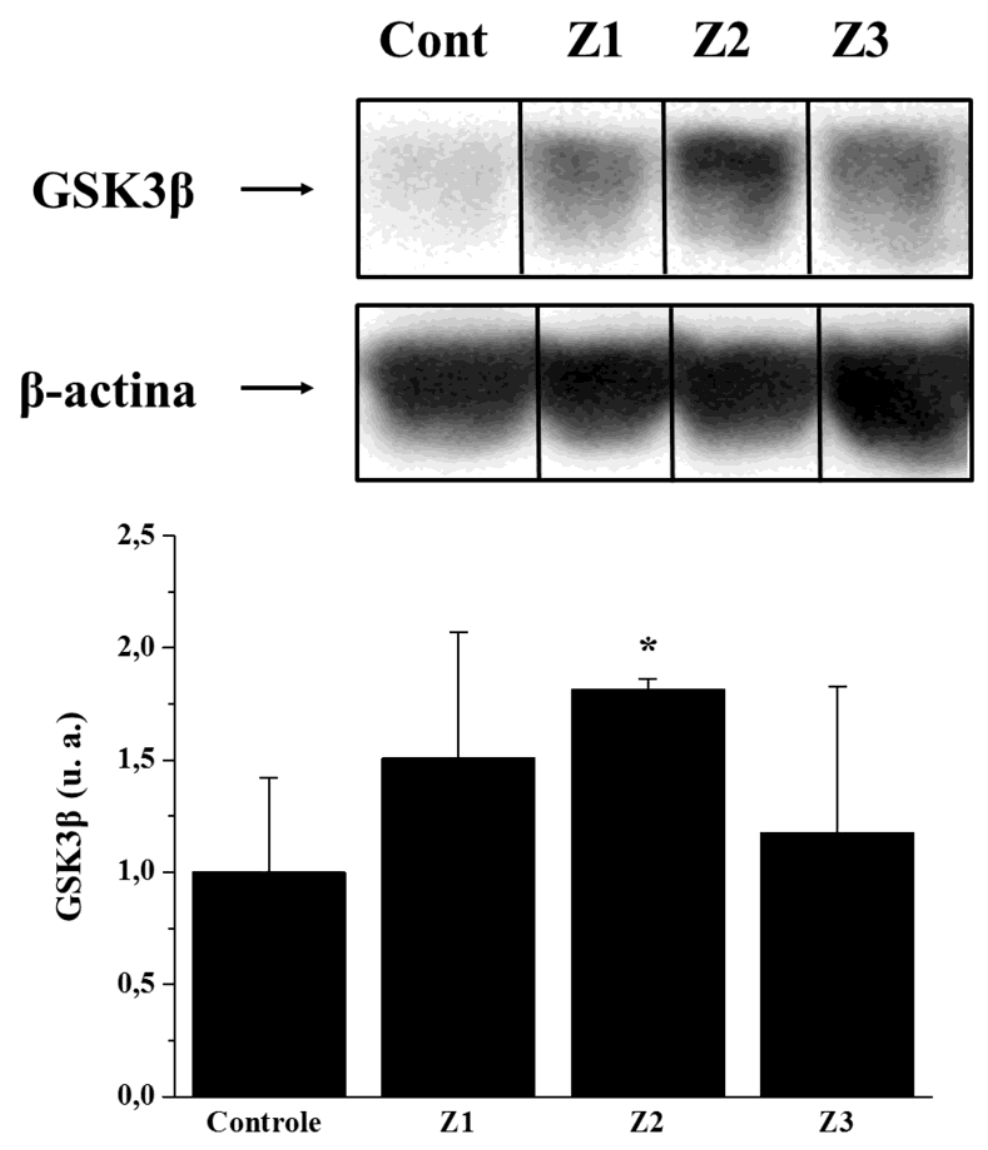

Figura 25. Conteúdo proteico da GSK3$\beta$ no músculo sóleo dos quatro grupos experimentais após 5 semanas de intervenção. $\mathrm{Z1}$ = grupo treinamento em baixa intensidade; Z2 = grupo treinamento em moderada intensidade; Z3 = grupo treinamento em alta intensidade. 

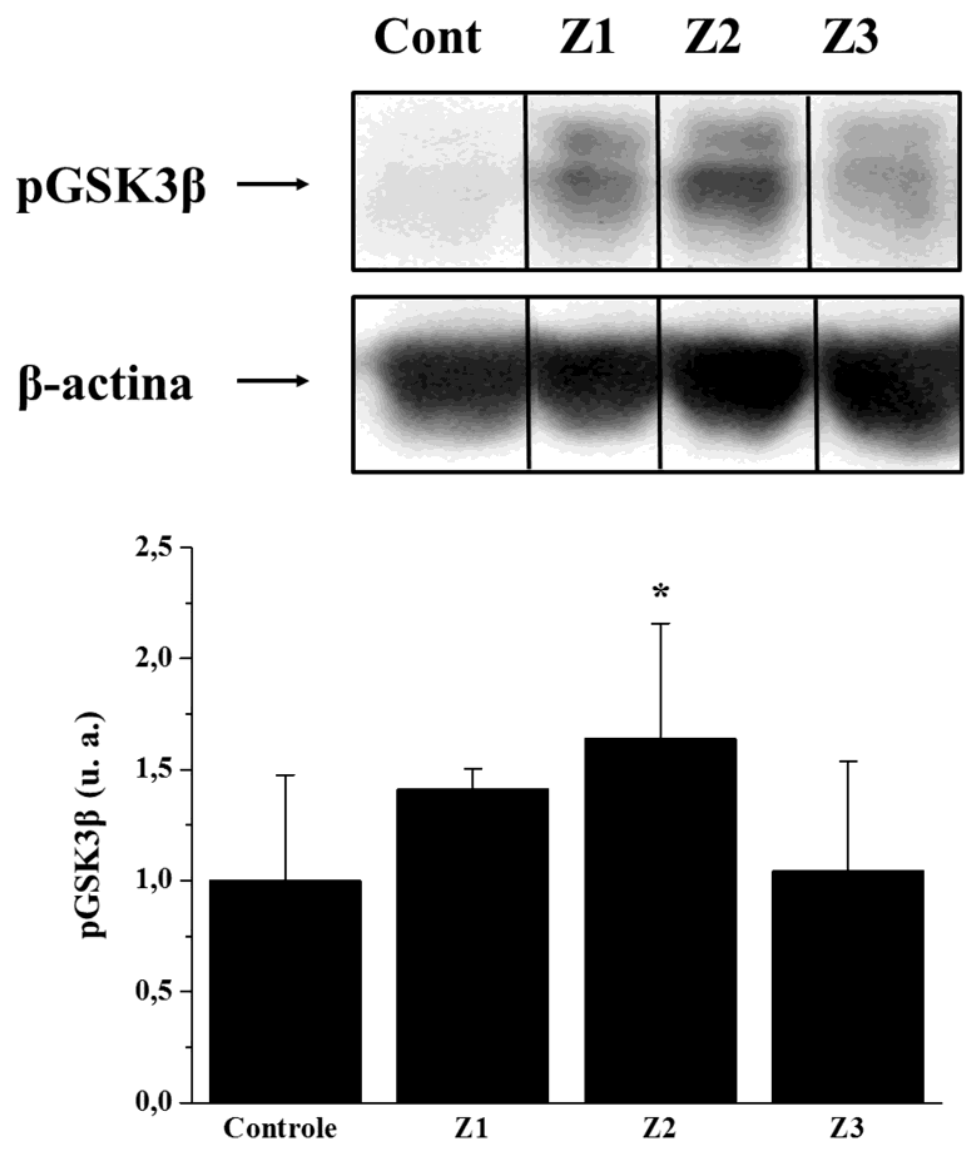

Figura 26. Conteúdo proteico da GSK3 $\beta$ fosforilada no músculo sóleo dos quatro grupos experimentais após 5 semanas de intervenção. $\mathrm{Z1}$ = grupo treinamento em baixa intensidade; Z2 = grupo treinamento em moderada intensidade; Z3 = grupo treinamento em alta intensidade. 

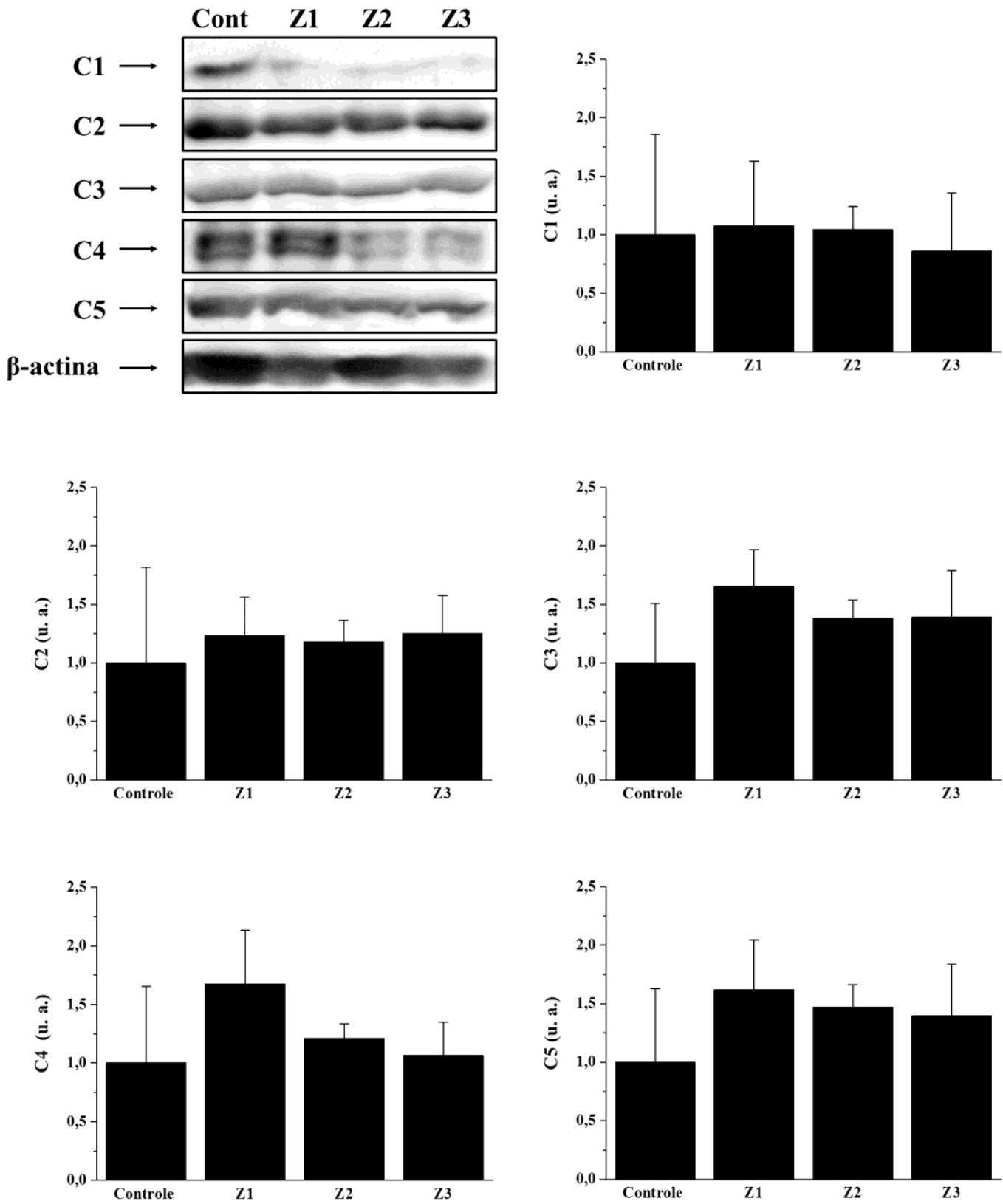

Figura 27. Conteúdo proteico dos cinco complexos da fosforilação oxidativa (OXPHOS) no músculo sóleo dos quatro grupos experimentais após 5 semanas de intervenção. C1 $=\mathrm{NADH}$-desidrogenase; $\mathrm{C} 2=$ succinato-desidrogenase; $\mathrm{C} 3=$ citocromo e $\mathrm{c}-$ oxidorredutase; $\mathrm{C} 4$ = citocromo c-oxidase; $\mathrm{C} 5$ = ATP-sintase; $\mathrm{Z} 1$ = grupo treinamento em baixa intensidade; $\mathrm{Z2}$ = grupo treinamento em moderada intensidade; $\mathrm{Z3}$ = grupo treinamento em alta intensidade. 


\subsection{DISCUSSÃO}

No presente estudo comparamos as adaptações biomoleculares e o desempenho de ratos submetidos a três protocolos de 5 semanas de treinamento de corrida em esteira, nas Zonas 1, 2 e 3 de intensidade respectivamente, porém com cargas equiparadas. Foi observado aumento na Vmáx após 4 semanas de treinamento para os três grupos que treinaram, sem diferença entre os grupos. Também foram observadas maiores [Glic] no músculo sóleo após 5 semanas de treinamento para os três grupos que treinaram em comparação ao grupo controle. Ainda verificamos que o grupo Z2 apresentou maior conteúdo de proteico de GSK3- $\beta$ (proteína total e fosforilada) em comparação ao grupo controle após as 5 semanas de treinamento.

Confirmando nossa hipótese inicial e corroborando com Milanović et al. (2015), observamos aumentos no índice de desempenho (i. e., Vmáx) para todos os animais submetidos aos protocolos de treinamento em comparação à avaliação anterior à intervenção, sem alterações no grupo controle. Os protocolos de treinamento foram prescritos contendo a mesma carga externa, ou seja, a "dose" de exercício a qual os animais foram submetidos foi a mesma para os grupos Z1, Z2 e Z3, assim é possível considerar que aumentos no desempenho são dependentes da carga que é imposta, pois não encontramos diferença na Vmáx entre os grupos que treinaram.

Na comparação entre modelos de treinamento, Milanović et al. (2015) mostraram por meio de uma meta-análise, uma possível pequena chance em considerar o treinamento de alta intensidade melhor que o de moderada intensidade para aumentos no consumo máximo de oxigênio. A intensidade que compreende a Zona 2 (i. e., delimitada pelos limiares metabólicos de lactato e ventilatório) representa as maiores intensidades de exercício que podem ser mantidas por extensos períodos de tempo em estado estável, tornando-se atrativa para compor um programa de treinamento (Seiler e Kjerland, 2006). Durante décadas foi assumido que a intensidade "ideal" para o desenvolvimento da capacidade aeróbia e consequentemente melhora de desempenha em provas de média e longa duração, é a intensidade de limiar anaeróbio, ou seja, intensidades próximas a intensidade da MFEL e para indivíduos sedentários e pouco treinados isto parece ser verdadeiro (Kindermann et al., 1979; Stegmann et al., 1981; Svedahl e Macintosh, 2003), porém recentes estudos descritivos apontam que para atletas de alto rendimento o modelo polarizado parece ser mais efetivo. No presente estudo não encontramos diferenças no 
desempenho dos animais na comparação entre os modelos de treinamento. De Araujo et al. (2015) mostraram aumento na capacidade aeróbia de ratos após 4 semanas de treinamento de corrida em esteira composto por sessões de exercício contínuo, corroborando com os achados do presente estudo, pois a sessão utilizada foi similar à do nosso grupo Z2, porém que não se manteve após as 8 semanas que compunham este protocolo e, este mesmo, estudo não observou diferença nos parâmetros analisados de outro grupo de animais submetido ao um protocolo intervalado com variação de intensidade durante a sessão.

Com relação ao glicogênio, é de se esperar a partir da Teoria Geral da Adaptação (Selye, 1936), que maiores [Glic] sejam encontradas após a recuperação de maior depleção deste substrato. Como foi mostrado no estudo 1, sessões de treinamento desempenhadas em zonas diferentes de intensidade, porém com cargas equiparadas, não apresentam diferença na cinética de depleção e recuperação do glicogênio muscular e hepático, portanto é lógico hipotetizar que os programas de treinamento utilizados no presente estudo apresentarem similar adaptação acerca das [Glic] após 5 semanas de treinamento, o que foi verdadeiro para o músculo sóleo, que apresentaram maiores concentrações deste substrato em comparação com o grupo controle, enquanto que para o fígado não foram observadas diferenças entre os grupos.

Já foi mostrado que a disponibilidade de glicogênio muscular é um fator determinante para a manutenção de um exercício, de modo que maiores [Glic] antes de um exercício realizado até a exaustão podem aumentar o tempo de esforço, realizado em altas intensidades (Hermansen et al., 1967; Tarnopolsky et al., 1995; Balsom et al., 1999) e possivelmente também para exercícios de baixa a moderada intensidade (Ahlborg et al., 1967; Alghannam et al., 2016). Assim é possível relacionar a melhora de desempenho observada nos grupos Z1, Z2 e Z3, com maiores [Glic] em comparação ao grupo controle.

Para análise das proteínas optamos por utilizar o músculo sóleo (músculo de predominância oxidativa), tendo em vista que este músculo apresentou diferenças nas [Glic] entre os grupos submetidos aos programas de treinamento e o grupo controle, portanto nós supomos que poderíamos associar esta adaptação com as vias de sinalização das proteínas analisadas (pAMPK, citrato sintase, GSK3- $\beta$, pGSK3- $\beta$ e complexos da OXPHOS). 
Após um período de treinamento é de se esperar aumento no conteúdo de AMPK e da citrato sintase e dos complexos da fosforilação oxidativa (OXPHOS), como consequência (Winder et al., 2006). De Souza Cordeiro et al. (2019) mostraram que 10 semanas de treinamento de corrida aumentou a atividade da CS após semanas no músculo sóleo de ratos Wistar. Fiorenza et al. (2019) observaram aumentos significativos dos complexos I, II, III e IV após 6 semanas de um treinamento de alta intensidade em um grupo de homens saudáveis, nas comparações com o momento anterior à intervenção e com o grupo controle. No presente experimento não observamos diferenças tanto na CS, quanto nos complexos da OXPHOS entre os grupos, indicando que as 5 semanas de treinamento não alteraram o conteúdo dos proteico destes complexos no músculo sóleo, indicando que não houve alteração da atividade mitocondrial perceptível neste músculo específico.

A GSK3- $\beta$, quando fosforilada, torna-se inativa e já foi demonstrado por Nikoulina et al. (2002) que a inibição da GSK3 leva a um aumento na ativação da glicogênio sintase e, por consequência, um aumento no conteúdo de glicogênio (Patel e Woodgett, 2017). Assim as maiores [Glic] observadas nos grupos que realizaram os protocolos de treinamento, apenas para o grupo Z2 podem ser explicadas pelo concomitante aumento proteico de GSK3- $\beta$ e pGSK3- $\beta$ para este grupo.

Seria esperado que tanto a supercompensação do glicogênio quanto a melhoria de desempenho fossem acompanhados de aumento da ativação de vias energéticas sinalizadas pelas proteínas analisadas no presente estudo. Com base nos resultados apresentados anteriormente, pode-se especular que a sinalização das proteínas já teria diminuído no momento em que a eutanásia aconteceu (72 horas após a última sessão de treinamento). Outra hipótese que deve ser considerado para explicar esses resultados, se dá pelo fato de que a magnitude de aumento da atividade da AMPK é maior em músculo com predominância de fibras de contração rápida em comparação às de contração lenta (músculo sóleo, no caso do presente estudo) (Winder et al., 2006).

\subsection{CONCLUSÃO}

Cinco semanas de treinamento de corrida em esteira baseados nas zonas 1,2 e 3 de intensidade melhoraram o desempenho e aumentaram as [Glic] no músculo sóleo, 
portanto a modulação da intensidade não traz alteração na adaptação proveniente de programa de treinamento desde que as cargas de distintos programas estejam equiparadas. 


\section{CONCLUSÃO DA DISSERTAÇÃO}

A partir dos resultados dos estudos 1 e 2 pode-se concluir que, durante cinco semanas de treinamento, a independentemente da relação entre volume e intensidade do treinamento, desde que a carga seja equiparada, as alterações na cinética das variáveis fisiológicas biomoleculares e o desempenho, no que diz respeito as respostas agudas e adaptações crônicas de ratos são semelhantes entre os diferentes modelos de treinamento. 


\section{REFERÊNCIAS}

ADAN, C. et al. Carbohydrate handling in the hind leg muscle of exercising rats. IUBMB Life, v. 41, n. 4, p. 735-751, 1997. ISSN 1521-6543.

AHLBORG, B. et al. Human muscle glycogen content and capacity for prolonged exercise after different diets. Acta Physiologica Scandinavica, v. 3, n. Suppl 1, p. 85-89, 1967.

ALGHANNAM, A. F. et al. Impact of muscle glycogen availability on the capacity for repeated exercise in man. Medicine and science in sports and exercise, v. 48, n. 1, p. 123-131, 2016. ISSN 0195-9131.

ANDERSSON, U. et al. Exercise in rats does not alter hypothalamic AMP-activated protein kinase activity. Biochemical and Biophysical Research Communications, v. 329, n. 2, p. 719725, 2005. ISSN 0006-291X.

ARAUJO, G. G. D. et al. Padronização de um protocolo experimental de treinamento periodizado em natação utilizando ratos Wistar. Revista Brasileira de Medicina do Esporte, p. 51-56, 2010. ISSN 1517-8692.

ARETA, J. L.; HOPKINS, W. G. Skeletal muscle glycogen content at rest and during endurance exercise in humans: a meta-analysis. Sports Medicine, v. 48, n. 9, p. 2091-2102, 2018. ISSN 0112-1642.

ARNE, G.; EIKE, E. Training methods and intensity distribution of young world-class rowers. International journal of sports physiology and performance, v. 4, n. 4, p. 448-460, 2009. ISSN 1555-0265.

BALDWIN, K. et al. Glycolytic enzymes in different types of skeletal muscle: adaptation to exercise. American Journal of Physiology-Legacy Content, v. 225, n. 4, p. 962-966, 1973. ISSN 0002-9513.

BALSOM, P. D. et al. High-intensity exercise and muscle glycogen availability in humans. Acta Physiologica Scandinavica, v. 165, p. 337-346, 1999. ISSN 0001-6772.

BENEKE, R.; LEITHÄUSER, R. M.; OCHENTEL, O. Blood lactate diagnostics in exercise testing and training. International journal of sports physiology and performance, v. 6, n. 1, p. 8-24, 2011. ISSN 1555-0265.

BERGSTRÖM, J.; HULTMAN, E. Muscle glycogen synthesis after exercise: an enhancing factor localized to the muscle cells in man. Nature, v. 210, n. 5033, p. 309, 1966. ISSN 1476-4687. 
BINDER, R. K. et al. Methodological approach to the first and second lactate threshold in incremental cardiopulmonary exercise testing. European Journal of Preventive Cardiology, v. 15, n. 6, p. 726-734, 2008. ISSN 1741-8267.

BRUCE, C. R.; LEE, J. S.; HAWLEY, J. A. Postexercise muscle glycogen resynthesis in obese insulin-resistant Zucker rats. Journal of Applied Physiology, v. 91, n. 4, p. 1512-1519, 2001. ISSN 1522-1601.

BURGOMASTER, K. A. et al. Similar metabolic adaptations during exercise after low volume sprint interval and traditional endurance training in humans. The Journal of physiology, v. 586, n. 1, p. 151-160, 2008. ISSN 1469-7793.

BURGOMASTER, K. A. et al. Six sessions of sprint interval training increases muscle oxidative potential and cycle endurance capacity in humans. Journal of applied physiology, v. 98, n. 6, p. 1985-1990, 2005. ISSN 8750-7587.

CASEY, A. et al. Effect of carbohydrate ingestion on glycogen resynthesis in human liver and skeletal muscle, measured by 13C MRS. American Journal of Physiology-Endocrinology and Metabolism, v. 278, n. 1, p. E65-E75, 2000. ISSN 1522-1555.

CHEN, Z.-P. et al. Effect of exercise intensity on skeletal muscle AMPK signaling in humans. Diabetes, v. 52, n. 9, p. 2205-2212, 2003. ISSN 0012-1797.

CHIU, L.-L. et al. Acute Effect of Exercise-Hypoxia Challenge on GLUT4 Protein Expression in Rat Cardiac Muscle. Japanese Journal of Physiology, v. 6, n. 3, p. 256-262, 2005. ISSN 1527-0297.

CHOU, C.-H. et al. Glycogen overload by postexercise insulin administration abolished the exercise-induced increase in GLUT4 protein. Journal of Biological Science, v. 12, n. 6, p. 991 998, 2005. ISSN 1021-7770.

CLASSICS LOWRY, O. et al. Protein measurement with the Folin phenol reagent. Journal of Biological Chemistry, v. 193, p. 265-275, 1951.

COFFEY, V. G.; HAWLEY, J. A. The molecular bases of training adaptation. Sports Medicine, v. 37, n. 9, p. 737-763, 2007. ISSN 0112-1642.

CONLEE, R. K.; LAWLER, R. M.; ROSS, P. E. Effects of glucose or fructose feeding on glycogen repletion in muscle and liver after exercise or fasting. Annals of nutrition and metabolism, v. 31, n. 2, p. 126-132, 1987. ISSN 0250-6807. 
COSTILL, D. et al. Adaptations to swimming training: influence of training volume. Med Sci Sports Exerc, v. 23, n. 3, p. 371-377, 1991. ISSN 0195-9131.

CUNANAN, A. J. et al. The general adaptation syndrome: a foundation for the concept of periodization. Sports medicine, v. 48, n. 4, p. 787-797, 2018. ISSN 0112-1642.

DE ARAUJO, G. et al. Interval versus continuous training with identical workload: physiological and aerobic capacity adaptations. Physiological Research, v. 64, n. 2, p. 209, 2015. ISSN 08628408 .

DE ARAUJO, G. G. et al. Physiological responses during linear periodized training in rats. European journal of applied physiology, v. 112, n. 3, p. 839-852, 2012. ISSN 1439-6319.

DE BRITO VIEIRA, W. H. et al. Photobiomodulation increases mitochondrial citrate synthase activity in rats submitted to aerobic training. Lasers in Medical Science, v. 33, n. 4, p. 803-810, 2018. ISSN 0268-8921.

DE SOUZA CORDEIRO, L. M. et al. Aerobic training induces differential expression of genes involved in lipid metabolism in skeletal muscle and white adipose tissues. Journal of Cellular Biochemistry, v. 11, p. 18883-18893, 2019. ISSN 0730-2312.

DOERING, T. M. et al. Repeated muscle glycogen supercompensation with four days' recovery between exhaustive exercise. Journal of Science and Medicine in Sport, 2019. ISSN 14402440.

DUBOIS, M. et al. Colorimetric method for determination of sugars and related substances. Analytical chemistry, v. 28, n. 3, p. 350-356, 1956. ISSN 0003-2700.

ESSÉN, B.; HENRIKSSON, J. Glycogen content of individual muscle fibres in man. Acta Physiologica Scandinavica, v. 90, n. 3, p. 645-647, 1974. ISSN 0001-6772.

ESTEVE-LANAO, J. et al. Impact of training intensity distribution on performance in endurance athletes. Journal of Strength and Conditioning Research, v. 21, n. 3, p. 943, 2007. ISSN 1064 8011.

FIORENZA, M. et al. High-intensity exercise training enhances mitochondrial oxidative phosphorylation efficiency in a temperature-dependent manner in human skeletal muscle: implications for exercise performance. FASEB Journal, v. 8, p. 8976-8989, 2019. ISSN 08926638. 
FOURNIER, P. A. et al. Post-exercise muscle glycogen repletion in the extreme: effect of food absence and active recovery. Journal of sports science \& medicine, v. 3, n. 3, p. 139, 2004.

FRITZEN, A. M. et al. 5'-AMP activated protein kinase $\alpha 2$ controls substrate metabolism during post-exercise recovery via regulation of pyruvate dehydrogenase kinase 4 . The Journal of Physiology, v. 593, n. 21, p. 4765-4780, 2015. ISSN 1469-7793.

FUEGER, P. T. et al. Control of exercise-stimulated muscle glucose uptake by GLUT4 is dependent on glucose phosphorylation capacity in the conscious mouse. Journal of Biological Chemistry, v. 279, n. 49, p. 50956-50961, 2004. ISSN 0021-9258.

FUEGER, P. T. et al. Hexokinase II protein content is a determinant of exercise endurance capacity in the mouse. The Journal of physiology, v. 566, n. 2, p. 533-541, 2005. ISSN 14697793.

FUJII, N. et al. Exercise induces isoform-specific increase in 5' AMP-activated protein kinase activity in human skeletal muscle. Biochemical and Biophysical Research Communications, v. 273 , n. 3 , p. $1150-1155$, 2000. ISSN 0006-291X.

ULLER, S. E. et al. Low-intensity exercise induces acute shifts in liver and skeletal muscle substrate metabolism, but not chronic adaptations in tissue oxidative capacity. Journal of Applied Physiology, v. 1, p. 143-156, 2019. ISSN 8750-7587.

GIBALA, M. Molecular responses to high-intensity interval exercise This paper is one of a selection of papers published in this Special Issue, entitled 14th International Biochemistry of Exercise Conference-Muscles as Molecular and Metabolic Machines, and has undergone the Journal's usual peer review process. Applied Physiology, Nutrition, and Metabolism, v. 34, n. 3, p. 428-432, 2009. ISSN 1715-5312.

GIBALA, M. J. et al. Short-term sprint interval versus traditional endurance training: similar initial adaptations in human skeletal muscle and exercise performance. The Journal of physiology, v. 575, n. 3, p. 901-911, 2006. ISSN 1469-7793.

GOLLNICK, P.; PIEHL, K.; SALTIN, B. Selective glycogen depletion pattern in human muscle fibres after exercise of varying intensity and at varying pedalling rates. The Journal of physiology, v. 241, n. 1, p. 45-57, 1974. ISSN 0022-3751.

GONZALEZ, J. T. et al. Liver glycogen metabolism during and after prolonged endurance-type exercise. American Journal of Physiology-Endocrinology and Metabolism, v. 311, n. 3, p. E543-E553, 2016. ISSN 0193-1849. 
GREIWE, J. S. et al. Effects of endurance exercise training on muscle glycogen accumulation in humans. Journal of Applied Physiology, v. 87, n. 1, p. 222-226, 1999. ISSN 1522-1601.

HALLING, J. F. et al. PGC-1 $\alpha$ promotes exercise-induced autophagy in mouse skeletal muscle. Physiological reports, v. 4, n. 3, 2016. ISSN 2051-817X.

HANDSCHIN, C. Regulation of skeletal muscle cell plasticity by the peroxisome proliferatoractivated receptor $\gamma$ coactivator $1 \alpha$. Journal of receptors and signal transduction, v. 30, n. 6 , p. 376-384, 2010. ISSN 1079-9893.

HAWLEY, J. A. Molecular responses to strength and endurance training: are they incompatible? Applied Physiology, Nutrition, and Metabolism, v. 34, n. 3, p. 355-361, 2009. ISSN 17155312.

HEARRIS, M. A. et al. Regulation of Muscle Glycogen Metabolism during Exercise: Implications for Endurance Performance and Training Adaptations. Nutrients, v. 10, n. 3, p. 298, 2018.

HERMANSEN, L.; HULTMAN, E.; SALTIN, B. J. A. P. S. Muscle glycogen during prolonged severe exercise. Acta Physiologica Scandinavica, v. 71, n. 2-3, p. 129-139, 1967. ISSN 00016772 .

HINGST, J. R. et al. Exercise-induced molecular mechanisms promoting glycogen supercompensation in human skeletal muscle. Molecular metabolism, v. 16, p. 24-34, 2018. ISSN 2212-8778.

HOLLOSZY, J. O. Regulation of mitochondrial biogenesis and GLUT4 expression by exercise. Comprehensive Physiology, v. 1, n. 2, p. 921-940, 2011.

IKEDA, S.-I. et al. Exercise-induced increase in IL-6 level enhances GLUT4 expression and insulin sensitivity in mouse skeletal muscle. Biochemical and Biophysical Research Communications, v. 473, n. 4, p. 947-952, 2016. ISSN 0006-291X.

ISSURIN, V. B. New horizons for the methodology and physiology of training periodization. Sports Medicine, v. 40, n. 3, p. 189-206, 2010. ISSN 0112-1642.

JENTJENS, R.; JEUKENDRUP, A. E. J. S. M. Determinants of post-exercise glycogen synthesis during short-term recovery. Sports Medicine, v. 33, n. 2, p. 117-144, 2003. ISSN 0112-1642.

JØRGENSEN, S. B. et al. Effects of $\alpha$-AMPK knockout on exercise-induced gene activation in mouse skeletal muscle. FASEB Journal, v. 19, n. 9, p. 1146-1148, 2005. ISSN 0892-6638. 
KARLSSON, L. et al. Constitutive PGC-1 $\alpha$ Overexpression in Skeletal Muscle Does Not Improve Morphological Outcome in Mouse Models of Brain Irradiation or Cortical Stroke. Neuroscience, v. 384, p. 314-328, 2018. ISSN 0306-4522.

KIDO, K. et al. Acute resistance exercise-induced IGF 1 expression and subsequent GLUT 4 translocation. Physiological reports, v. 4, n. 16, p. e12907, 2016. ISSN 2051-817X.

KIELY, J. J. S. M. Periodization theory: confronting an inconvenient truth. Sports Medicine, v. 48, n. 4, p. 753-764, 2018. ISSN 0112-1642.

KIILERICH, K. et al. PGC- $1 \alpha$ increases PDH content but does not change acute PDH regulation in mouse skeletal muscle. American Journal of Physiology, v. 299, n. 5, p. R1350-R1359, 2010. ISSN 0363-6119.

KINDERMANN, W.; SIMON, G.; KEUL, J. The significance of the aerobic-anaerobic transition for the determination of work load intensities during endurance training. European journal of applied physiology and occupational physiology, v. 42, n. 1, p. 25-34, 1979. ISSN 0301-5548.

KJØBSTED, R. et al. AMPK in skeletal muscle function and metabolism. FASEB Journal, v. 32, n. 4, p. 1741-1777, 2018. ISSN 0892-6638.

KNUDSEN, J. G. et al. Exercise-induced regulation of key factors in substrate choice and gluconeogenesis in mouse liver. Molecular and celular biochemistry, v. 403, n. 1-2, p. 209217, 2015. ISSN 0300-8177.

KOLTAI, E. et al. Age-associated declines in mitochondrial biogenesis and protein quality control factors are minimized by exercise training. American Journal of Physiology, v. 303, n. 2, p. R127-R134, 2012. ISSN 0363-6119.

KOOPMAN, R. et al. Increase in S6K1 phosphorylation in human skeletal muscle following resistance exercise occurs mainly in type II muscle fibers. American Journal of Physiology, v. 290, n. 6, p. E1245-E1252, 2006. ISSN 0193-1849.

KOSHINAKA, K. et al. Effect of acute high-intensity intermittent swimming on post-exercise insulin responsiveness in epitrochlearis muscle of fed rats. Metabolism: clinical and experimental, v. 58, n. 2, p. 246-253, 2009. ISSN 0026-0495.

KOULMANN, N. et al. Physical exercise during muscle regeneration improves recovery of the slow/oxidative phenotype. Muscle and nerve, v. 55, n. 1, p. 91-100, 2017. ISSN 0148-639X. 
KUIPERS, H. et al. Variability of aerobic performance in the laboratory and its physiologic correlates. International journal of sports medicine, v. 6, n. 04, p. 197-201, 1985. ISSN 01724622.

KUO, C.-H. et al. Effect of carbohydrate supplementation on postexercise GLUT-4 protein expression in skeletal muscle. Journal of Applied Physiology, v. 87, n. 6, p. 2290-2295, 1999. ISSN 1522-1601.

KUO, C.; BROWNING, K.; IVY, J. Regulation of GLUT4 protein expression and glycogen storage after prolonged exercise. Acta physiologica Scandinavica, v. 165, n. 2, p. 193-201, 1999. ISSN 0001-6772.

LAMBERT, B. et al. Regulation of glycogen synthase and phosphorylase during recovery from high-intensity exercise in the rat. Biochemical journal, v. 322, n. 1, p. 303-308, 1997. ISSN 0264-6021.

LAURSEN, P. B. Training for intense exercise performance: high-intensity or high-volume training? Scandinavian journal of medicine \& science in sports, v. 20, n. s2, p. 1-10, 2010. ISSN 1600-0838.

LOON, L. J. et al. The effects of increasing exercise intensity on muscle fuel utilisation in humans. The Journal of physiology, v. 536, n. 1, p. 295-304, 2001. ISSN 1469-7793.

MATSUNAGA, Y. et al. Effects of Glucose with Casein Peptide Supplementation on PostExercise Muscle Glycogen Resynthesis in C57BL/6J Mice. Nutrients, v. 10, n. 6, p. 753, 2018.

MILANOVIĆ, Z.; SPORIŠ, G.; WESTON, M. J. S. M. Effectiveness of high-intensity interval training (HIT) and continuous endurance training for VO2max improvements: a systematic review and meta-analysis of controlled trials. Sports Medicine, v. 45, n. 10, p. 1469-1481, 2015. ISSN 0112-1642.

MINOKOSHI, Y. et al. AMP-kinase regulates food intake by responding to hormonal and nutrient signals in the hypothalamus. Nature, v. 428, n. 6982, p. 569, 2004. ISSN 1476-4687.

MUÑOZ, I. et al. Does polarized training improve performance in recreational runners? International journal of sports physiology and performance, v. 9, n. 2, p. 265-272, 2014. ISSN 1555-0265.

MUSI, N. et al. AMP-activated protein kinase activity and glucose uptake in rat skeletal muscle. Endocrinology and Metabolism, v. 280, n. 5, p. E677-E684, 2001. ISSN 1522-1555. 
NAKATANI, A. et al. Effect of endurance exercise training on muscle glycogen supercompensation in rats. Journal of Applied Physiology, v. 82, n. 2, p. 711-715, 1997. ISSN 1522-1601.

NEAL, C. M. et al. Six weeks of a polarized training-intensity distribution leads to greater physiological and performance adaptations than a threshold model in trained cyclists. Journal of applied physiology, v. 114, n. 4, p. 461-471, 2013. ISSN 8750-7587.

NIKOULINA, S. E. et al. Inhibition of glycogen synthase kinase 3 improves insulin action and glucose metabolism in human skeletal muscle. Diabetes, v. 51, n. 7, p. 2190-2198, 2002. ISSN 0012-1797.

O'DOHERTY, R. M. et al. Rat skeletal muscle hexokinase II mRNA and activity are increased by a single bout of acute exercise. American Journal of Physiology-Endocrinology And Metabolism, v. 266, n. 2, p. E171-E178, 1994. ISSN 0193-1849.

$\mathrm{OE}, \mathrm{K}$. et al. The effect of transcutaneous application of carbon dioxide (CO2) on skeletal muscle. Biochemical and Biophysical Research Communications, v. 407, n. 1, p. 148-152, 2011. ISSN 0006-291X.

ØRTENBLAD, N.; WESTERBLAD, H.; NIELSEN, J. Muscle glycogen stores and fatigue. The Journal of physiology, v. 591, n. 18, p. 4405-4413, 2013. ISSN 0022-3751.

PAGANO, A. F. et al. Autophagy and protein turnover signaling in slow-twitch muscle during exercise. Medicine and science in sports and exercise, v. 46, n. 7, p. 1314-1325, 2014. ISSN 0195-9131.

PATEL, P.; WOODGETT, J. R. Glycogen synthase kinase 3: a kinase for all pathways? In: (Ed.). Current topics in developmental biology: Elsevier, v.123, 2017. p.277-302. ISBN 0070-2153.

PAULI, J. R. et al. Acute physical exercise reverses S-nitrosation of the insulin receptor, insulin receptor substrate 1 and protein kinase B/Akt in diet-induced obese Wistar rats. The Journal of physiology, v. 586, n. 2, p. 659-671, 2008. ISSN 1469-7793.

RAJA, G. et al. Fiber-specific responses of muscle glycogen repletion in fasted rats physically active during recovery from high-intensity physical exertion. American Journal of Physiology, v. 295, n. 2, p. R633-R641, 2008. ISSN 0363-6119.

RAJA, G. et al. Lactate availability is not the major factor limiting muscle glycogen repletion during recovery from an intense sprint in previously active fasted rats. The Journal of experimental biology, v. 207, n. 26, p. 4615-4621, 2004. ISSN 0022-0949. 
RASMUSSEN, B.; HANCOCK, C.; WINDER, W. Postexercise recovery of skeletal muscle malonyl-CoA, acetyl-CoA carboxylase, and AMP-activated protein kinase. Journal of Applied Physiology, v. 85, n. 5, p. 1629-1634, 1998. ISSN 1522-1601.

RASMUSSEN, B.; WINDER, W. J. J. O. A. P. Effect of exercise intensity on skeletal muscle malonyl-CoA and acetyl-CoA carboxylase. Journal of Applied Physiology, v. 83, n. 4, p. 11041109, 1997. ISSN 1522-1601.

REZAEE, Z. et al. Effects of Preventive Treadmill Exercise on the Recovery of Metabolic and Mitochondrial Factors in the 6-Hydroxydopamine Rat Model of Parkinson's Disease. Neurotoxicity reaserch, v. 35, n. 4, p. 908-917, 2019. ISSN 1029-8428.

RINGHOLM, S. et al. PGC-1 $\alpha$ is required for exercise-and exercise training-induced UCP1 upregulation in mouse white adipose tissue. PLoS One, v. 8, n. 5, p. e64123, 2013. ISSN 19326203.

RÖCKL, K. S. et al. Skeletal muscle adaptation to exercise training: AMP-activated protein kinase mediates muscle fiber type shift. Diabetes, v. 56, n. 8, p. 2062-2069, 2007. ISSN 00121797.

RUDERMAN, N. et al. AMPK as a metabolic switch in rat muscle, liver and adipose tissue after exercise. Acta physiologica Scandinavica, v. 178, n. 4, p. 435-442, 2003. ISSN 0001-6772.

RYDER, J. W. et al. Postexercise glucose uptake and glycogen synthesis in skeletal muscle from GLUT4-deficient mice. The FASEB Journal, v. 13, n. 15, p. 2246-2256, 1999. ISSN 08926638 .

SAFDAR, A. et al. Exercise increases mitochondrial PGC-1 $\alpha$ content and promotes nuclearmitochondrial cross-talk to coordinate mitochondrial biogenesis. The Journal of biological chemistry, v. 286, n. 12, p. 10605-10617, 2011. ISSN 0021-9258.

SALEEM, A.; CARTER, H. N.; HOOD, D. A. J. A. J. O. P.-C. P. p53 is necessary for the adaptive changes in cellular milieu subsequent to an acute bout of endurance exercise. American Journal of Physiology, v. 306, n. 3, p. C241-C249, 2013. ISSN 0363-6143.

SANO, A. et al. The effect of high-intensity intermittent swimming on post-exercise glycogen supercompensation in rat skeletal muscle. The Journal of physiological sciences, v. 62, n. 1, p. 1-9, 2012. ISSN 1880-6546. 
SEILER, K. S.; KJERLAND, G. Ø. Quantifying training intensity distribution in elite endurance athletes: is there evidence for an "optimal" distribution? Scandinavian journal of medicine \& science in sports, v. 16, n. 1, p. 49-56, 2006. ISSN 1600-0838.

SEILER, S.; HAUGEN, O.; KUFFEL, E. Autonomic recovery after exercise in trained athletes: intensity and duration effects. Medicine \& Science in Sports \& Exercise, v. 39, n. 8, p. 13661373, 2007. ISSN 0195-9131.

SELYE, H. A syndrome produced by diverse nocuous agents. Nature, v. 138, n. 3479, p. 32, 1936.

SERRANO, V. S. Otimização de Protocolos para Determinação da Capacidade Aeróbia em Camundongos Corredores. Simpósio Internacional de Iniciação Científica e Tecnológica, 2014, Ribeirão Preto.

STEGMANN, H.; KINDERMANN, W.; SCHNABEL, A. Lactate kinetics and individual anaerobic threshold. International journal of sports medicine, v. 2, n. 03, p. 160-165, 1981. ISSN 0172-4622.

STELLINGWERFF, $\mathrm{T}$. et al. Carbohydrate supplementation during prolonged cycling exercise spares muscle glycogen but does not affect intramyocellular lipid use. Pflügers ArchivEuropean Journal of Physiology, v. 454, n. 4, p. 635-647, 2007. ISSN 0031-6768.

STÖGGL, T.; SPERLICH, B. Polarized training has greater impact on key endurance variables than threshold, high intensity, or high volume training. Frontiers in Physiology, v. 5, 2014.

SVEDAHL, K.; MACINTOSH, B. R. Anaerobic threshold: the concept and methods of measurement. Canadian Journal of Applied Physiology, v. 28, n. 2, p. 299-323, 2003. ISSN 1066-7814.

TAKAHASHI, Y. et al. Pre-Exercise High-Fat Diet for 3 Days Affects Post-Exercise Skeletal Muscle Glycogen Repletion. Journal of nutricional science and vitaminology, v. 63, n. 5, p. 323-330, 2017. ISSN 0301-4800.

TAKAHASHI, Y. et al. Effects of $\beta$-hydroxybutyrate treatment on glycogen repletion and its related signaling cascades in epitrochlearis muscle during $120 \mathrm{~min}$ of post-exercise recovery. Applied physiology, nutrition and metabolism, v. 12, n. 44, p. 1311-1319, 2019. ISSN 17155312.

TARNOPOLSKY, M. et al. Carbohydrate loading and metabolism during exercise in men and women. Journal of Applied Physiology, v. 78, n. 4, p. 1360-1368, 1995. ISSN 8750-7587. 
TEIXEIRA-COELHO, F. et al. Effects of manipulating the duration and intensity of aerobic training sessions on the physical performance of rats. PLoS One, v. 12, n. 8, p. e0183763, 2017. ISSN 1932-6203.

TOWBIN, H.; STAEHELIN, T.; GORDON. Electrophoretic transfer of proteins from polyacrylamide gels to nitrocellulose sheets: procedure and some applications. Biotechnology, v. 76, n. 9, p. 4350-4354, 1979. ISSN 0027-8424.

TRIMMER, J. K. et al. Measurement of gluconeogenesis in exercising men by mass isotopomer distribution analysis. Journal of applied physiology, v. 93, n. 1, p. 233-241, 2002. ISSN 15221601.

TSINTZAS, O.-K. et al. Carbohydrate ingestion and glycogen utilization in different muscle fibre types in man. The Journal of Physiology, v. 489, n. 1, p. 243-250, 1995. ISSN 0022-3751. . Carbohydrate ingestion and single muscle fiber glycogen metabolism during prolonged running in men. Journal of applied physiology, v. 81, n. 2, p. 801-809, 1996. ISSN 8750-7587.

VAN DEN TILLAAR, R.; MARQUES, M. A comparison of three training programs with the same workload on overhead throwing velocity with different weighted balls. The Journal of Strength and Conditioning Research, v. 25, n. 8, p. 2316-2321, 2011. ISSN 1064-8011.

VECHETTI-JUNIOR, I. J. et al. Aerobic exercise recovers disuse-induced atrophy through the stimulus of the LRP130/PGC-1 $\alpha$ complex in aged rats. The Journals of Gerontology, v. 71, n. 5, p. 601-609, 2015. ISSN 1758-535X.

VIGELSØ, A.; ANDERSEN, N. B.; DELA, F. The relationship between skeletal muscle mitochondrial citrate synthase activity and whole body oxygen uptake adaptations in response to exercise training. International journal of physiology, pathophysiology and pharmacology, v. 6, n. 2 , p. $84,2014$.

WENDE, A. R. et al. A role for the transcriptional coactivator PGC- $1 \alpha$ in muscle refueling. The Journal of biological chemistry, v. 282, n. 50, p. 36642-36651, 2007. ISSN 0021-9258.

WILLIAMSON, M. J. A. C. I. M. A Return to Love: Reflections on the Principles of. 1992.

WINDER, W. W.; TAYLOR, E. B.; THOMSON, D. M. Role of AMP-activated protein kinase in the molecular adaptation to endurance exercise. Medicine and science in sports and exercise, v. 38, n. 11, p. 1945-1949, 2006. ISSN 0195-9131. 
WOJTASZEWSKI, J. F. et al. Isoform-specific and exercise intensity-dependent activation of 5'-AMP-activated protein kinase in human skeletal muscle. The Journal of physiology, v. 528, n. 1, p. 221-226, 2000. ISSN 0022-3751.

YU, H. et al. A quasi-experimental study of Chinese top-level speed skaters' training load: threshold versus polarized model. International journal of sports physiology and performance, v. 7, n. 2, p. 103-112, 2012. ISSN 1555-0265. 